\title{
Pharmacological Modulation of Immune Responses by Nutritional Components
}

\author{
Marthe T. van Daal, Gert Folkerts, Johan Garssen, and Saskia Braber
}

Division of Pharmacology, Utrecht Institute for Pharmaceutical Sciences, Faculty of Science, Utrecht University, 3584 CG, Utrecht, The Netherlands (M.T.v.D., G.F., J.G., S.B.); and Danone Nutricia Research, 3584 CT, Utrecht, The Netherlands (J.G.)

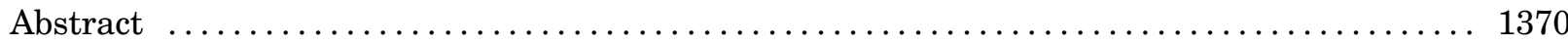

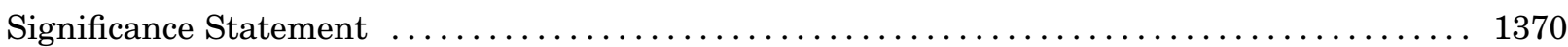

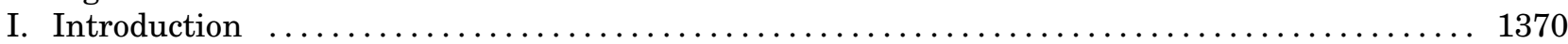

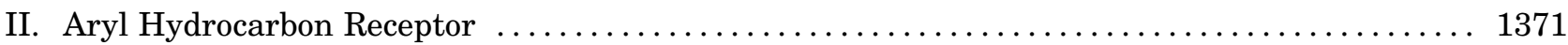

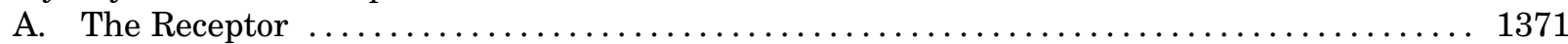

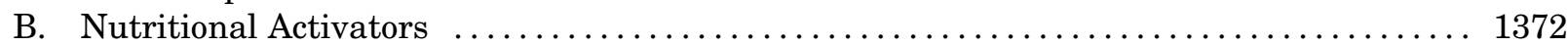

C. Immune Modulators . . . . . . . . . . . . . . . . . . . . . . . . . . . . . . . . . . . . . . 1372

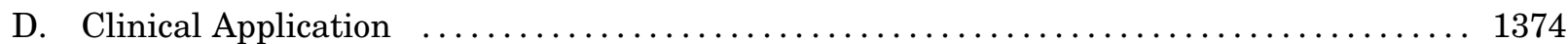

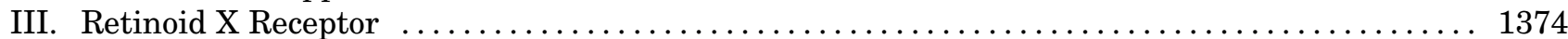

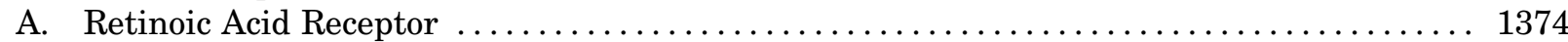

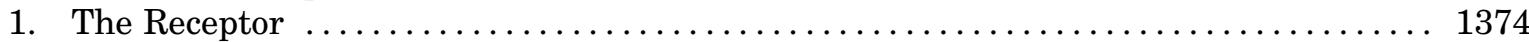

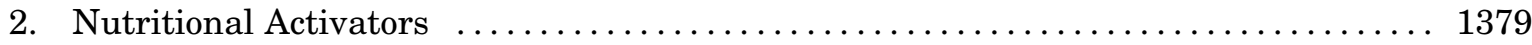

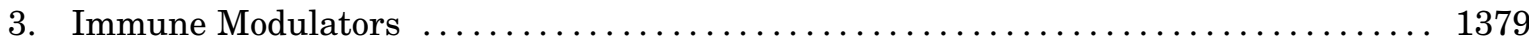

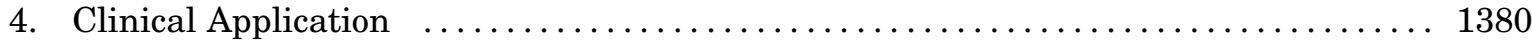

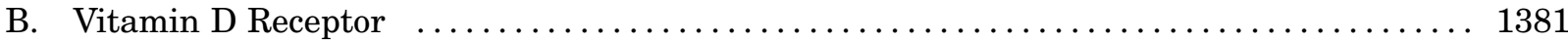

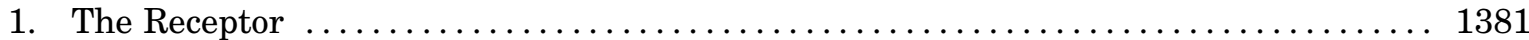

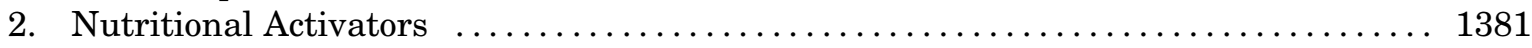

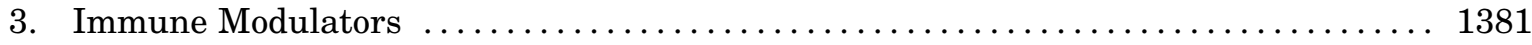

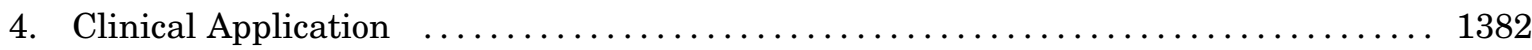

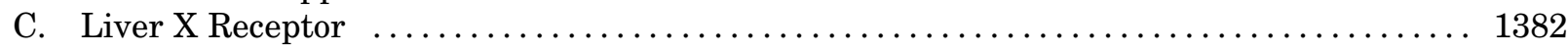

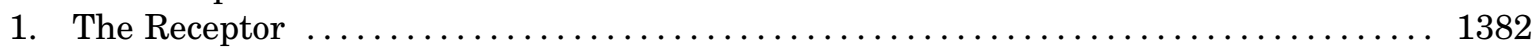

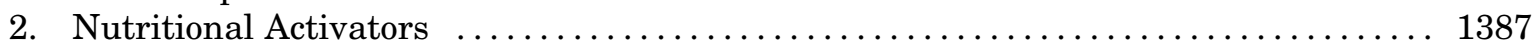

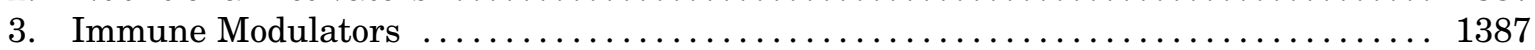

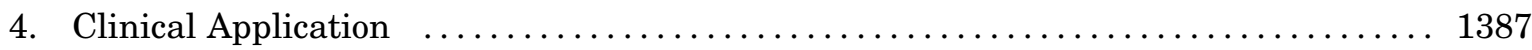

D. Peroxisome Proliferator-Activated Receptor $\ldots \ldots \ldots \ldots \ldots \ldots \ldots \ldots \ldots \ldots \ldots \ldots \ldots \ldots$

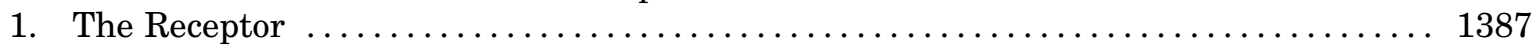

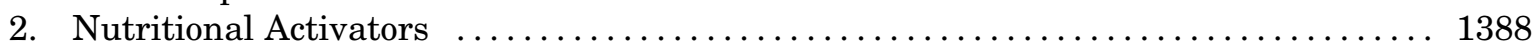

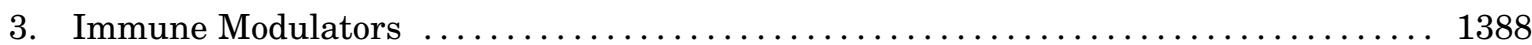

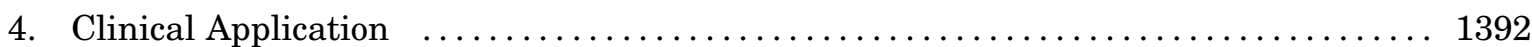

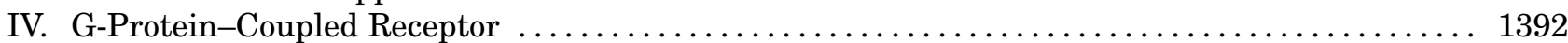

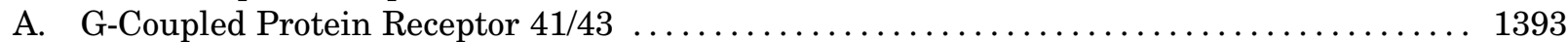

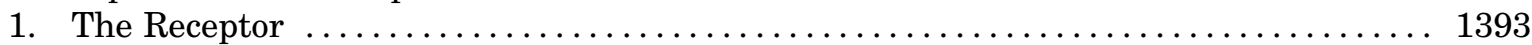

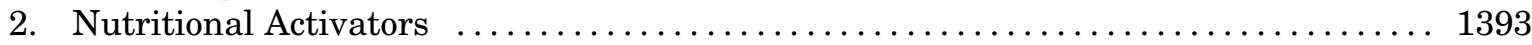

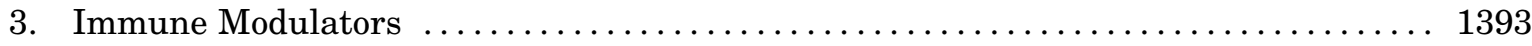

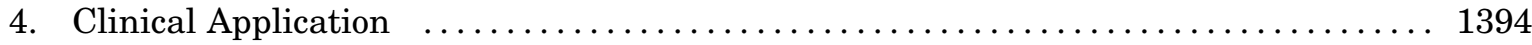

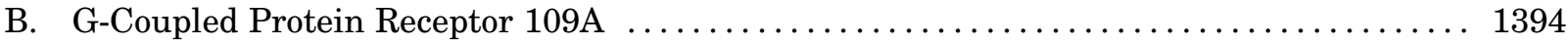

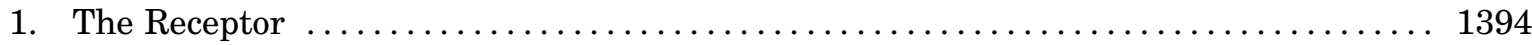

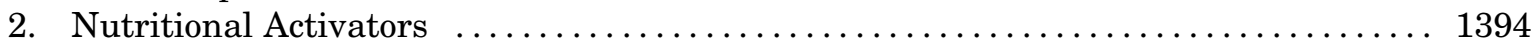

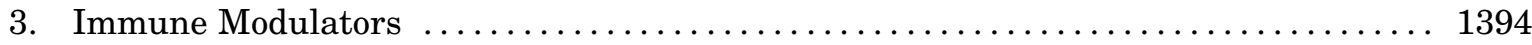

Address correspondence to: Dr. S. Braber, Division of Pharmacology, Utrecht Institute for Pharmaceutical Sciences, Faculty of Science, Utrecht University, 3584 CG, Utrecht, The Netherlands. E-mail: S.Braber@uu.nl

This paper received no external funding.

No author has an actual or perceived conflict of interest with the contents of this article.

https://doi.org/10.1124/pharmrev.120.000063 


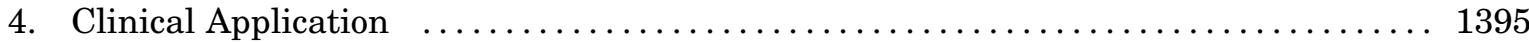

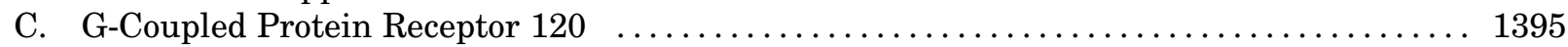

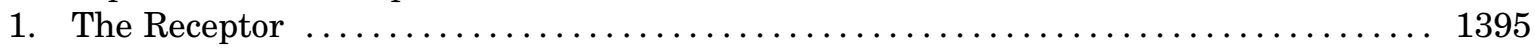

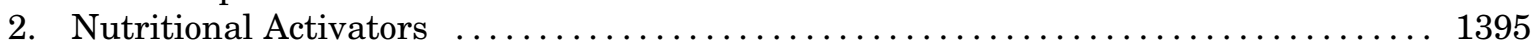

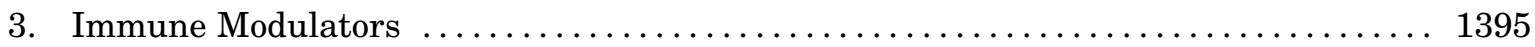

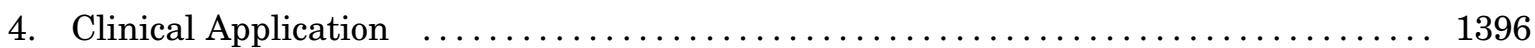

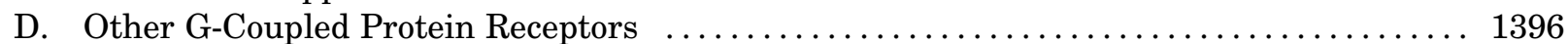

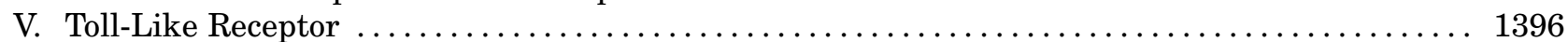

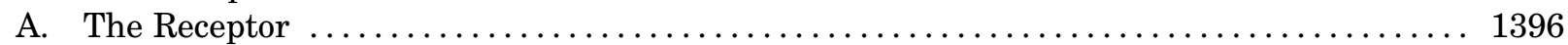

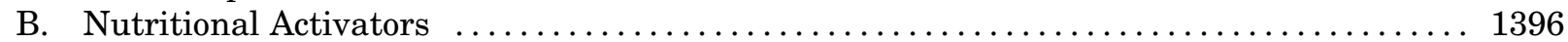

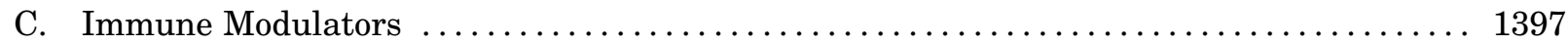

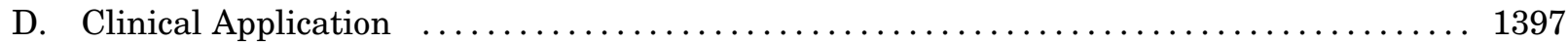

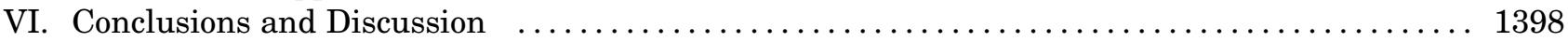

A. Analytical Discussion (Murine) Experimental Models $\ldots \ldots \ldots \ldots \ldots \ldots \ldots \ldots \ldots \ldots \ldots 1398$

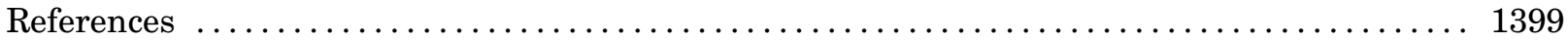

\begin{abstract}
The incidence of noncommunicable diseases (NCDs) has increased over the last few decades, and one of the major contributors to this is lifestyle, especially diet. High intake of saturated fatty acids and low intake of dietary fiber is linked to an increase in NCDs. Conversely, a low intake of saturated fatty acids and a high intake of dietary fiber seem to have a protective effect on general health. Several mechanisms have been identified that underlie this phenomenon. In this review, we focus on pharmacological receptors, including the aryl hydrocarbon receptor, binding partners of the retinoid $X$ receptor, G-coupled protein receptors, and toll-like receptors, which can be activated by nutritional components and their metabolites. Depending on the nutritional component and the receptors involved, both proinflammatory and anti-inflammatory effects occur, leading to an altered

immune response. These insights may provide opportunities for the prevention and treatment of NCDs and their inherent (sub)chronic inflammation.

Significance Statement-This review summarizes the reported effects of nutritional components and their metabolites on the immune system through manipulation of specific (pharmacological) receptors, including the aryl hydrocarbon receptor, binding partners of the retinoid $X$ receptor, G-coupled protein receptors, and toll-like receptors. Nutritional components, such as vitamins, fibers, and unsaturated fatty acids are able to resolve inflammation, whereas saturated fatty acids tend to exhibit proinflammatory effects. This may aid decision makers and scientists in developing strategies to decrease the incidence of noncommunicable diseases.
\end{abstract}

\section{Introduction}

The incidence of noncommunicable diseases (NCDs) is growing rapidly, particularly, though not exclusively, in developed countries (Alwan and Maclean, 2009; World Health Organization, 2013). NCDs are not caused by infectious agents and are therefore not transmissible from person to person (Kim and $\mathrm{Oh}$, 2013). The World Health Organization estimates that the major NCDs (cancer, diabetes, cardiovascular diseases, and chronic respiratory diseases) account for
$63 \%$ of the disease burden in 2008 (World Health Organization, 2013). The World Health Organization's goal is to reduce mortality by $25 \%$ by the year 2025 in those between the ages of 30 and 70 years old (World Health Organization, 2013). To reach this goal, there is a need for better preventive and therapeutic measures to manage these "modern" diseases. A major contributor to the increase in prevalence of NCDs during the last century is lifestyle, particularly diet (World Health Organization, 2013).

ABBREVIATIONS: ABC, ATP binding cassette; AHR, aryl hydrocarbon receptor; Aldh, Aldehyde dehydrogenase; AP-1, activator protein 1; BMDC, bone marrow-derived dendritic cell; CCR, C-C chemokine receptor type; COX, cyclooxygenase; CXCL, chemokine (C-X-C motif) ligand; DC, dendritic cell; DHA, docosahexaenoic acid; DIM, 3-3'-diindolylmethane; DSS, dextran sulfate sodium; EAE, experimental autoimmune encephalomyelitis; EPA, eicosapentaenoic acid; ERK, extracellular signal-regulated kinase; FOS, fructo-oligosaccharides; GATA3, GATA-binding protein; GATA3, GATA-binding protein 3; GOS, galacto-oligosaccharides; GPR, G-coupled protein receptor; I3C, indole-3-carbinol; IBD, inflammatory bowel disease; IFN, interferon; Ig, immunoglobulin; IL, interleukin; IRF, interferon regulatory factor; KO, knockout; LPS, lipopolysaccharide; LXR, liver X receptor; MCP, monocyte chemoattractant protein; MEK, mitogen-activated protein kinase kinase; MHC, major histocompatibility complex; MMP, matrix metalloproteinase; NCD, noncommunicable disease; NDO, nondigestible oligosaccharide; NF- $\kappa \mathrm{B}$, nuclear factor $\kappa$-light chain enhancer of activated B cells; Niacr, niacin receptor; NOS, nitric oxide synthase; NLRP, NOD-like receptor protein; NR, nuclear receptor; PBMC, peripheral blood mononuclear cells; PPAR, peroxisome proliferator-activated receptor; PUFA, polyunsaturated fatty acid; 3ROR, retinoic acid receptor-related orphan receptor; RA, retinoic acid; RAR, retinoic acid receptor; ROR, retinoic acid receptor-related orphan; RXR, retinoid X receptor; SCFA, short-chain fatty acid; SFA, saturated fatty acid; siRNA, small interfering RNA; TGF- $\beta$, transforming growth factor $\beta$; Th, T helper cell; TLR, toll-like receptor; TNBS, 2,4,6-trinitrobenzene sulfonic-acid; TNF- $\alpha$, tumor necrosis factor $\alpha$; Treg, T regulatory cell; VDR, vitamin D receptor; WT, wild type; ZO, zonula occludens. 
Diet is an important contributor to diabetes, cardiovascular disease, chronic respiratory disease, and inflammatory bowel disease (IBD) among others (Castro-Rodriguez et al., 2008; Park et al., 2011; Berthon et al., 2013; Lopez-Garcia et al., 2014; Myles, 2014; Thorburn et al., 2014; Di Daniele, 2019; Phillips et al., 2019). A Western diet, which is characterized by high amounts of saturated fatty acids (SFAs) and low amounts of fiber, fruit, and vegetables, is associated with an increased risk of NCDs (Myles, 2014; Thorburn et al., 2014). On the other hand, a Mediterranean diet rich in fiber, fresh fruit, and vegetables and low in SFAs is linked to a lower risk of these diseases (Castro-Rodriguez et al., 2008; Park et al., 2011; Lopez-Garcia et al., 2014; Thorburn et al., 2014; Di Daniele, 2019). These studies emphasize the potential of certain food components being used in therapeutic prevention or treatment of NCDs. A particularly promising route is the influence of nutritional components on the inflammatory response of the immune system (Phillips et al., 2019). In recent decades, it has become clear that nutrition is more than just a source of nourishment or energy, and the Hippocrates quote (400 BC), "Let food be thy medicine and medicine be thy food," remains highly relevant nowadays; however, this may be a historical misquotation. It has been observed that drugs and food can exhibit overlapping mechanisms, show therapeutic synergy (not necessarily using the same primary target), and reduce side effects (MacDonald et al., 2009; Eussen et al., 2010; Georgiou et al., 2011).

Nutraceuticals have received much attention in the last few years from the scientific community, consumers, and food manufacturers. Nutraceuticals are foods or food ingredients (e.g., natural bioactive and chemical compounds) that provide medical or health benefits, including the prevention and treatment of a disease, which blurs the line between food and drugs (da Costa, 2017). The term "nutraceutical," a hybrid of "nutrition" and "pharmaceutical," was coined by Stephen DeFelice, founder and chairman of the Foundation for Innovation in Medicine located in Cranford, New Jersey in 1979 (DeFelice, 1995). In this review, we make use of the broader term "nutritional components," since not all described components are beneficial for health or have not yet been proven to prevent and treat a disease.

Three main modes of actions of nutritional components have been identified. First, nutritional components can interact with intestinal bacteria and change the gut microbiota composition, leading to physiologic and immunologic changes in the body. In addition, during the digestion of food, an abundance of metabolites can be produced, such as amino-acid derivatives and short-chain fatty acids (SCFAs), which can affect human physiology in both positive and negative ways (Kolodziejczyk et al., 2019). The second mechanism by which diet can alter the immunologic response is via epigenetic modifications (Thorburn et al., 2014; Zhang and Kutateladze, 2018). For example, the activation or inhibition of specific histone deacetylases by nutritional components can alter the transcription of proteins and, therefore, the activity of the immune system (Thorburn et al., 2014). The third mechanism is the involvement of pharmacological receptors on the surface of cells to which nutritional molecules can bind and either activate or inhibit the pathway downstream of the receptor (Kau et al., 2011; Witkamp and van Norren, 2018). This third mechanism is the main focus of this review.

Nutritional biology can significantly contribute to the discovery of new molecular targets in both health and diseases. To progress the therapeutic use of nutritional components, a detailed understanding of the underlying mechanism by which nutritional components can alter the immune system is required. The aim of this paper is to provide an overview of the current literature regarding the direct and indirect effects of nutrition via the modulation of pharmacological receptors. We will discuss the receptor structure and mechanism of action, nutritional components able to interact with the receptor, and effects on immunologic status.

\section{Aryl Hydrocarbon Receptor}

\section{A. The Receptor}

The aryl hydrocarbon receptor (AHR) is a ligandactivated transcription factor expressed by several immune cells, which can be activated by small environmental, dietary, microbial, and metabolic molecules, which subsequently trigger molecular immune response pathways. Research has shown that AHR signaling plays relevant roles in immune responses during health and disease, including modulation of biologic processes important for tissue homeostasis and development of pathologic conditions related to autoimmune, neoplastic, metabolic, degenerative, inflammatory diseases, and tumorigenesis (Schulte et al., 2017; Gutiérrez-Vázquez and Quintana, 2018; Rothhammer and Quintana, 2019). AHR is a part of a family of transcription factors containing a basic helix-loop-helix-PER-ARNT-SIM with a C-terminus transcription activation domain (Xue et al., 2017). Inactive AHR resides in the cytoplasm where the nuclear localization sequence is shielded by chaperone proteins. When an AHR agonist binds to the receptor, a conformational change leads to the uncovering of the nuclear localization sequence. The AHR complex is then translocated toward the nucleus where the chaperone proteins dissociate. The AHR nuclear translocator then forms a heterodimer with AHR. The 
complex subsequently binds to the dioxin responsive element in the DNA, inducing the transcription of target genes, including cytochrome P450-dependent monooxygenases and AHR repressors, as is shown in Fig. 1 (Schulte et al., 2017).

\section{B. Nutritional Activators}

AHR has a broad range of endogenous activators in addition to dietary components, among which the toxin high-affinity 2,3,7,8-tetrachlorodibenzo-p-dioxin is the best-known ligand (Schulte et al., 2017). The first class of AHR dietary activators includes indoles, which are highly present in cruciferous (brassica) vegetables (Stockinger et al., 2014; Hubbard et al., 2015). The indoles comprise indole-3-acetonitrile and indole3 -carbinol (I3C), both of which can be further converted into indolo-[3,2-b]-carbazole and 3-3'-diindolylmethane (DIM) under acidic conditions in the stomach (Hubbard et al., 2015). In addition, AHR is activated by the flavonoids quercetin and resveratrol, also known as polyphenols, which are found in fruits and vegetables (Xue et al., 2017). The immunomodulatory effects of these nutritional components related to AHR signaling have been described in detail below and summarized in Table 1.

\section{Immune Modulators}

The best-described effect of dietary components on the immune system via AHR activation is in context of T-cell differentiation. The balance between antiinflammatory $\mathrm{T}$ regulatory cells (Treg) and proinflammatory $\mathrm{T}$ helper (Th) 17 cells is crucial in maintaining homeostasis. In vitro studies showed that the Treg-related gene Foxp3 is upregulated after DIM administration, whereas the Th17-related gene retinoic acid receptor-related orphan receptor $\gamma \tau$ was

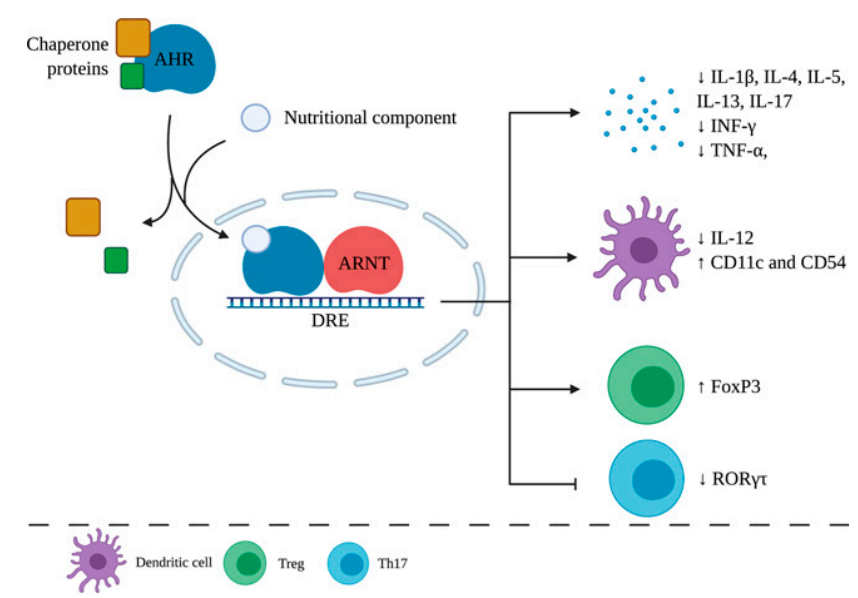

Fig. 1. Effects of nutritional components via AHR on the immune system. After AHR activation by a nutritional component, chaperone proteins dissociate and form a heterodimer with an aryl hydrocarbon receptor nuclear translocator. Target genes are transcribed and lead to antiinflammatory effects on the immune system. ARNT, aryl hydrocarbon receptor nuclear translocator; DRE, dioxin responsive element. Created with BioRender.com. downregulated in anti-CD3/CD28 monoclonal antibody-stimulated nave Th cells (Huang et al., 2013). This indicates a shift in the homeostasis toward an anti-inflammatory state induced by DIM, which is abolished by pretreatment with short hairpin RNA directed at AHR, indicating direct involvement of the AHR in the observed in vitro effects (Huang et al., 2013). Although the involvement of AHR was not proven in vivo, Huang et al. (2013) pointed out that DIM supplementation reduced mucosal inflammation and reduced colonic Th17 infiltration while expanding the Treg population in a murine oxazolone-induced colitis model.

Imbalance of the Treg and Th17 populations is the underlying problem of multiple autoimmune diseases. Pretreatment with DIM and I3C in a murine model of multiple sclerosis [experimental autoimmune encephalomyelitis (EAE)] showed reduced numbers of inflammatory cells in the spinal cord and decreased levels of the proinflammatory cytokines, tumor necrosis factor $\alpha(\mathrm{TNF}-\alpha)$, interleukin (IL)-17, and IL-6 in serum (Rouse et al., 2013). Additionally, post-treatment with the indoles caused a growing population of Treg cells in the inguinal lymph nodes and brain of mice suffering from EAE, possibly providing an explanation for the reduced inflammation. An AHR-specific antagonist CH223191 was found to reduce the clinical scores as well as growing Treg populations induced by DIM and I3C (Rouse et al., 2013). The growing Treg population as a result of DIM and I3C treatment was found in vitro as well (Rouse et al., 2013). A recent study also using a murine EAE model displayed similar results after DIM administration (Yang et al., 2020). DIM alleviated the severity of EAE by a reduction in proinflammatory cytokines and decrease in Th1 and Th17 cells in serum, which was abolished in the presence of the AHR antagonist CH223191. The effects of DIM and I3C treatment on delayed-type hypersensitivity to methylated bovine serum albumin were measured in a murine study performed by Singh et al. (2016). The indoles DIM and I3C attenuated the delayed-type hypersensitivity and promoted Treg proliferation in lymph nodes. Since the increased Treg proliferation was notably absent in $\mathrm{AHR}^{-/-}$mice, this effect is dependent on AHR activation (Singh et al., 2016). The benefits of increased Treg development were shown as well in a mouse model of Clostridium difficile-associated disease (Julliard et al., 2017). Dietary I3C resulted in greater survival from the bacterial infection caused by an increased Treg population but also by enhanced group 3 innate lymphoid cells and $\gamma \delta \mathrm{T}$ cell populations in the gut. Mice not treated with I3C developed severe infections, had a mortality rate of $87.5 \%$, and showed increased translocation of Clostridium difficile toward liver and lungs. Additionally, $\mathrm{AHR}^{-1-}$ mice fed with I3C lost this observed 
Nutrition, Pharmacological Receptors, and Immune Responses

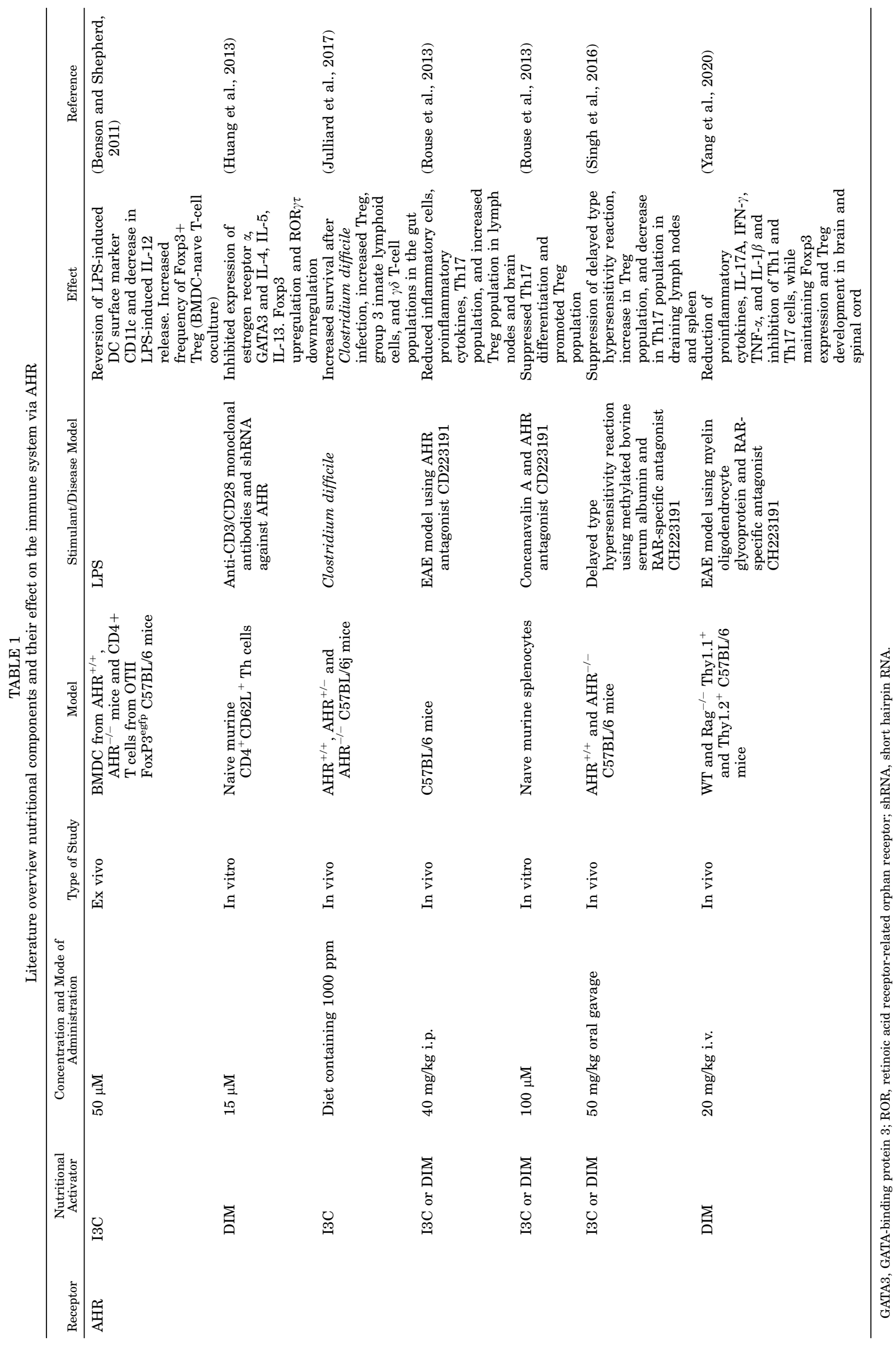

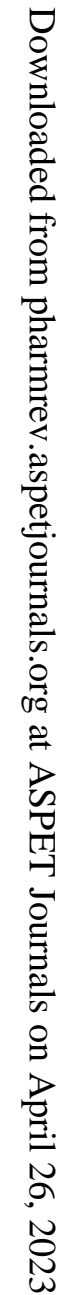


protection against Clostridium difficile infection (Julliard et al., 2017).

Dendritic cells (DCs), the link between innate and adaptive immunity, are also affected by cruciferous vegetables via AHR. Benson and Shepherd (2011) hypothesized that I3C is able to suppress the immune response and inflammation in DCs. To investigate this hypothesis, the researchers performed a study in which BMDCs from both $\mathrm{AHR}^{+/+}$and $\mathrm{AHR}^{-/-}$mice were activated with lipopolysaccharide (LPS) with or without the presence of I3C (Benson and Shepherd, 2011). I3C appeared to reverse the LPS-induced CD surface marker CD11c and suppressed the LPS-induced production of IL-12 in an AHR-dependent manner. This underlines the antiinflammatory effects of I3C.

I3C induced oral tolerance against ovalbumin and reduced peanut allergy symptoms in mice, which might be due an increased number of tolerogenic DCs in the lamina propria as investigated by HammerschmidtKamper et al. (2017). However, I3C-fed AHR-deficient mice (AHR lost in intestinal epithelial cells or in CD11c+ DCs) also supported tolerance, suggesting presence of AHR in one of these cell types is not sufficient for the I3C-induced positive effect. Mohammadi et al. (2018) observed that monocyte-derived macrophages from patients with systemic lupus erythematosus treated with I3C expressed an anti-inflammatory cytokine profile compared with untreated cells from these patients. Since other genes related to AHR activation are also altered, AHR is likely to be involved in this process (Mohammadi et al., 2018). Furthermore, Ociepa-Zawal et al. (2007) showed that I3C is able to increase AHR mRNA expression in a breast cancer cell line [monocyte chemoattractant protein (MCP) 7].

Taken together these studies show that a shift from a proinflammatory environment toward an anti-inflammatory environment involves AHR-mediated pathways and has been observed in different NCDs (Fig. 1). Therefore, a dietary intervention targeting AHR could be beneficial particularly for autoimmune disorders wherein an immune system imbalance is observed.

\section{Clinical Application}

The effects of I3C and DIM have been studied in clinical trials for the treatment of several cancers, including prostate cancer, cervical dysplasia, and breast cancer (Del Priore et al., 2010; Li et al., 2014; Thomson et al., 2017). The beneficial effects of I3C and DIM on prostate cancer observed in clinical research studies have been reviewed by $\mathrm{Li}$ et al. (2014), and potent I3C- and DIMinduced effects are mainly related to tumor growth inhibition. Oral treatment with DIM in patients with cervical dysplasia improved clinical scores, although no significant differences were identified between the control and experimental group (Del Priore et al., 2010). DIM in combination with tamoxifen-an anti-breast cancer drughas been observed to be associated with lower risk of breast cancer in a phase I clinical trial (Thomson et al., 2017). To the best of our knowledge, there have been no clinical trials investigating the immunomodulatory effects of DIM or I3C, and therefore further research is needed to confirm the observed in vitro and in vivo findings as described above.

\section{Retinoid X Receptor}

The retinoid $\mathrm{X}$ receptor (RXR) plays a pivotal role in the control of multiple intracellular receptor signaling pathways and is part of the nuclear receptor (NR) superfamily. It features a ligand-binding transactivation domain at the $\mathrm{C}$ terminus and a DNA-binding domain in the center connected by a hinge region (Kojetin et al., 2015). The N-terminus transactivation domain has two activation components, one dependent and one independent of the ligand. This structure is similar across all NRs. RXR forms a homodimer with one other RXR or a heterodimer with other NRs, such as the retinoic acid receptor (RAR), vitamin $\mathrm{D}$ receptor (VDR), liver $\mathrm{X}$ receptor (LXR), or peroxisome proliferator-activated receptor (PPAR) (Dawson and Xia, 2012). The thyroid hormone receptor and farnesoid $\mathrm{X}$ receptor can also form a heterodimer but are not known to be activated by nutritional components and are therefore not discussed further in this article. The binding partner of RXR determines the genes transcribed upon activation (Dawson and Xia, 2012). The immunomodulatory effects of different nutritional components related to RAR, VDR, LXR, and PPAR signaling have been described in detail below and summarized in Table 2.

\section{A. Retinoic Acid Receptor}

1. The Receptor. One of the RXR binding partners is RAR (Dawson and Xia, 2012). There are three RAR isoforms, $\operatorname{RAR} \alpha, \beta$, and $\gamma$ (Cunningham and Duester, 2015). RAR has the ability to modify the expression of numerous genes in multiple immune-cell types, such as $\mathrm{T}$ cells, B cells, macrophages, and dendritic cells, via transcriptional activity and downstream signaling pathway activation (Larange, 2017). The RAR/RXR receptor is involved in wound healing, development of the nervous and skeletal systems, myeloid development, and embryonic development (Nagy et al., 2012).

In an inactive state, the RAR/RXR complex is bound to a retinoic acid response element with corepressors 1 and 2, histone deacetylase, and Polycomb repressive complex 2 . This causes trimethylation of H3K9 and H3K27 and ubiquitination of H2AK119, which leads to gene silencing. After the binding of the ligand, the corepressors dissociate and nuclear receptor coactivators 1,2 , or 3 can associate with intrinsic histone acetyltransferase because of a conformational change (Fig. 2A). This dissociation-association 


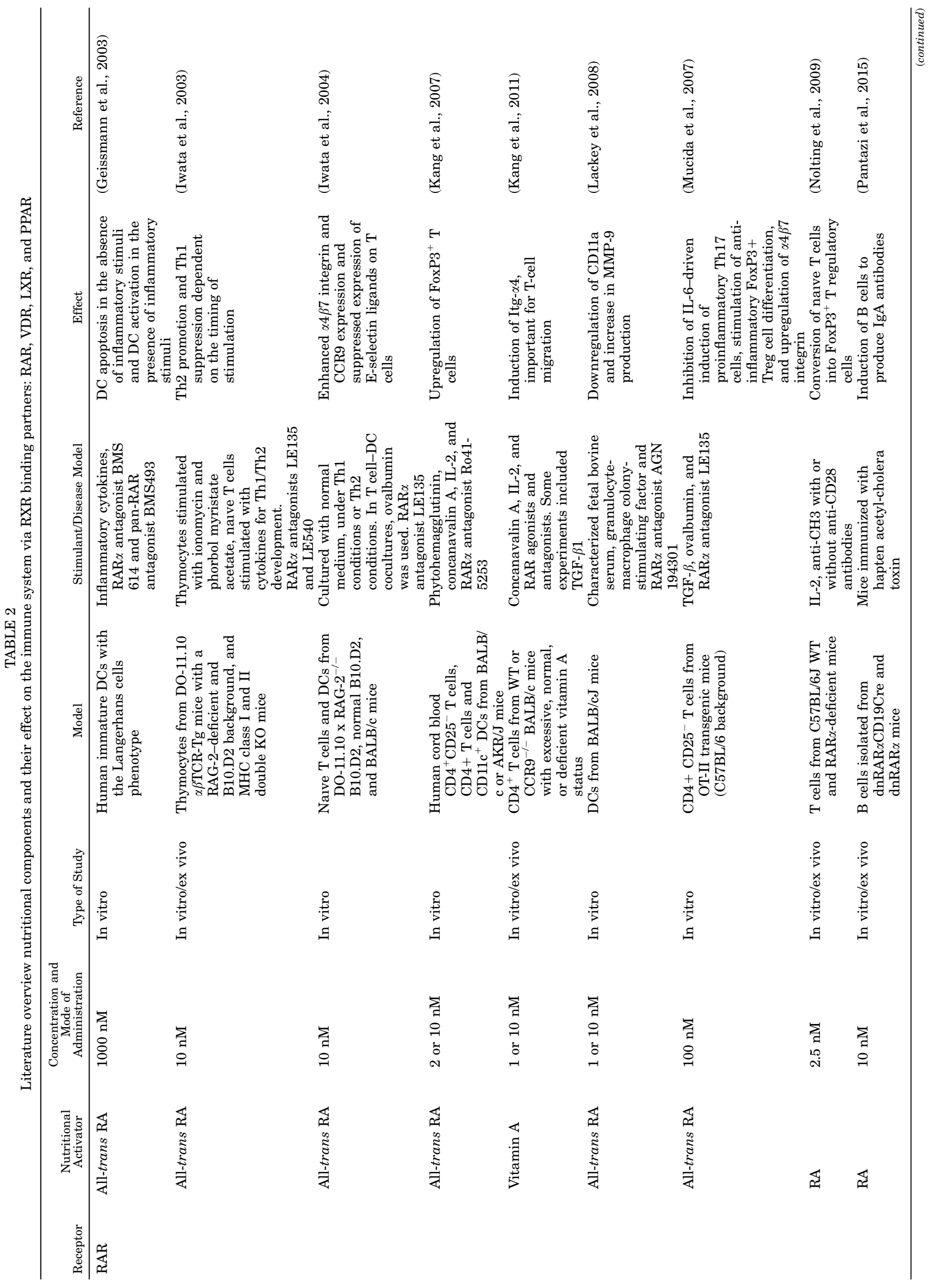


van Daal et al.

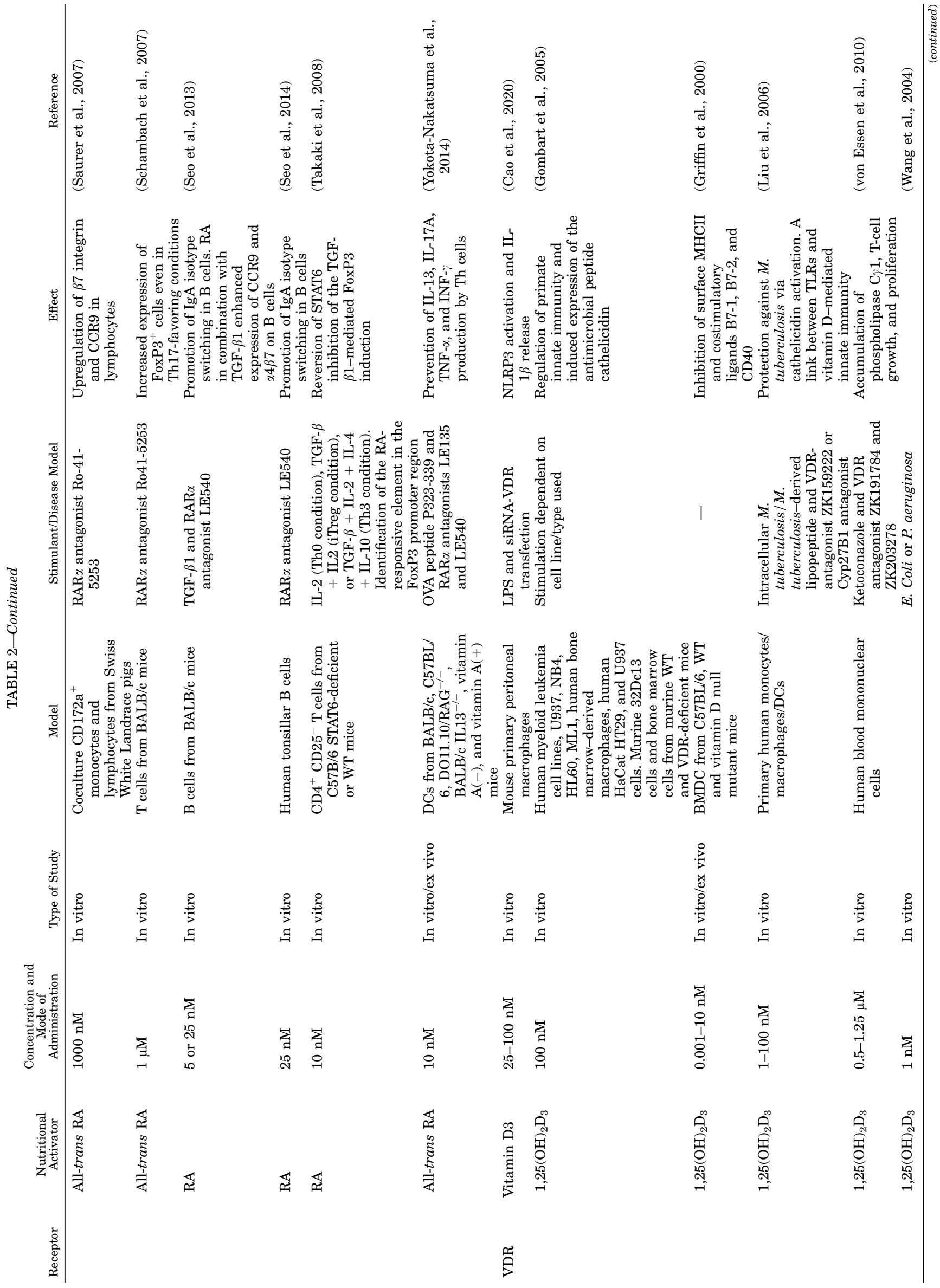




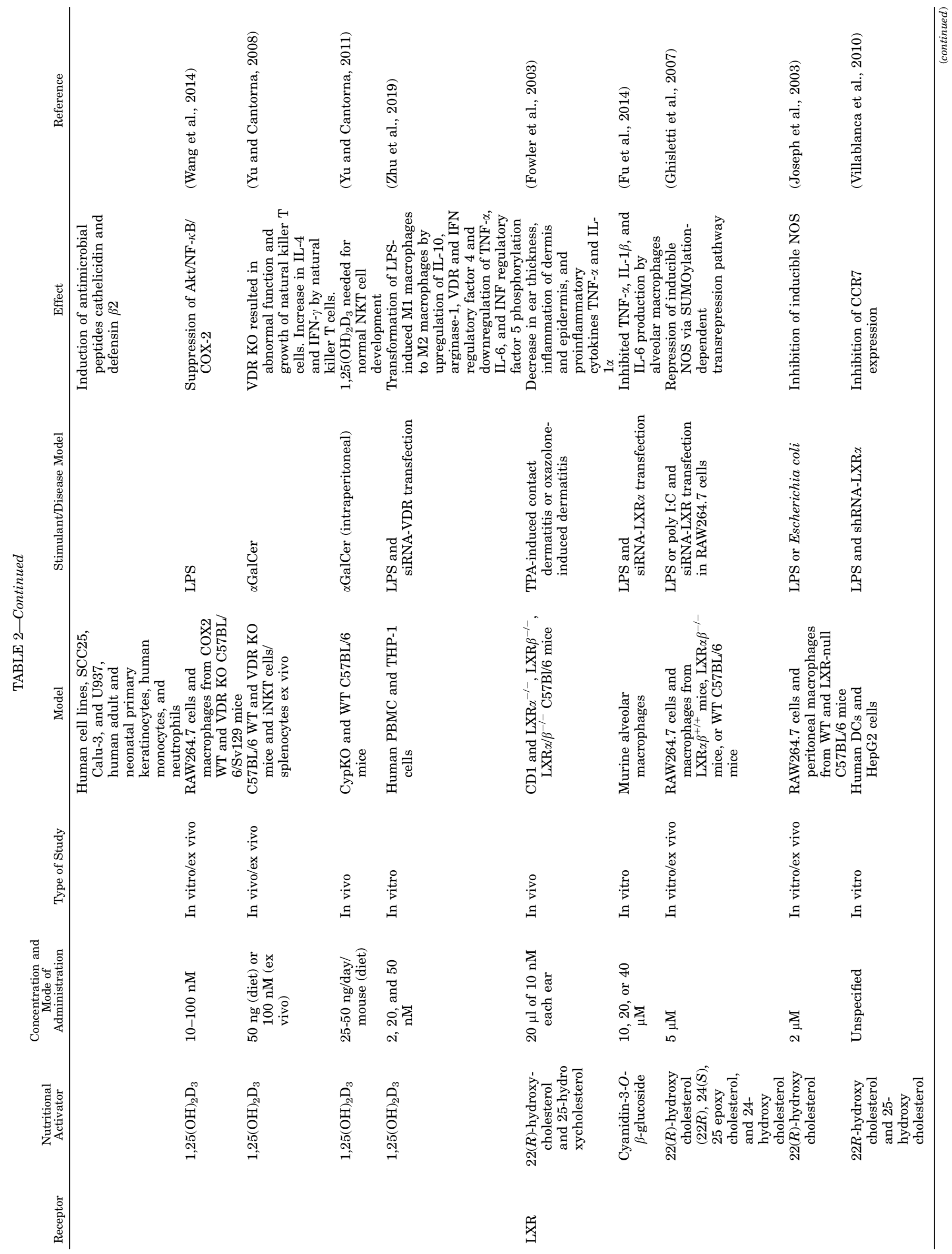

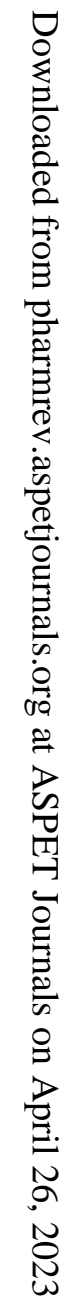




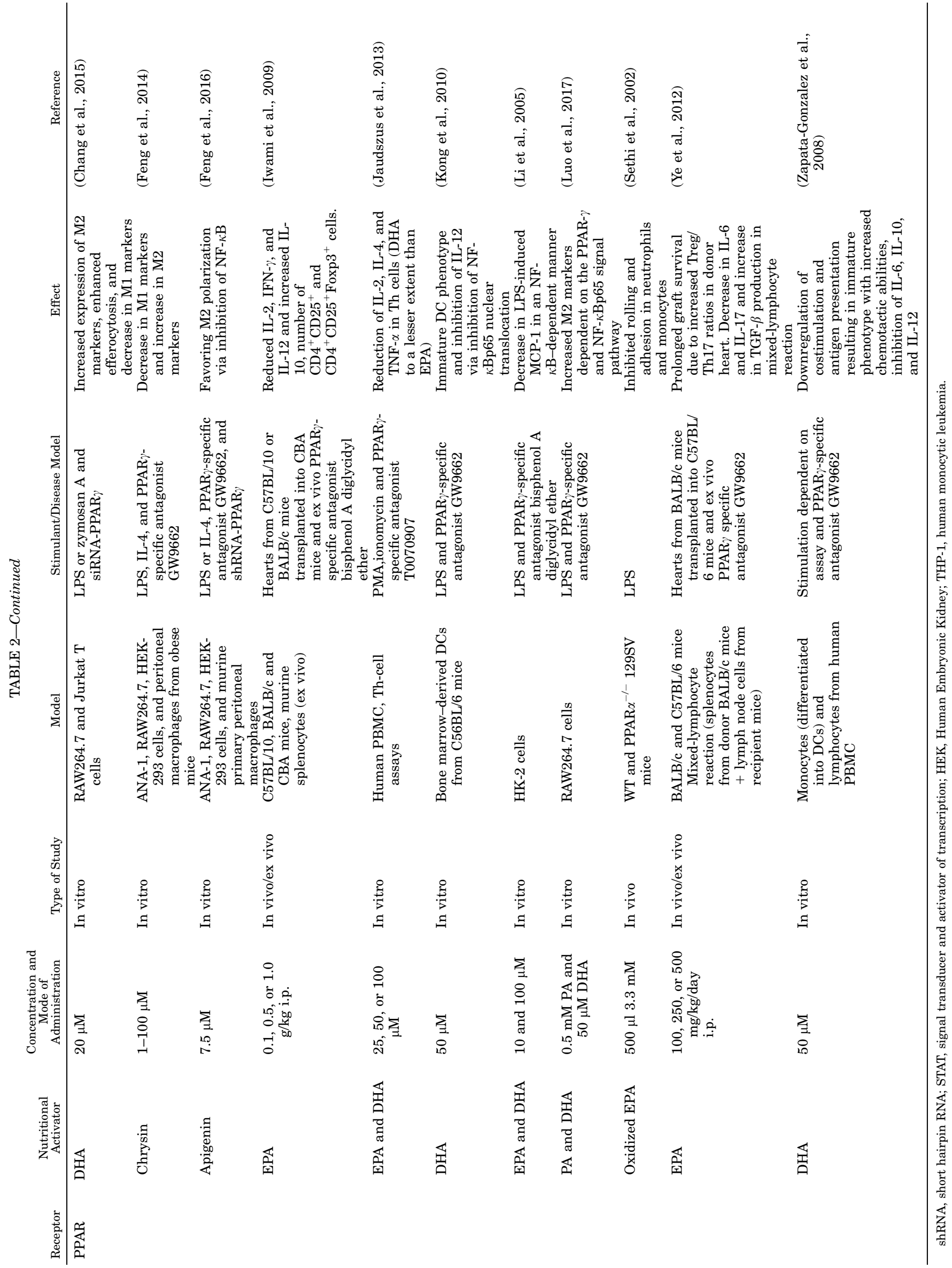


impacts genes controlling cell proliferation and differentiation (Dawson and Xia, 2012).

2. Nutritional Activators. Vertebrates are not able to synthesize vitamin A de novo and must obtain this vitamin via their diet-mainly from carotenoids and meat (Larange and Cheroutre, 2016). Vitamin A is metabolized into active forms by cells that express alcohol dehydrogenases and retinal dehydrogenases, of which two active forms, all-trans and 9-cis retinoic acid (RA), are known to activate RAR (Mora et al., 2008).
3. Immune Modulators. RA is involved in a broad spectrum of functions that influence the immune system via the RXR/RAR heterodimer (Fig. 2A). Within DCs, the phenotype and migration are altered upon RA supplementation. In porcine-derived DC monocytes pretreated with all-trans RA and cocultured with autologous lymphocytes, the lymphocytes show higher mRNA expression of the integrin $\beta 7$ and C-C chemokine receptor type (CCR) 9, which is important for mucosal homing of $\mathrm{T}$ cells (Saurer et al., 2007).
A
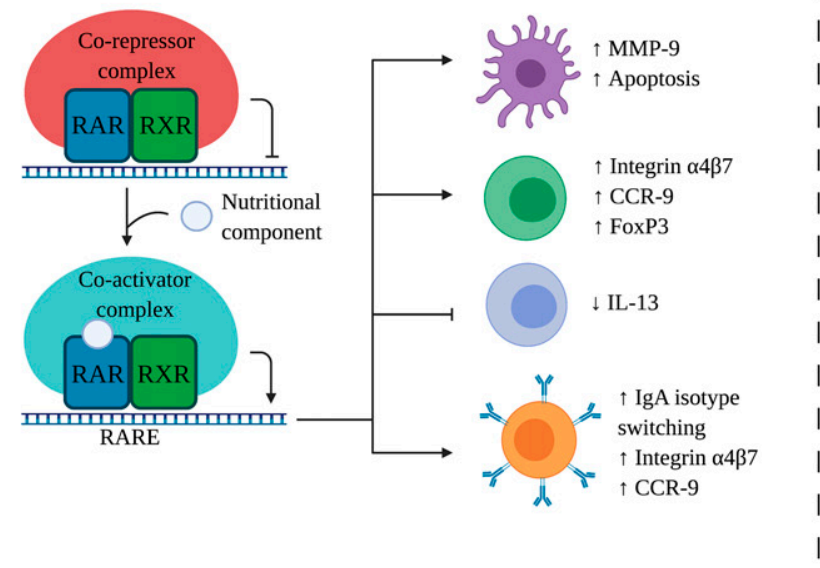

C
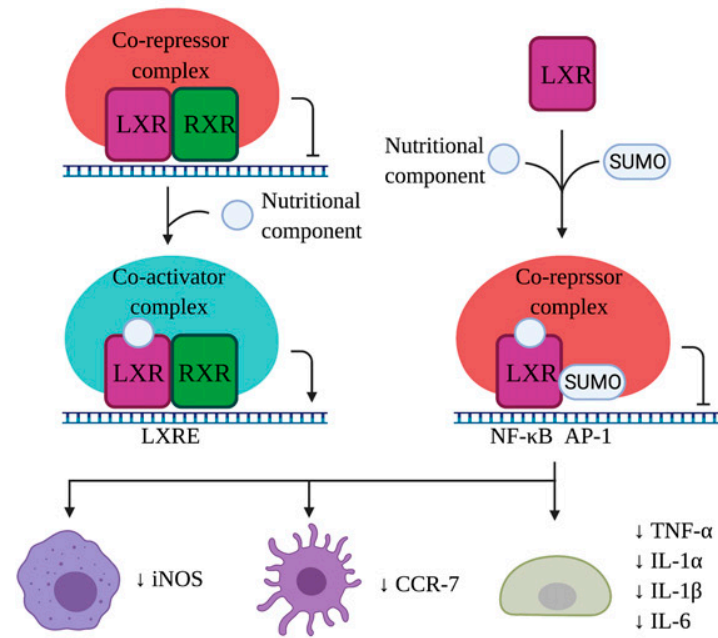

(n)

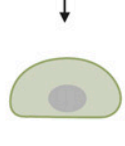

$\downarrow$ TNF- $\alpha$

$\downarrow \mathrm{IL}-1 \alpha$

$\downarrow$ IL-1 $\beta$

$\downarrow$ IL-6
B
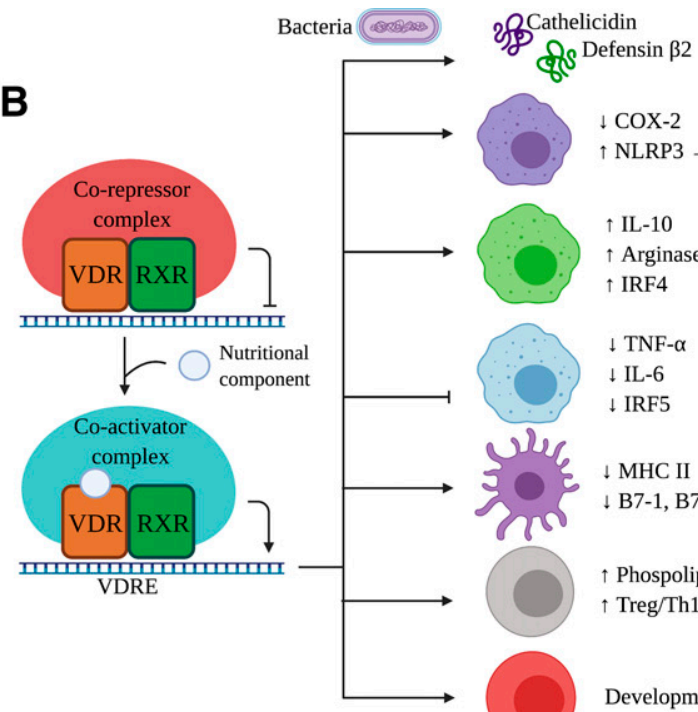

$\uparrow \mathrm{NLRP3} \rightarrow \uparrow \mathrm{IL}-1 \beta$

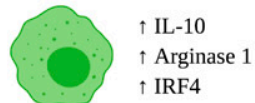

$\uparrow$ IRF4

$\downarrow$ TNF- $\alpha$

$\downarrow$ IL-6

$\downarrow$ IRF5
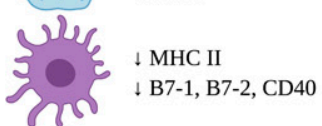

$\uparrow$ Phospolipase $\mathrm{C} \gamma 1$

$\uparrow$ Treg/Th17

Development

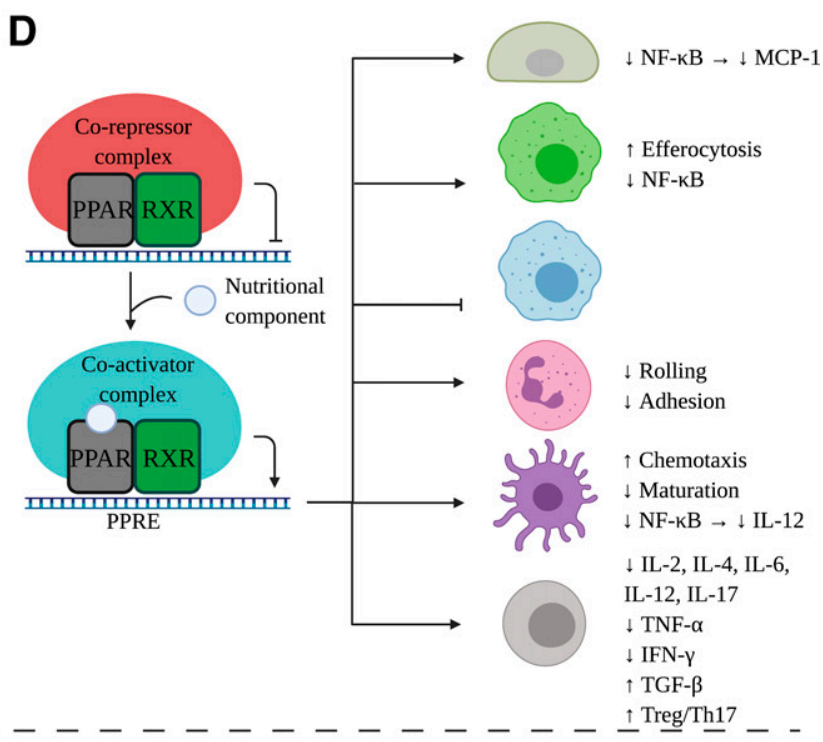

Non-immune cell
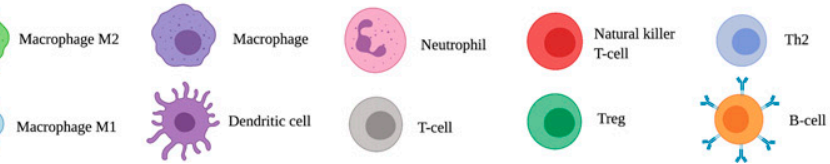

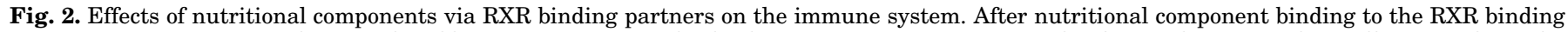

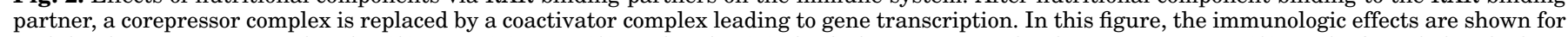

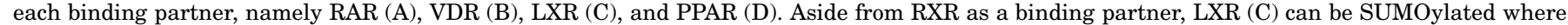

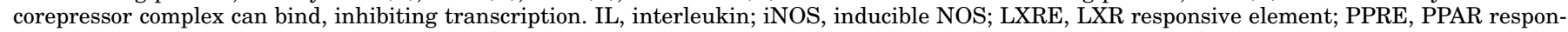
sive element; RARE, retinoic acid responsive element; VDRE, vitamin D responsive element. Created with BioRender.com. 
Therefore, all-trans RA possibly plays an important role in the mucosal immunity by targeting DCs. Moreover, matrix metalloproteinase (MMP)-9, which is important for DC migration, was upregulated in bone marrow-derived DCs from BALB/cJ mice, whereas this upregulation was absent in the presence of the RAR $\alpha$-specific antagonist AGN 194301 (Lackey et al., 2008). Furthermore, RAs exhibit the ability to induce apoptosis of human DCs, which is inhibited by inflammatory cytokines, such as TNF- $\alpha$. In this experiment, antagonists selective for a specific subtype or a pan-RAR antagonist were used, outlining the involvement of the RAR receptor on DCs (Geissmann et al., 2003). RA also influences the movement of $\mathrm{T}$ cells toward the intestine and Peyer's Patches via the expression of Itg- $\alpha_{4}$ in CCR9-deficient mice, whereas T-cell migration through the vascular cell adhesion molecule 1-coated transwell membranes is defective after in vitro treatment with an $\operatorname{RAR} \alpha$ antagonist (RO41-5253) (Kang et al., 2011). Iwata et al. (2004) showed that murine DCs are unable to stimulate $\mathrm{T}$ cells to express $\alpha 4 \beta 7$ integrins when treated with an RAR-antagonist LE135. This indicates that specific gut homing molecules are not adequately expressed when RAR is blocked.

In vitro studies found that supplementation of alltrans $\mathrm{RA}$ to $\mathrm{CD} 4^{+} \mathrm{CD} 25^{-} \mathrm{T}$ cells from cord blood or to $\mathrm{CD} 4^{+} \mathrm{T}$ cells from Balb/c mice leads to an increase in the Foxp3 ${ }^{+}$Treg cell population, even in Th17-favorable environments, and RAR-specific antagonists and retroviral overexpression indicated RAR involvement (Kang et al., 2007; Schambach et al., 2007). In addition, the RAR $\alpha$ expression in $\mathrm{CD} 4^{+} \mathrm{CD} 25^{-} \mathrm{T}$ cells from cord blood incubated with all-trans RA was increased (Kang et al., 2007). Also, in healthy mice RA has been shown to favor Treg induction (Mucida et al., 2007; Nolting et al., 2009), whereas the RAR antagonist LE135 (Mucida et al., 2007) and RAR-deficient mice (Nolting et al., 2009) showed no Treg favorability. This is confirmed by Takaki et al. (2008), who displayed that disruption of the RAR/RXR responsive element within the Foxp3 gene stopped the increase in Treg cell numbers in vitro, implying a role for RA and RAR/RXR in this process. Thus, these studies show promotion of a more anti-inflammatory phenotype due to the increase in the number of Treg cells in the presence of RA.

Vitamin A or all-trans RA are also involved in the modulation of the ratio of Th2/Th1 cells. The effects of RA on Th1 and Th2 cell populations were dependent on the timing of RA supplementation in vitro (Iwata et al., 2003). Supplementation of RA to nave T cells after initial stimulation with anti-CD3 and anti-CD28 in the presence of IL-12 or IL-4 enhanced the Th2 development, whereas supplementation of RA at the beginning of the nave $\mathrm{T}$ cell culture before the initial stimulation suppressed this development (Iwata et al., 2003). Yokota-Nakatsuma et al. (2014) showed that all-trans RA prevented the mesenteric lymph node/DCs from T cell-induced IL-13, IL-17A, TNF- $\alpha$, and interferon (IFN)- $\gamma$ production in vitamin A-deficient mice, thus inhibiting an allergic response to oral antigens. Especially the mesenteric lymph node/ DC-induced, IL-13-producing inflammatory Th2 cells were inhibited by all-trans RA. Wild-type (WT) mice without vitamin A deficiency did not exhibit Th2 development, indicating that vitamin A is responsible for the suppression of the proinflammatory Th2 phenotype (Yokota-Nakatsuma et al., 2014).

In murine B cells, it was found that RA could induce isotype switching in B cells, leading to more neutralizing immunoglobulin (Ig) A antibodies. RAR antagonist LE540 or silencing of RA signaling abolished the observed effect on neutralizing IgA antibodies (Seo et al., 2013, 2014; Pantazi et al., 2015). Furthermore, expression of homing receptors CCR-9 and $\alpha 4 \beta 7$ on murine $B$ cells is upregulated in response to RA alone or RA in combination with transforming growth factor $\beta$ (TGF- $\beta$ ), although the involvement of RAR is yet to be investigated (Seo et al., 2013). These findings together indicate that RA is important for the (intestinal) humoral response and maintaining mucosal homeostasis.

4. Clinical Application. There are multiple clinical trials investigating the effects of vitamin A or RA alone or in combination with existing therapy. The positive effects of vitamin $\mathrm{A}$ in clinical cancer studies have been reviewed before, including halting cancer progression, induction of differentiation, and reduction in proliferation of tumors in different types of cancer, such as pancreatic cancer, skin cancer, and renal cancer (Tang and Gudas, 2011; Davis-Yadley and Malafa, 2015). However, some studies do not report significant improvements of vitamin $A$ in the treatment of cancer (Tang and Gudas, 2011; DavisYadley and Malafa, 2015). Important to note is that the beneficial response to RA supplementation is dependent on the combination of vitamin A (or alltrans RA) and existing therapy and that limited effects in patients with cancer were partly due to vitamin A resistance. Furthermore, clinical evidence shows that RAR $\beta$ expression is often inversely correlated with the tumor grade (Tang and Gudas, 2011).

The role of vitamin A has also been investigated in allergies, including asthma, eczema, rhinitis, and atopy, as reviewed by Hufnagl and Jensen-Jarolim (2019). Results with maternal or neonatal vitamin A supplementation have reported contradicting results (Hufnagl and Jensen-Jarolim, 2019). There are studies reporting a decreased risk of wheezing, eczema, asthma, and allergic rhinitis via maternal intake of vitamin $\mathrm{A}$, although other studies failed to observe 
this correlation. In adults with chronic airway inflammation and asthma, vitamin $\mathrm{A}$ in combination with other supplements, such as antioxidants, other vitamins, and fish oil, and healthy diet exhibits the capacity to alleviate allergic symptoms, including improvement of clinical outcomes and reduction in the occurrence of exacerbations (Nurmatov et al., 2011; Hufnagl and Jensen-Jarolim, 2019). In obese women, vitamin A supplementation leads to reduced IL- $1 \beta$ serum levels. In addition, the ratio IL- $1 \beta /$ IL 4 in serum related to the $\mathrm{Th} 1 / \mathrm{Th} 2$ ratio is reduced as a result of vitamin A supplementation in women with obesity, promoting an anti-inflammatory phenotype (Farhangi et al., 2013). Multiple sclerosis and atherosclerosis are both associated with dysregulation of Treg cells, whereas vitamin A or RA supplementation increased the expression of TGF- $\beta$ and FoxP3 in peripheral blood mononuclear cells of these patients, indicating an upregulation of the anti-inflammatory Treg phenotype (Mottaghi et al., 2012; Saboor-Yaraghi et al., 2015).

\section{B. Vitamin D Receptor}

1. The Receptor. The VDR is expressed by a majority of immune cells, such as T cells, B cells, monocytes, macrophages, and dendritic cells. Various immunomodulating activities of vitamin D-VDR signaling have been described, including suppression of autoimmunity and inflammation, modulation of differentiation of dendritic cells and $\mathrm{B} / \mathrm{T}$ cells, and inhibition of inflammatory cytokine secretion (Sassi et al., 2018). Additionally, the VDR is involved in several physiologic functions, including cell cycle progression, apoptosis, and calcium homeostasis (Khammissa et al., 2018). The VDR encloses the ligand after binding, resulting in the linking of coactivators and the binding partner RXR (Bikle, 2014). The VDR then binds to the Vitamin D Responsive Element and recruits coregulatory complexes, including histone acetyltransferases or deacetylases, methyltransferases, and demethylases (Fig. 2B). The genes that are transcribed differ for each vitamin D-VDR complex and are cell-specific.

2. Nutritional Activators. The ligand of the VDR, vitamin $\mathrm{D}$, can be obtained via different sources (Kulie et al., 2009; Khammissa et al., 2018). The precursor of the vitamin is formed in the skin after exposure to UV B radiation or obtained from vitamin D-rich foods, such as oily fish, eggs, and plants. Vitamin $\mathrm{D}$ from the sun or fish is pre-vitamin $\mathrm{D}_{3}$, whereas other nutritional components contain mostly pre-vitamin $\mathrm{D}_{2}$ (Bikle, 2014). Both precursors are metabolized in three main steps: 25-hydroxylation, $1 \alpha$-hydroxylation, and 24 -hydroxylation. This is performed by the cytochrome P450 oxidases (Bikle, 2014). The final product is $1,25(\mathrm{OH})_{2} \mathrm{D}$, the most active form of vitamin $\mathrm{D}$.
3. Immune Modulators. Functions of vitamin D have been described in different immune cells, including macrophages, dendritic cells, and $\mathrm{T}$ cells as summarized in Fig. 2A. 1,25(OH $)_{2} \mathrm{D}_{3}$ is responsible for the stabilization and inhibits the degradation of VDR (Costa and Feldman, 1987). Primarily, $1,25(\mathrm{OH})_{2} \mathrm{D}_{3}$ exhibits the capacity to counter bacterial infections. Airway epithelial cell lines SCC25 or Calu-3 incubated with Escherichia coli and Pseudomonas aeruginosa showed an increase in the expression and protein levels of antibacterial peptides, cathelicidin and defensin $\beta 2$, in response to $1,25(\mathrm{OH})_{2} \mathrm{D}_{3}$ treatment (Wang et al., 2004). The production of these antibacterial peptides was mediated via the vitamin D-responsive element in the DNA sequence of the peptides (Gombart et al., 2005). Similarly, the production of the antibacterial peptide cathelicidin increased after vitamin $\mathrm{D}$ induced VDR activation in monocytes and macrophages infected with Mycobacterium tuberculosis, compromising the bacterial viability (Liu et al., 2006). A study of Wang et al. (2014) pointed out that the basal expression and LPS-induced cyclooxygenase (COX)-2 in WT murine monocytes and macrophages were inhibited by vitamin $\mathrm{D}$ supplementation. This was mediated via VDR, since COX-2 expression was increased in monocytes and macrophages obtained from VDR knockout (KO) mice.

$1,25(\mathrm{OH})_{2} \mathrm{D}_{3}$ also has the ability to activate NODlike receptor protein (NLRP) 3 inflammasome and subsequently triggers IL- $1 \beta$ release, as observed in mouse primary peritoneal macrophages stimulated with LPS (Cao et al., 2020). The $1,25(\mathrm{OH})_{2} \mathrm{D}_{3}$-induced NLRP3 activation was dependent on VDR, since there was no difference in NLRP3 activation in macrophages transfected with siRNA. Additionally, attenuation of dextran sulfate sodium (DSS)-induced colitis was observed after $1,25(\mathrm{OH})_{2} \mathrm{D}_{3}$ supplementation by changing the M1/M2 ratio and inhibiting Th1 and Th17 cell populations in blood, spleen, and lymph nodes. Although it is likely that VDR is involved, this was not proven in this DSS colitis model (Cao et al., 2020).

Another study showed that supplementation of $1,25(\mathrm{OH})_{2} \mathrm{D}_{3}$ to LPS-stimulated human peripheral mononuclear cells displayed a transformation toward the M2 phenotype with upregulation of IL-10, arginase-1, and interferon regulatory factor 4 (IRF4) expression dependent on VDR, since macrophages transfected with siRNA-VDR and microRNA-125b mimic impaired $1,25(\mathrm{OH})_{2} \mathrm{D}_{3}$ activity. In addition, $1,25(\mathrm{OH})_{2} \mathrm{D}_{3}$ supplementation led to an upregulation of VDR in these human peripheral mononuclear cells (Zhu et al., 2019). In a murine DSS-induced colitis model, $1,25(\mathrm{OH})_{2} \mathrm{D}_{3}$ increased the phosphorylation and expression of IRF4 in lamina propria mononuclear cells and converted M1 macrophages to the M2 subtype, subsequently ameliorating the disease activity index, whereas 
microRNA-125b agomir injections reversed the action of $1,25(\mathrm{OH})_{2} \mathrm{D}_{3}$ (Zhu et al., 2019). Although no $\mathrm{KO}$ model was used in the in vivo part of this study, the results suggest involvement of VDR in the amelioration of DSSinduced colitis after $1,25(\mathrm{OH})_{2} \mathrm{D}_{3}$ treatment, which might be a promising target for future IBD treatment.

In murine $\mathrm{DCs}$, vitamin $\mathrm{D}$ induces a more tolerogenic phenotype with a reduction of major histocompatibility complex (MHC) II and costimulatory ligands B7-1, B7-2, and CD40, whereas this was not observed in DCs from VDR KO mice (Griffin et al., 2000). T-cell populations have also been shown to be altered by vitamin D, specifically shifting Treg/Th17 populations toward an anti-inflammatory phenotype as reviewed before by Bikle (2014) and Medrano et al. (2018). Phospholipase $\mathrm{C} \gamma 1$ is a crucial protein for $\mathrm{T}$ cell receptor signaling and T-cell activation, whereas activation of VDR via $1,25(\mathrm{OH})_{2} \mathrm{D}_{3}$ leads to accumulation of phospholipase $\mathrm{C} \gamma 1$ and, subsequently, T-cell growth and proliferation (von Essen et al., 2010). The absence of vitamin $\mathrm{D}$ has a great impact on $\mathrm{CD}^{+} \mathrm{T}$ cell effector differentiation, as observed by lower granzyme B expression and reduction in B-cell lymphoma 2 expression. Additionally, an inhibition in antigen-specific and memory $\mathrm{CD}{ }^{+} \mathrm{T}$ cells in VDR KO models was observed (Yuzefpolskiy et al., 2014). This shows that VDR is important for $\mathrm{CD}^{+} \mathrm{T}$-cell survival and immunity to fight against viral and bacterial infections. Finally, vitamin D/VDR signaling is important for the development of natural killer $\mathrm{T}$ cells, which are involved in fighting infections, cancer, and autoimmune diseases (Yu and Cantorna, 2008, 2011).

4. Clinical Application. The role of vitamin D in allergies is under discussion, and multiple systematic reviews observed contrasting results with vitamin D supplementation (Bozzetto et al., 2012; Jolliffe et al., 2013; Yepes-Nuñez et al., 2018). A possible explanation for these contrasting results could be the occurrence of VDR polymorphisms or the dosages of vitamin D that are used (Trombetta et al., 2018; Martens et al., 2020). It is remarkable that the dosages in in vivo studies described in this review are generally higher compared with dosages used in clinical studies (Martens et al., 2020). Low serum vitamin D concentrations in observational studies, however, are correlated with higher risk of autoimmune diseases, multiple sclerosis, and IBD (Trombetta et al., 2018). Sharifi et al. (2019) observed that patients with ulcerative colitis showed decreased TNF- $\alpha$, IFN- $\gamma$, and IL12p70 serum levels 3 months after a single muscular dose of vitamin $\mathrm{D}_{3}$ compared with saline as placebo. Vitamin D has the ability to inhibit the Th1 response related to the observed decreased in Th1related cytokines observed in their clinical study and previously performed in vitro studies (Sharifi et al., 2019). In contrary, vitamin D supplementation had clinical benefit in patients with both IBD and hypovitaminosis $\mathrm{D}$, since the release of proinflammatory cytokines IL-2, IL-12, IL-13, and IL-17 were downregulated, suggesting suppression of the Th17 phenotype, whereas TNF- $\alpha$ levels were decreased, in contrast to the results of Sharifi et al. (2019) (El Amrousy et al., 2020). Furthermore, vitamin D supplementation lowered the incidence of upper airway infections caused by the influenza virus investigated in patients with IBD (Arihiro et al., 2019). The protective effects of vitamin $D$ against airway infection, which is proposed to be linked to VDR activation, can be observed in other airway viruses as well. Several clinical studies have investigated the effects of vitamin D on coronavirus disease 2019 infection as additional supplement to the standard of care during hospitalization, hydroxychloroquine, and azithromycin treatment (Annweiler et al., 2020a, 2020b; Entrenas Castillo et al., 2020) . These studies all highlight better survival rate and less intensive care unit admissions with the inclusion of vitamin $\mathrm{D}$ in the treatment. One possible mechanism that is proposed is indeed VDR activation, leading to less severe acute respiratory distress syndrome (Entrenas Castillo et al., 2020).

\section{Liver X Receptor}

1. The Receptor. LXR is originally known for its role in cholesterol homeostasis but has been shown to be involved in cellular differentiation, apoptosis, lipid and carbohydrate metabolism, and immunity and inflammation (Patel et al., 2008). LXR exhibits antiinflammatory properties, and LXR agonists used in animal models displayed amelioration of inflammatory symptoms (Fessler, 2018). The NR LXR has two known isoforms ( $\operatorname{LXR} \alpha$ and $\beta$ ), and $\operatorname{LXR} \alpha$ is highly expressed in the liver, macrophages, intestine, adipose tissue, macrophages, and kidney, whereas $\operatorname{LXR} \beta$ is ubiquitously expressed (Fessler, 2018). LXR forms a heterodimer with RXR to perform the transactivation-the increased rate of gene expression-and two different pathways have been described (Fig. 2C). The first pathway involves binding of the LXR/RXR to the LXR response element. The corepressors are replaced with coactivators, resulting in the transcription of genes, including ATP Binding Cassette (ABC) A1 (Fessler, 2018). Another ABC, the ABCG1, is induced by the demethylation of DNA after ligand binding to the LXR/ RXR complex. Both ABCs are involved in cholesterol homeostasis. In addition to transactivation, LXR can induce transrepression without the heterodimerization with RXR. In macrophages, the LXR is SUMOylated after ligand and corepressor complex binding. This leads to the inhibition of proinflammatory genes via nuclear factor $\kappa$-light chain enhancer of activated $\mathrm{B}$ cells $(\mathrm{NF}-\kappa \mathrm{B})$ and activator protein 1 (AP-1) (Fessler, 2018). 


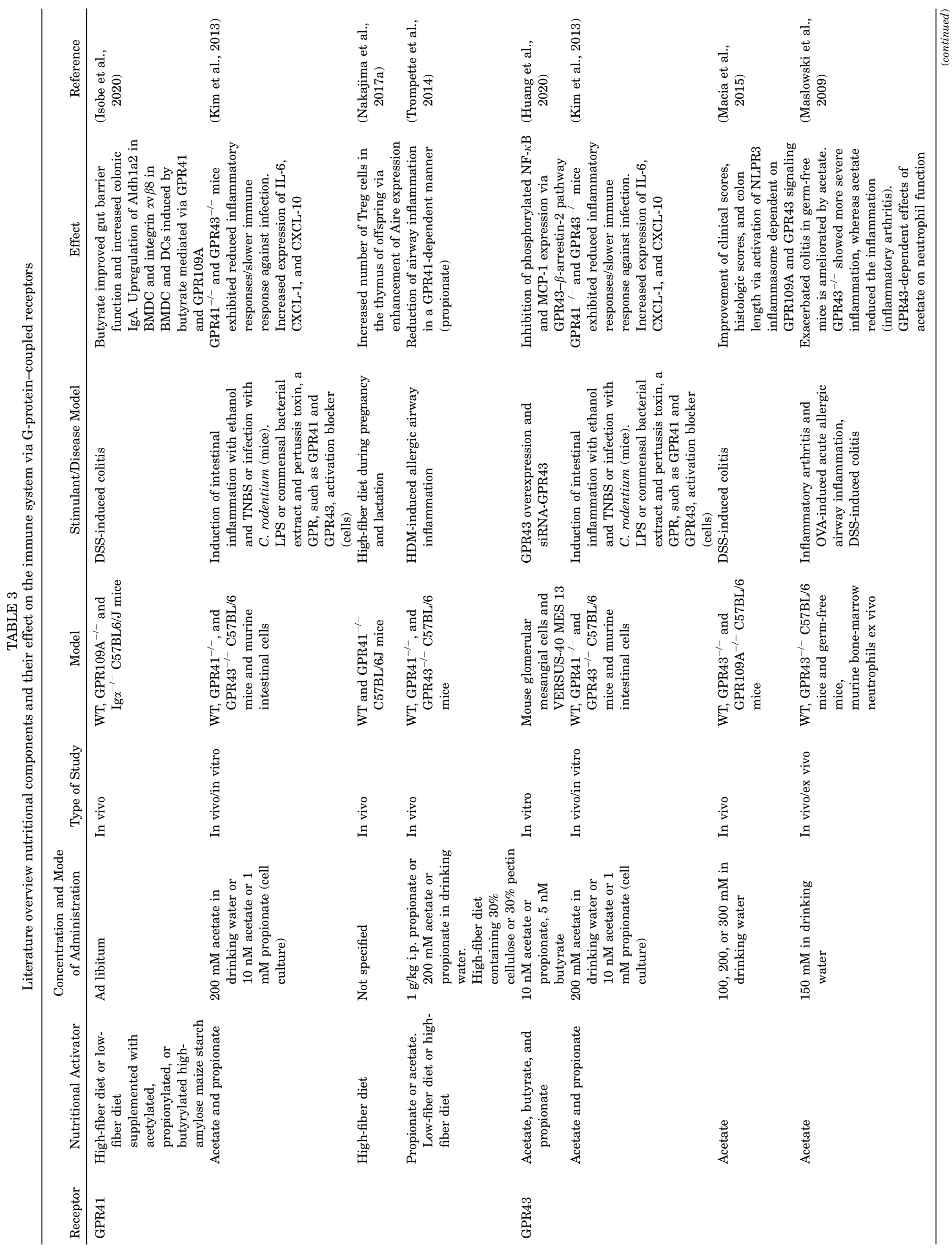

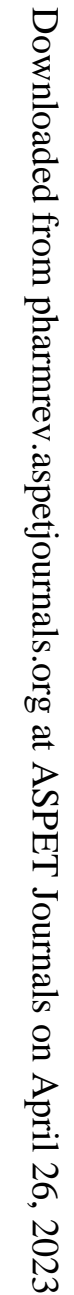


van Daal et al.
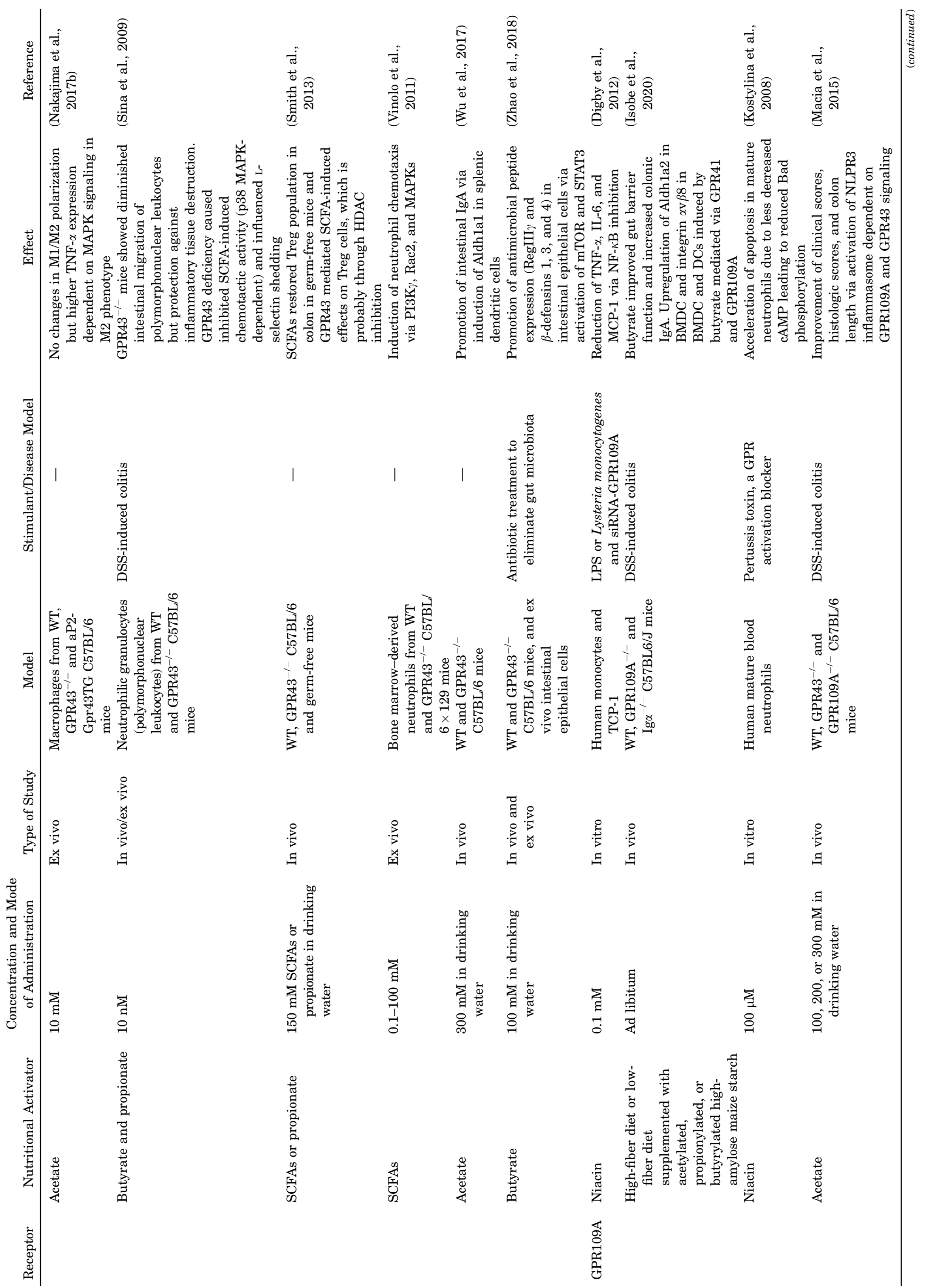


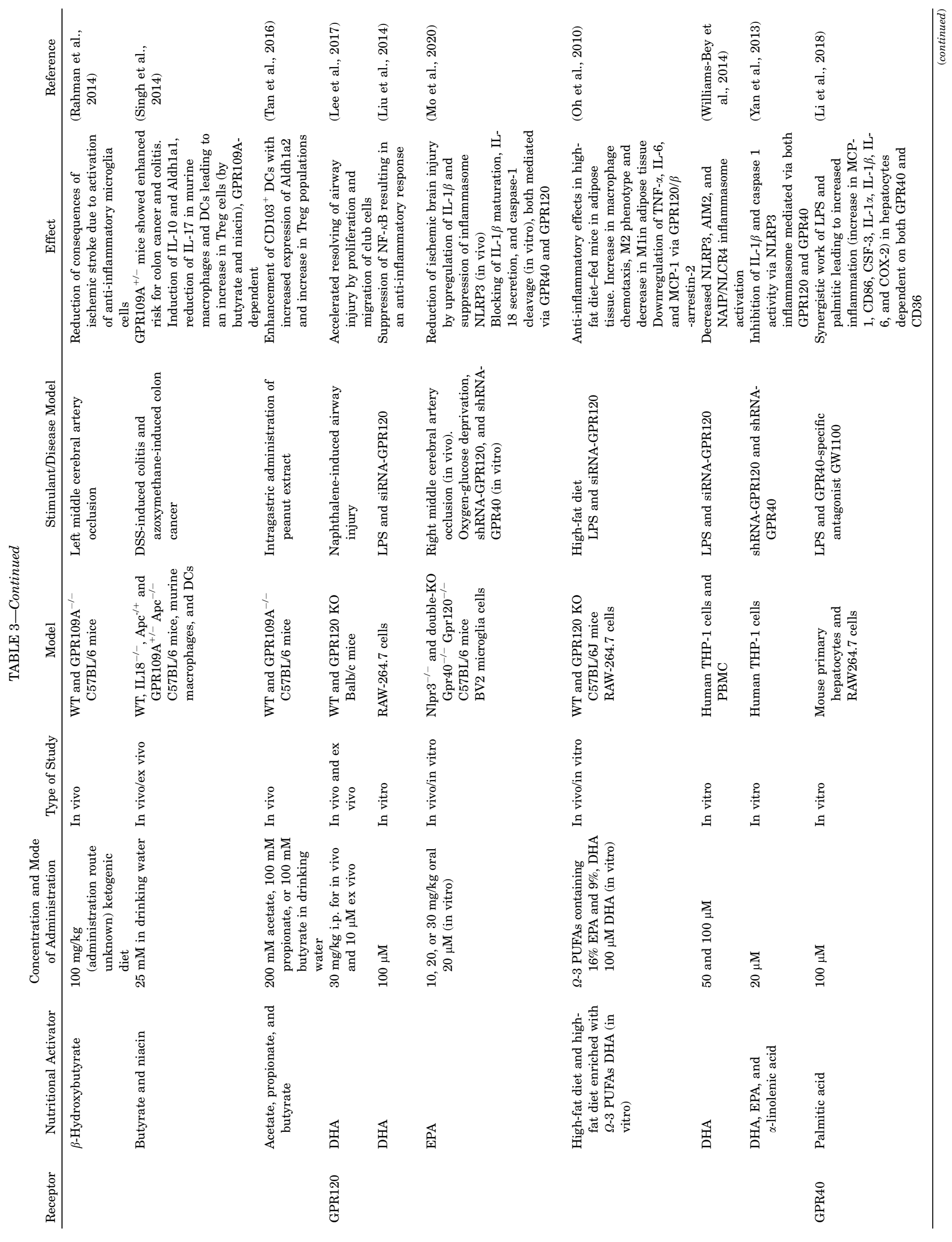

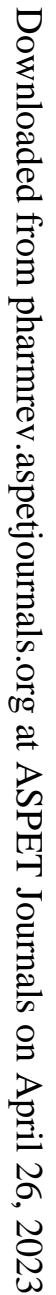




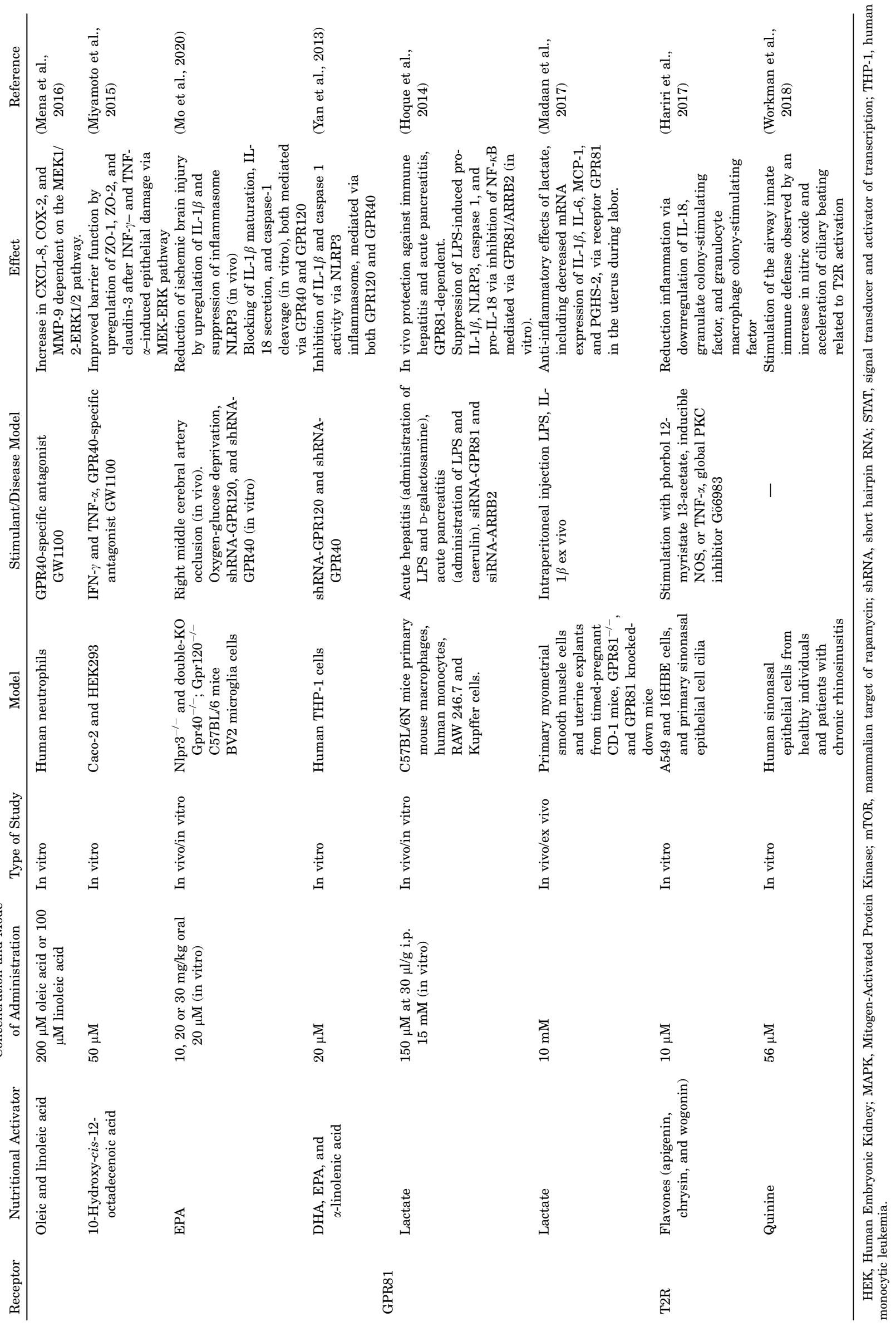


2. Nutritional Activators. The LXR has an important role in cholesterol metabolism, and the major activators are, intuitively, derivatives of cholesterol: oxysterols and cholesterol biosynthetic intermediates (Fessler, 2018). Different plant-derived flavonoids like cyanidin, naringenin, genistein, and others can also bind to LXR (Komati et al., 2017).

3. Immune Modulators. The effects of LXR are reported in a broad range of physiologic systems, including the inflammatory response, cell apoptosis, and phagocytosis (Fig. 2C). Synthetic ligands, such as GW9365A and T0901317, have been widely used in LXR research; however, we focus on studies that used natural ligands, including hydroxycholesterols and cyanidin-3-O- $\beta$-glucoside (Wang and Tontonoz, 2018). As previously mentioned, LXR can transrepress inflammatory genes, such as NF- $\kappa \mathrm{B}$, and suppress genes, such as inducible nitric oxide synthase (NOS), IL-6, COX-1, MMP-9, MCP-1, MCP-3, and IL-1 $\beta$ (Bensinger and Tontonoz, 2008). Moreover, the downstream targets of tolllike receptor (TLR) 4 , including IL- $1 \beta$, and TNF- $\alpha$, were antagonized by activating LXR (Bensinger and Tontonoz, 2008). In a murine model, allergic contact dermatitis was treated with $22(R)$-hydroxycholesterol, an oxysterol. This treatment led to a reduction of allergic symptoms as observed by a decrease in ear thickness accompanied with reduced TNF- $\alpha$ and IL- $1 \alpha$ secretion in the dermis and the epidermis (Fowler et al., 2003). The ear thickness and secretion of proinflammatory cytokines TNF- $\alpha$ and IL- $1 \alpha$ by keratinocytes in the dermis and the epidermis in this murine model were also reduced after oxysterol administration. These immunomodulatory effects were not observed in LXR $\beta$-deficient mice and were reduced with $50 \%$ in $\operatorname{LXR} \alpha$-deficient mice, indicating a role for the LXR receptor in this process (Fowler et al., 2003). After treatment with the flavonoid cyanidin-3-O- $\beta$-glucoside, the lungs of mice challenged with LPS showed a significant decrease in their histologic inflammatory profile with reduced cell infiltration, alveoli wall thickening, interstitial edema, and pulmonary congestion (Fu et al., 2014). This was accompanied with fewer proinflammatory cytokines, such as TNF- $\alpha$, IL- $1 \beta$, and IL-6, released by ex vivo LPS-restimulated alveolar macrophages treated with cyanidin-3-O- $\beta$-glucoside. This anti-inflammatory response was reversed by injection of $\operatorname{LXR} \alpha$ siRNA, indicating again the involvement of LXR. In addition, cyanidin-3-O- $\beta$-glucoside led to increased expression of LXR in these murine alveolar macrophages ( $\mathrm{Fu}$ et al., 2014). In murine macrophages, an anti-inflammatory response was observed after treatment with different oxysterols, as their actions appeared to repress inducible NOS (Joseph et al., 2003; Ghisletti et al., 2007). This was not observed in macrophages of $\mathrm{LXR}^{-/-}$mice, possibly because of the SUMOylation-dependent transrepression pathway, as described previously (Joseph et al., 2003; Ghisletti et al., 2007).
In murine macrophages, cholesterol and oxysterols are both implicated in phagocytosis of apoptotic debris induced by dexamethasone (A-Gonzalez et al., 2009). Furthermore, depletion of sterols in apoptotic thymocytes resulted in lowered expression of LXR target genes and Mer, a receptor tyrosine kinase involved in the apoptotic clearance (A-Gonzalez et al., 2009). Mice lacking the LXR gene exhibit a defect in phagocytosis of apoptotic cells causing a proinflammatory response leading to a breakdown in self-tolerance and development of autoantibodies (A-Gonzalez et al., 2009). Furthermore, oxysterols can inhibit the migration of DCs via inhibition of the CCR-7 receptor in murine BMDC (Villablanca et al., 2010). This effect is abrogated in the presence of short hairpin LXR, indicating a role for LXR in DC migration.

4. Clinical Application. Clinical studies showing beneficial effects in the clinic of LXR agonists are limited. Olivas-Aguirre et al. (2016) reviewed the effects of anthocyanins in humans, of which cyanidin-3-O$\beta$-glucoside is the most prevalent of this flavonoid family. In this review, anti-inflammatory effects induced by anthocyanins are described, including decrease in serum inflammatory biomarkers IL-6, MCP-1, C-reactive protein, and others, as well as benefits for cardiovascular protection and anticancer properties of anthocyanins (Cassidy et al., 2015; Olivas-Aguirre et al., 2016). Another review described the effects of the flavonoid naringin in different clinical trials (Salehi et al., 2019); also here, anti-inflammatory properties are reported, such as decreased Creactive protein and fibrinogen levels in blood samples and an inhibitory effect on oxidative stress in patients who are overweight or patients with chronic hepatitis C (Dallas et al., 2014; Gonçalves et al., 2017).

\section{Peroxisome Proliferator-Activated Receptor}

1. The Receptor. The final binding partner of the RXR that will be discussed is the NR PPAR. PPARs are known to be involved in the regulation of cellular differentiation, glucose and lipid metabolism, and carcinogenesis. PPAR signaling shows the ability to affect different features of inflammation and immunity, thereby contributing to the essential crosstalk between metabolism and immune system (Kidani and Bensinger, 2012).

$\operatorname{PPAR} \alpha, \operatorname{PPAR} \gamma$, and $\operatorname{PPAR} \beta / \delta$ are the three members of the PPAR subfamily (Kiss et al., 2013). After ligand binding, the receptor forms a heterodimer with RXR that binds to the PPAR responsive element in the DNA (Fig. 2D) (Rakhshandehroo et al., 2010). Activation is dependent on the removal of corepressors and the recruitment of coactivators. The activated genes downstream are primarily involved in lipid metabolism and homeostasis. On the other hand, if a corepressor complex is recruited, transrepression 


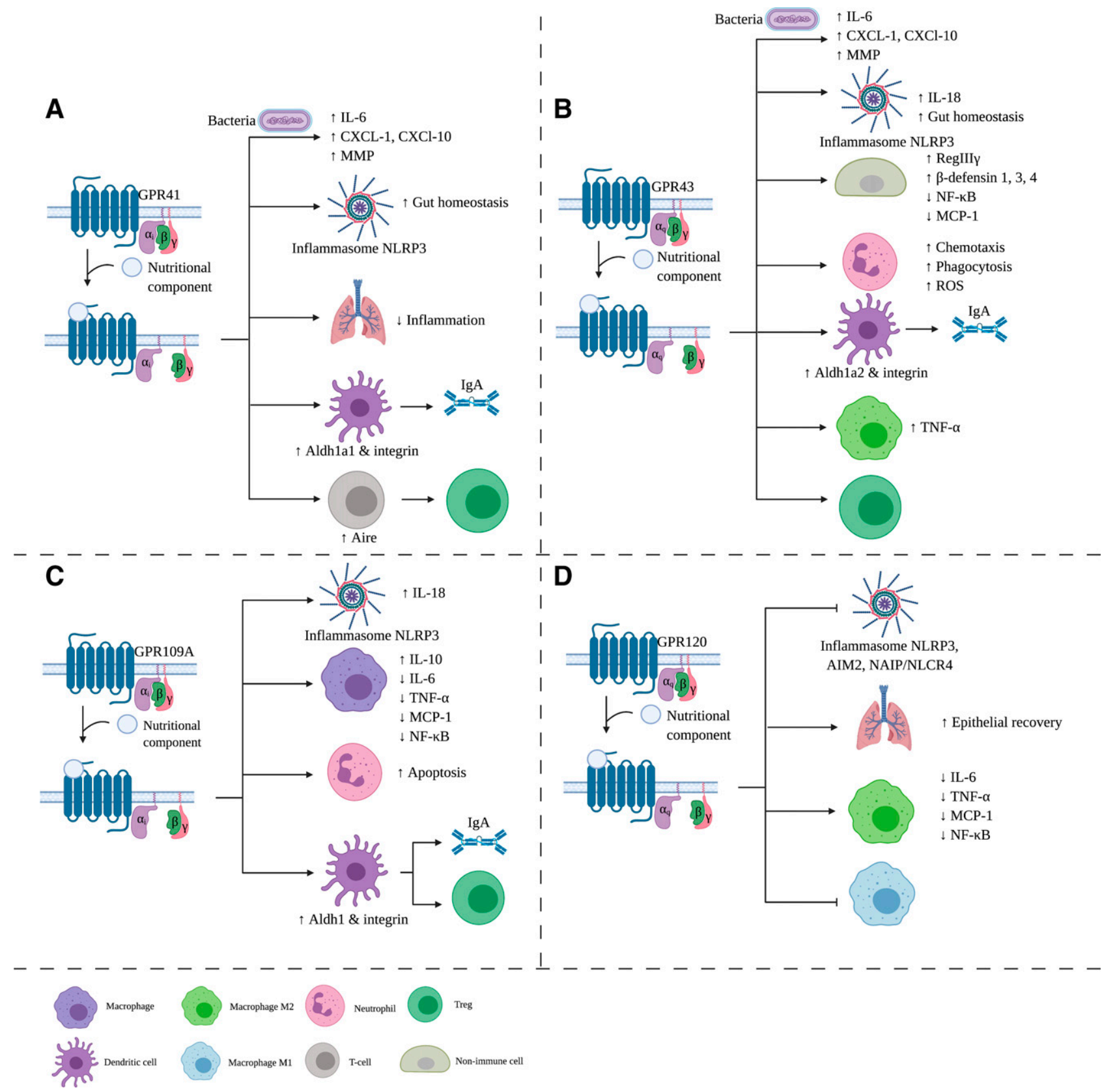

Fig. 3. Effects of nutritional components via GPR on the immune system. Binding of a nutritional component to one of the GPRs results in dissociation of the $\mathrm{G}_{\beta}$ and $\mathrm{G}_{\gamma}$ from the $\mathrm{G}_{\alpha}$ subunit. Depending on the $\mathrm{G}_{\alpha}$ subtype, signal transduction cascade is activated, leading to immunologic changes. GPR41 (A), GPR 43 (B), GPR109A (C), and GPR120 (D) are shown in this figure. ROS, reactive oxygen species. Created with BioRender.com.

of proinflammatory genes will occur, namely NF- $\kappa \mathrm{B}$ and AP-1 (Glass and Saijo, 2010).

2. Nutritional Activators. A range of nutritional activators binds to PPAR, namely polyunsaturated fatty acids (PUFAs), polyphenols, and natural carotenoids (Contreras et al., 2013). PUFAs have the highest binding affinity and can be divided into $\Omega-3$ and $\Omega-6$ based on the location of the double bond. PUFAs are lipid macronutrients present in the diet, the most studied of which are marine $\Omega-3$ PUFAs, including eicosapentaenoic acid (EPA) and docosahexaenoic acid
(DHA) (Wu et al., 2019). The polyphenols known to activate PPAR are resveratrol, which is in berries, grapes, and peanuts, and genistein, a soy isoflavone (Contreras et al., 2013).

3. Immune Modulators. Natural ligands of PPAR have been reported to exert immune regulatory functions; however, the described functions can be both PPAR-dependent and PPAR-independent. The PPARindependent functions are beyond the scope of this review. The most studied impact of natural ligands and PPAR is in the context of inflammation, and 
A

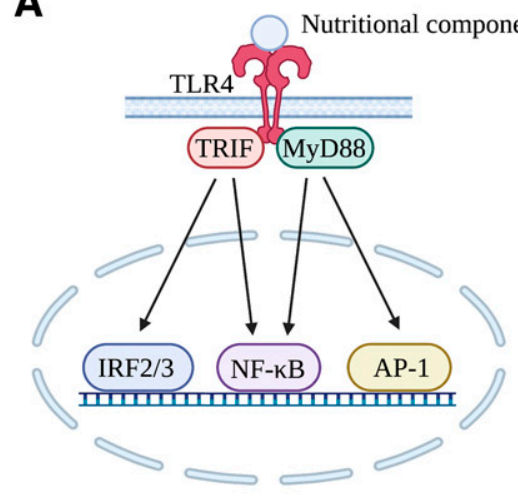

nat
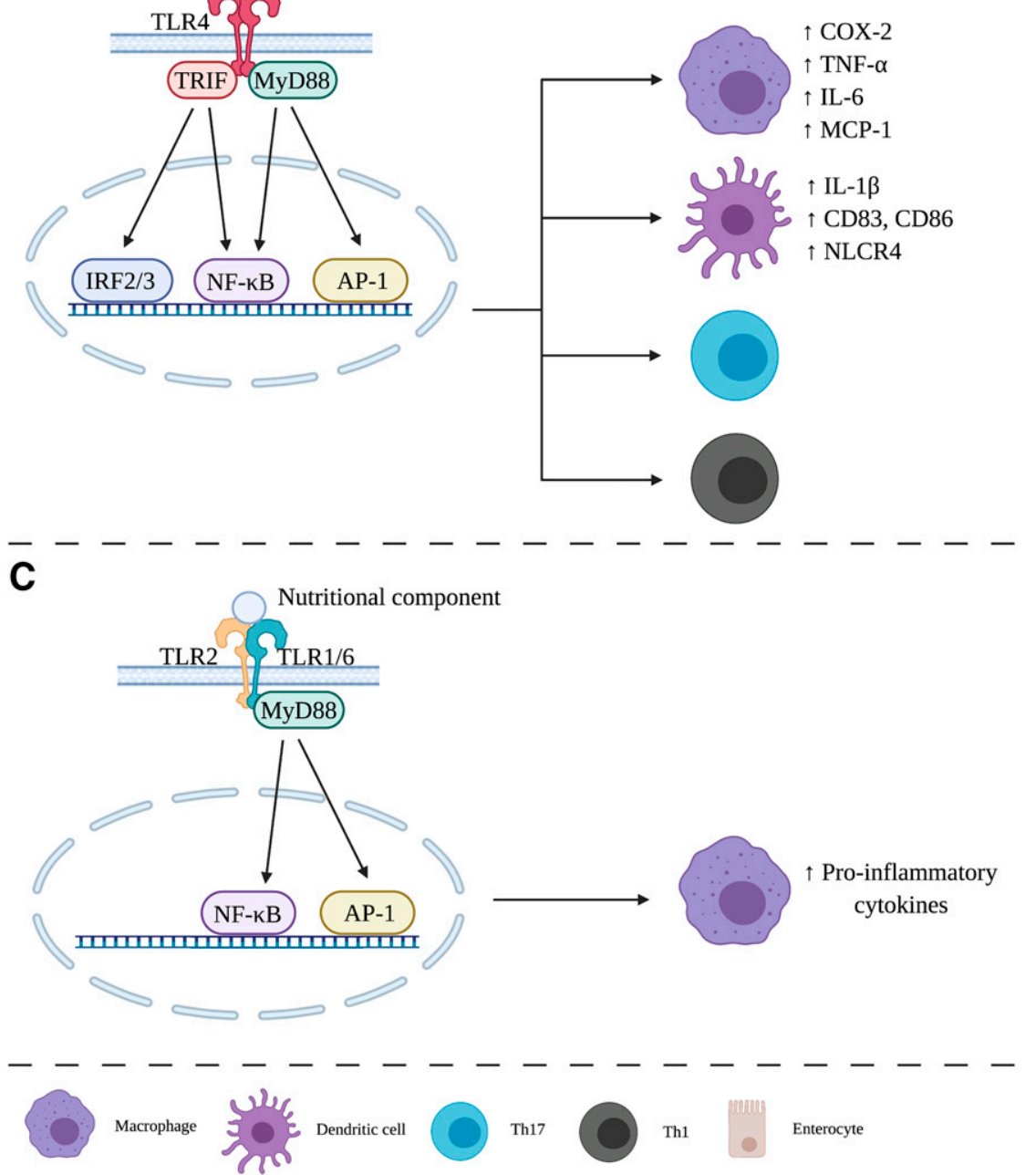

B

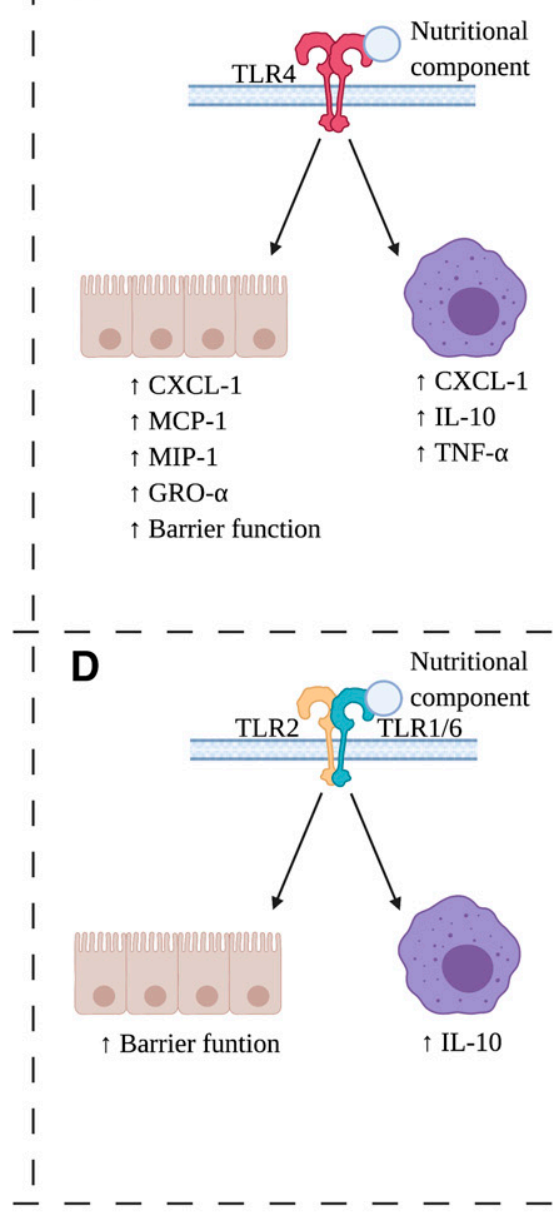

Fig. 4. Effects of nutritional components via TLR on the immune system. Dependent on the type of nutrition, TLR can have a proinflammatory or antiinflammatory effect. Anti-inflammatory effects of TLR4 (A) or TLR2 (C) are mediated through TRIF or MyD88-dependent signal transduction cascade. Other nutritional components binding to TLR4 (B) or TLR2 (D) lead to anti-inflammatory responses. GRO, human growth-related oncogene; MIP, macrophage inflammatory protein; TRIF, TIR-domain-containing adapter-inducing interferon- $\beta$. Created with BioRender.com.

generally, EPA and DHA stimulated anti-inflammatory cytokines in a PPAR $\gamma$-dependent manner (Fig. 2D) (Li et al., 2005; Jaudszus et al., 2013). Li et al. (2005) showed in an in vitro study using HK-2 human kidney cells that both EPA and DHA decreased LPSinduced NF- $\kappa \mathrm{B}$ activation and MCP-1 expression accompanied by a $\operatorname{PPAR} \gamma$ upregulation. With the PPAR $\gamma$-specific antagonist bisphenol A diglycidyl ether, these EPA- and DHA-induced effects were not observed ( $\mathrm{Li}$ et al., 2005). Another study pointed out that both EPA and DHA induced a concentrationdependent reduction of intracellular IL-2, IL-4, and TNF- $\alpha$ expression in Th cells (Jaudszus et al., 2013). EPA exhibited the strongest concentration-dependent effect, and again, the inhibitory effect of EPA and DHA on cytokine production in Th cells was reversed upon the addition of a PPAR $\gamma$-specific antagonist T0070907.
In the innate immune system, PUFAs influence the M1/M2 balance toward anti-inflammatory M2 macrophages. Luo et al. (2017) showed that DHA is able to shift the macrophage phenotype in murine Kupffer cells and RAW264.7 macrophages toward the more anti-inflammatory M2 phenotype, whereas treatment with a specific PPAR $\gamma$ antagonist GW9662 shifts the balance toward the proinflammatory M1 profile in RAW264.7 cells. This PPAR $\gamma$-specific effect of DHA was seen to be dependent of the NF- $\kappa$ Bp65 signaling pathway (Luo et al., 2017). Although PPAR $\gamma$ was undetectable in the control group, a significant increase in PPAR $\gamma$ protein expression was observed in RAW264.7 cells after DHA treatment (Luo et al., 2017). An important role of M2 macrophages is efferocytosis, the process of clearing apoptotic neutrophils during the final stages of an inflammatory response. In murine macrophage-like RAW264.7 cells, DHA 


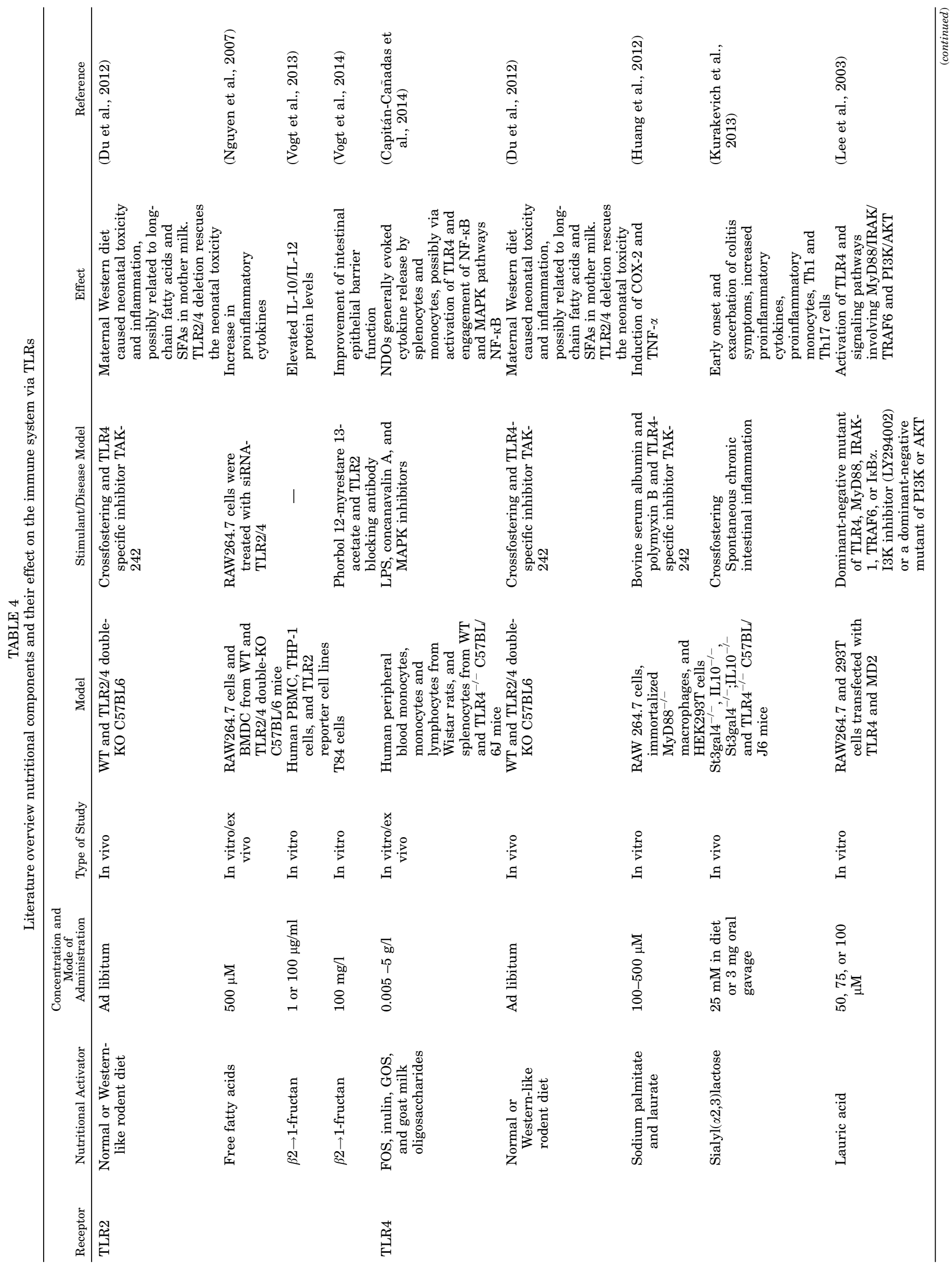

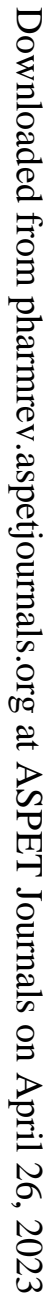




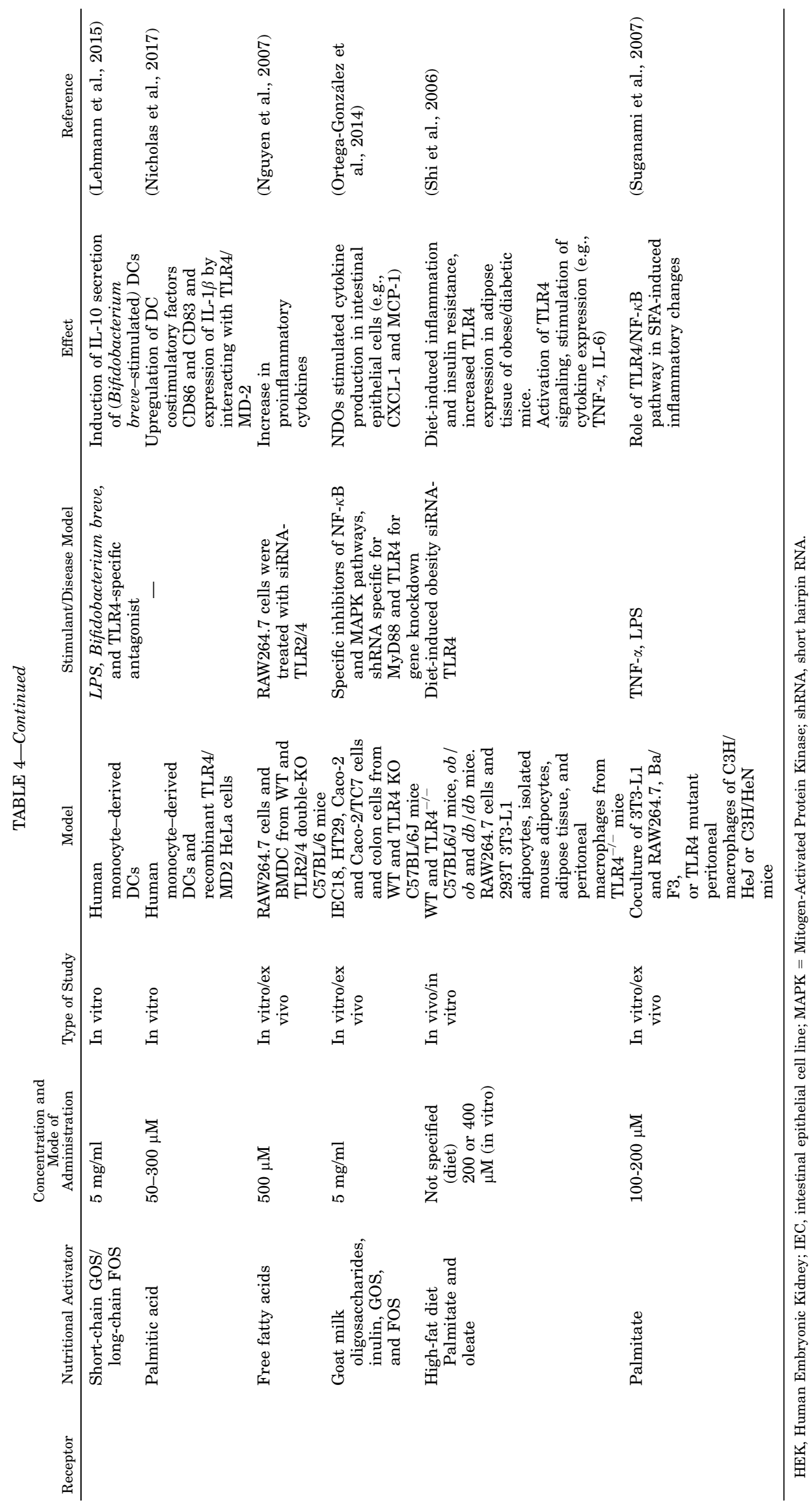


enhanced the efferocytosis, which was proven to be PPAR $\gamma$-dependent with the use of PPAR $\gamma$ siRNA (Chang et al., 2015). DHA not only increased the mRNA expression in RAW264.7 cells but also caused $\operatorname{PPAR} \gamma$ nuclear translocation (Chang et al., 2015). Aside from the PUFAs, two flavonoids, apigenin and chrysin, also induce a PPAR $\gamma$-dependent shift toward an M2 phenotype in murine peritoneal macrophages from obese mice or macrophage cell lines via NF- $\kappa \mathrm{B}$ inhibition (Feng et al., 2014, 2016). Oxidized EPA causes inhibition of rolling and adhesion of neutrophils in a model using leukocytes incubated with an HUVEC monolayer; however, PPAR-related effects were not indicated in vitro (Sethi et al., 2002). The neutrophil-related effects were also observed in the mesentery arteries of mice treated with LPS and oxidized EPA; however, this was not observed in PPAR $\alpha-$ deficient mice (Sethi et al., 2002).

The anti-inflammatory effects of DHA are also to be found in DCs. DHA supplementation prevents murine BMDC maturation associated with concentrationdependent PPAR binding to the PPAR-responsive element (Kong et al., 2010). Zapata-Gonzalez and colleagues (2008) linked the immature human DC phenotype to downregulation of costimulation and antigen presentation accompanied by increased chemotactic abilities of DCs in the presence of DHA, whereas mature DCs treated with DHA showed decreased IL- 6 expression and IL-10 and IL-12 secretion. When these DCs were cultured in the presence of a specific PPAR $\gamma$ inhibitor (GW9662), all DHAinduced changes were blocked (Zapata-Gonzalez et al., 2008). In addition, an inhibition of IL-12 mediated via inhibition of the $\mathrm{NF}-\kappa \mathrm{Bp} 65$ nuclear translocation was observed in DHA-treated murine BMDC (Kong et al., 2010).

The anti-inflammatory properties of EPA and DHA have also been described in $\mathrm{T}$ cells, but only a few articles include the role of PPAR in the mechanism of action. Two allograft transplant studies investigated the effect of EPA alone or EPA and DHA on heart transplantations (Iwami et al., 2009; Ye et al., 2012). In both studies the heart of a specific mouse strain was transplanted into another recipient mice strain treated with or without EPA, which resulted in less rejection and a more anti-inflammatory profile. This is represented by an inhibition of cytokine production in splenocytes, including IL-2, IL-6, IL-12, IL-17, IFN- $\gamma$, an increase in TGF- $\beta$, and changes in the ratio of different $\mathrm{T}$ cells in draining lymph nodes and heart. The ratio of Treg/Th17 was increased in mice supplemented with EPA because of the increase in the FoxP $3^{+}$Treg cells. In both in vitro and in vivo studies, these EPA-induced changes in cytokine production and $\mathrm{T}$ cell ratios were blocked with treatment of a specific PPAR $\gamma$ inhibitor, bisphenol A diglycidyl ether or GW9662 (Iwami et al., 2009; Ye et al., 2012). Interestingly, EPA also upregulated mRNA expression of PPAR $\gamma$ in spleen and cardiac allografts (Iwami et al., 2009; Ye et al., 2012).

4. Clinical Application. $\Omega-3$ PUFAs have been investigated in clinical trials for the exploration of their immunomodulatory effects in cancer and chronic inflammatory diseases. Reviews have described the Q-3 PUFA-induced reduction of pain and decrease in inflammatory markers in cancer, such as COX-2 expression and TNF- $\alpha$, IL- $1 \beta$, IL- 6 , and IFN- $\gamma$ in serum, although there is insufficient information to fully confirm the supportive effects of $\Omega$-3 PUFA supplementation in cancer (Aucoin et al., 2017; Freitas and Campos, 2019). Contradictory results have been reported in systemic reviews regarding the effects of $\Omega$-3 PUFAs in patients with IBD, including production of anti-inflammatory cytokines leading to IBD remission, as well as no protective effect (Marton et al., 2019; Mozaffari et al., 2020). These differences could be due to the mode of consumption, type of food, or different formulations (Marton et al., 2019). The same trend has been observed in allergic diseases, including asthma and eczema. There is a clear trend toward positive effects of $\Omega$-3 PUFA supplementation, which is possibly due to lower IgE levels or by inducing Th2 polarization, but this is not supported by all studies (Miles and Calder, 2017). A greater consensus can be found for the use of $\Omega$-3 PUFA supplementation in patients with rheumatoid arthritis and cardiovascular disease. Reduction of inflammation characterized by a decrease in proinflammatory cytokines TNF- $\alpha$, IL- 6 , and leukotriene B4, leading to improved clinical outcomes in these ailments, are described extensively in the following studies after $\Omega$-3 PUFA treatment (Yates et al., 2014; Gioxari et al., 2018; Innes and Calder, 2020; Kostoglou-Athanassiou et al., 2020). To confirm the clinical relevance of $\Omega-3$ PUFAs, more clinical studies are needed to further assess the potentials of these dietary components.

\section{G-Protein-Coupled Receptor}

G-coupled protein receptors (GPRs) represent the largest class of drug targets in the pharmaceutical world. They can be activated by multiple ligands, such as chemokines, peptides, lipids, and neurotransmitters. GPR signaling is involved in nearly all physiologic processes, and GPR $\mathrm{s}$ have been found to play an important role in the immune system (Hauser et al., 2017). GPR, a seven-transmembrane protein, has an associated G-protein in the inactive form (Moreira, 2014). Upon a ligand binding to the GPR, the $G \alpha$ and $\mathrm{G} \beta / \gamma$ subunits can dissociate, leading to various physiologic events, depending on the protein subfamily. All discussed GPRs are activated by fatty acids of varying lengths: SCFAs contain 2-6 carbon atoms, medium- 
chain fatty acids contain 7-12 carbon atoms, and long-chain fatty acids contain 13-22 carbon atoms (Ulven and Christiansen, 2015). The immunomodulatory effects of these nutritional components related to GPR signaling have been described in detail below and summarized in Table 3.

\section{A. G-Coupled Protein Receptor 41/43}

1. The Receptor. Both GPR41 and GPR43 can be activated in a $\mathrm{G} \alpha_{\mathrm{i} / \mathrm{o}} \beta$-gustducin-dependent manner (Sivaprakasam et al., 2016). Binding of the ligand causes a conformational change and inhibition of the second messenger cAMP (Sivaprakasam et al., 2016). GPR43 can also be activated in a $\mathrm{G} \alpha_{\mathrm{q}}$-dependent manner, leading to a decrease in cAMP (Fig. 3B). Other G-coupled proteins, such as $\beta$-arrestin, can associate with GPR41 and activate other signal transduction pathways (Fig. 3A). GPR41 is involved in metabolic homeostasis, namely leptin production and sympathetic activation, whereas GPR43 has functions in adipogenesis, energy homeostasis, and the immune response (Sivaprakasam et al., 2016).

2. Nutritional Activators. Both receptors are activated by SCFAs, fermentation products of dietary fiber by the microbiota in the gut (Sivaprakasam et al., 2016). SCFAs, are also present in grains, fruits, and vegetables and include pentanoate, butyrate, propionate, and acetate (Tan et al., 2017). The affinity for SCFAs differs between the receptors. GPR41 has high affinity for SCFAs, butyrate and propionate, whereas GPR43 had high-affinity acetate and propionate (Sivaprakasam et al., 2016).

3. Immune Modulators. Immune activation via GPR41/43 is mainly described in the gastrointestinal tract, as their dietary ligands, SCFAs, are produced by microbiota in the gut (Fig. 4, A and B).

Macia et al. (2015) showed that a high-fiber diet increases the butyrate and acetate concentration in the gut, activating GPR43 on intestinal epithelial cells. The cell hyperpolarization via GPR43 second messengers activates the NLRP3 inflammasome and converts pro-IL-18 into IL-18, leading to protection from DSS-induced colitis. This protection was observed as an improvement of clinical scores, histologic scores, and colon length and was not present in GPR43 ${ }^{-/-}$mice (Macia et al., 2015). SCFAs are needed for the production of antibacterial peptides by cells (e.g., RegIII $\gamma$ and $\beta$-defensins 1,3 , and 4 , which were absent in the intestinal epithelial cells of GPR43 ${ }^{-l-}$ mice) (Zhao et al., 2018). Furthermore, SFCA acetate promoted the IgA production via induction of Aldh 1a1 in murine splenic dendritic cells, which was also seen to be absent in GPR $43^{-/-}$mice (Wu et al., 2017). Moreover, Kim et al. (2013) showed that SCFAs induced a rapid production of different chemokines and cytokines, such as IL-6, CXCL-1, and CXCL-10, by murine intestinal epithelial cells, which was abolished after pretreatment with pertussis toxin, a GPR activation blocker, whereas GPR41 ${ }^{-/-}$ and GPR $43^{-/-}$mice exhibited reduced inflammatory responses after ethanol, 2,4,6-trinitrobenzene sulfonic-acid (TNBS), or Citrobacter rodentium administration. In WT mice, SCFAs restore the gut homeostasis in a GPR41- and GPR43-dependent manner by activation of the NLRP3 inflammasome (Macia et al., 2015). Although a majority of research has focused on the effects of SCFAs in the intestine, Trompette et al., (2014) displayed that a high-fiber diet is also able to positively affect the airways. Mice on a low-fiber diet exhibited more proinflammatory cytokines in the lungs, leading to an increased allergic airway responsiveness and subsequent DC activation in lung-draining lymph nodes. In addition, propionate promoted anti-inflammatory effects in the lungs, which was mediated by GPR41 rather than GPR43 (Trompette et al., 2014). An in vitro study indicated that acetate, butyrate, and propionate inhibited phosphorylated NF- $\kappa \mathrm{B}$ and MCP-1 expression via the GPR43- $\beta$-arrestin- 2 pathway in mouse glomerular mesangial cells and SV-40 MES 13 cell line (Huang et al., 2020). The anti-inflammatory effects of SCFAs were more pronounced by the GPR43 overexpression, whereas they were inhibited by siRNA-GPR43. Furthermore, GPR43 mRNA and protein levels were increased in kidney tissue after SCFA incubation (Huang et al., 2020).

It has also been observed that neutrophil recruitment is increased after treatment with acetate, propionate, or butyrate, and this occurs via GPR43 activation, since this is not detected in GPR43-deficient mice (Sina et al., 2009; Vinolo et al., 2011). This chemotactic capacity is promoted via phosphoinositide 3 kinase $\gamma$, Rac2, and mitogen-activated protein kinase (Vinolo et al., 2011) and inhibition of the Lselectin concentration (important for adhesion to epithelial cells and migration) via p38 mitogen-activated protein kinase in murine neutrophilic granulocytes (polymorphonuclear leukocytes) (Sina et al., 2009). Acetate exhibited the capacity to stimulate the calcium flux in mouse neutrophils, which was not observed in neutrophils from $G p r 43^{-1-}$ mice. In addition, acetate reduced the expression of other proinflammatory receptors on neutrophils, including C5aR and CXC chemokine receptor 2, but it is not known whether this is GPR43-dependent (Maslowski et al., 2009).

A more recent study investigated SCFA signaling via GPR43 in macrophages in vitro and in vivo and pointed out that SCFA treatment promoted the M2 phenotype, whereas it did not alter the murine M1 phenotype in adipose tissue. This SCFA-induced M2 phenotype expressed more TNF- $\alpha$ compared with untreated M2 macrophages, resulting in the 
maintenance of adipose tissue homeostasis (Nakajima et al., 2017b).

SCFA activation of GPR41 and GPR43 has been shown to increase the proliferation of the $\mathrm{FoxP}^{+}$ Treg population in lamina propria, spleen, and thymic lobes without influencing the number of Th17 or Th1 cells in mice (Smith et al., 2013; Nakajima et al., 2017a). Nakajima et al. (2017a) also promoted the importance of butyrate via GPR41 during pregnancy in mice, as it enhanced the Aire expression in fetal thymic Treg cells, which is crucial for the negative selection of $\mathrm{T}$ cells and development of immunotolerance in the fetus. In murine colonic T cells, propionate influences the activity of histone deacetylases in a GPR43-dependent manner, leading to an increase in the Treg population (Smith et al., 2013). Finally, GPR41 is critical for the T-cell independent butyrateinduced IgA response and improved gut barrier function in the mouse colon, which is mediated via the upregulation of Aldh1a2 and integrin $\alpha \mathrm{v} \beta 8$ in DCs (Isobe et al., 2020).

4. Clinical Application. Roduit et al. (2019) suggested that strategies to increase the SCFA concentrations by dietary intervention could be a possible strategy for preventing allergic diseases in children, since higher levels of propionate and butyrate in feces of 1-year-old children are related to decreased incidence of atopic sensitization and asthma (Roduit et al., 2019). The metabolic potential of the gut microbiota responsible for the availability of the SCFAs, plays an important role in this allergy sensitization (Cait et al., 2019). The SCFA composition in feces is changed in patients with IBD, and the link between IBD and intestinal microbiota has been intensely investigated in the recent decades (Hedin et al., 2007; Lavelle and Sokol, 2020). There are changes in the microbiota composition comparing healthy individuals with patients with IBD, leading to changes in SCFA availability (Silva et al., 2018). In patients with ulcerative colitis or Crohn disease, an 8-week treatment with butyrate decreased the $\mathrm{NF}-\kappa \mathrm{B}$ signaling in the lamina propria or ileum, respectively (Lührs et al., 2002; Di Sabatino et al., 2005). In addition to the downregulation of $\mathrm{NF}-\kappa \mathrm{B}$, a butyrateinduced decrease in ileal IL- $1 \beta$ associated with an antiinflammatory state, was observed in patients suffering from Crohn disease (Di Sabatino et al., 2005). In patients with ulcerative colitis, butyrate treatment also induced a reduction in neutrophil infiltration in gut crypts and surface epithelia (Lührs et al., 2002). In turn, these anti-inflammatory effects correlated with decreased disease activity. Another study showed a decrease in the colonic IL-10/IL-12 ratio, a marker for a more anti-inflammatory phenotype, in patients with ulcerative colitis after butyrate treatment (Hamer et al., 2010). Additionally, a negative association between inflammation, as measured by calprotectin and the antioxidant glutathione levels, and butyrate intervention has been reported in these patients (Hamer et al., 2010). It however has to be noted that not all research found beneficial effects of SCFAs in the treatment of IBD-ulcerative colitis or Crohn-as has been reviewed before (Hedin et al., 2007; Fernández et al., 2016; Sun et al., 2017; Gill et al., 2018). Autoimmune diseases multiple sclerosis and rheumatoid arthritis are characterized by a disbalance in the Treg and Th17 population in tissue, lower proportions of Treg cells, and higher levels of Th17 cells compared with healthy individuals. An elaborate study by Duscha et al. (2020) showed a significant decrease in the number of Th17 cells and increase in Treg cells after treatment with propionate in patients suffering from multiple sclerosis and rheumatoid arthritis. This gives opportunities for future treatment of autoimmune diseases with propionate supplementation.

\section{B. G-Coupled Protein Receptor 109A}

1. The Receptor. GPR109 consists of two isoforms in humans: GPR109A and GPR109B, wherein GPR109B is a duplicate of GPR109A (Sivaprakasam et al., 2016). GPR109A is activated in a $\mathrm{G} \alpha_{\mathrm{i} / \mathrm{o}}$ $\beta$-arrestin 1 similar to GPR41/43 (Fig. 3C). GPR109A is involved in intestinal homeostasis, inhibition of lipolysis, high-density lipoprotein biosynthesis, tolllike receptor TLR responsiveness, and the NF- $\kappa \mathrm{B}$ pathway (Chai et al., 2013; Sivaprakasam et al., 2016).

2. Nutritional Activators. The receptor is activated by the SCFAs, butyrate, hydroxybutyrate, and niacin-a form of vitamin B3 (Sivaprakasam et al., 2016).

3. Immune Modulators. GPR109A is present on innate immune cells but not on natural killer cells, $\mathrm{T}$ cells, and B cells (Singh et al., 2014). Hence, the immunomodulatory effects of GPR109A are restricted to the innate immune system and only indirectly influence the adaptive immune system (Fig. 3C). The expression of epithelial GPR109A in intestinal mucosal tissue in both human and mice is most likely related to the proximity of SCFAs produced by the microbiota (Parada Venegas et al., 2019).

Butyrate induces activation of the NLRP3 inflammasome in murine epithelial cells of the colon via GPR109A in vitro as well as in vivo (Macia et al., 2015). A high amount of dietary fiber resulted in the improvement of clinical and histologic scores in mice with DSS-induced colitis via this NLRP3 inflammasome mechanism dependent on GPR109A and GPR43 signaling (Macia et al., 2015). The importance of GPR109A in gut immunity is furthermore highlighted by research conducted by Singh et al. (2014), who showed that butyrate and niacin treatment promotes the induction of anti-inflammatory IL-10 and Aldh1a1 expression and splenic DCs and macrophages 
accompanied by a reduction of IL-17, leading to an increase in Treg cells. This was not observed in Niacr $1^{-/-}$DCs and macrophages. Additionally, mice lacking the GPR109A showed increased pathology after DSS-induced colitis and azoxymethane-induced colon cancer (Singh et al., 2014).

Niacin also demonstrates anti-inflammatory activity in human macrophages by reducing the level of proinflammatory cytokines after TLR2 or 4 stimulation (Digby et al., 2012). Stimulation of TLR2 and 4 with heat-killed Listeria monocytogenes or LPS, respectively, led to an increase in proinflammatory cytokines TNF- $\alpha$, IL- 6 , and MCP-1. Niacin reduced this effect, which was mediated via GPR109A and by inhibiting DNA binding of GPR109A to the NF- $\kappa$ B gene. This anti-inflammatory effect of niacin was not observed in knockdown of GPR109A using siRNA (Digby et al., 2012). Activation of GPR109A via $\beta$-hydroxybutyrate also leads to fewer brain infarcts due to activation of anti-inflammatory microglia cells, which are absent in GPR109A ${ }^{-/-}$mice (Rahman et al., 2014).

Less is known about GPR109A function in neutrophils, but niacin acid binding to GPR109A induced a reduction of cAMP, resulting in a reduced proapoptotic factor Bad phosphorylation, and subsequently increased apoptosis via caspase activation in mature blood neutrophils from healthy donors (Kostylina et al., 2008). Blocking the GPR109A signal transduction cascade using pertussis toxin abolished these effects. It appears that only mature neutrophils express GPR109A.

To date, the effect of GPR109A activation in DCs is much less clear. Some studies concluded that GPR109A is not involved in the anti-inflammatory activity of DCs, but HDAC inhibition or retinal dehydrogenase 1 induction is supposed to be responsible (Arpaia et al., 2013; Goverse et al., 2017). In contrast, other studies found that GPR109A (encoded by Niacr1) activation is responsible for the anti-inflammatory action of murine DCs (Singh et al., 2014; Tan et al., 2016; Isobe et al., 2020). Both butyrate and niacin increased the expression of the anti-inflammatory molecules Aldh1 and Il-10 in WT splenic DCs, whereas butyrate and niacin failed to modulate these expression levels in Niacr $1^{-/-}$splenic DCs. This in turn led to increased capacity of DCs to induce the differentiation of nave $\mathrm{T}$ cells into Treg cells, which are also dependent on GPR109A (Singh et al., 2014). Another study showed that butyrate enhanced the Aldh1a2 expression in DCs in vitro and in vivo and promoted IgA responses in the colon, contributing to the maintenance of the colonic barrier function and the gut immune homeostasis (Isobe et al., 2020). Finally, a high-fiber diet showed increased tolerance and protection against food allergies when GPR43,
GPR109A, and RAR signaling were involved (Tan et al., 2016).

4. Clinical Application. The effects of SCFA in human studies have been described before in IV.D.4. Clinical Application.

\section{G-Coupled Protein Receptor 120}

1. The Receptor. The GPR120, also known as the free fatty acid receptor, has a long and a short isoform in humans (Ulven and Christiansen, 2015). The difference between the two isoforms is the presence or absence of a 16-amino-acid-long segment in the third loop. Only the short isoform can associate with the $\mathrm{G}_{\alpha \mathrm{q} / 11}$ protein, but both receptors can associate with the $\beta$-arrestin-2 protein (Fig. 3D) (Milligan et al., 2017). This receptor is involved in several physiologic functions, including hormone production in the liver and intestines, perception of fat in the taste buds, and several anti-inflammatory processes (Ulven and Christiansen, 2015).

2. Nutritional Activators. The receptor can be activated by medium-chain fatty acids as well as longchain fatty acids (Ulven and Christiansen, 2015). The most potent $\Omega-3$ PUFAs activating GPR120 include EPA and DHA in fish and seafood and $\alpha$-linolenic acid in seeds, nuts, and vegetable oils (Calder, 2013; Ulven and Christiansen, 2015). Lastly, the $\Omega-6$ fatty acid arachidonic acid can activate GPR120 (Ulven and Christiansen, 2015).

3. Immune Modulators. The immunomodulatory effects of GPR120 are mostly related to macrophages, and these effects are summarized in Fig. 3D.

The GPR120-dependent anti-inflammatory effects of $\Omega$-3 PUFAs have also been observed in rat hypothalamic cells and murine in vivo models (Cintra et al., 2012; Wellhauser and Belsham, 2014; Li et al., 2015). Mice with naphthalene-induced airway injury show completely destroyed bronchial epithelium, whereas dietary $\Omega$-3 fatty acids increased clinical epithelial recovery dependent on GPR120 (Lee et al., 2017). In addition, DHA stimulated the proliferation and migration of mouse lung epithelial club cells in an in vitro model, which was also dependent on GPR120 (Lee et al., 2017). The expression of GPR120 is dependent on $\Omega-3$ PUFAs as well. Sprague-Dawley rats fed a diet supplemented with purified fish oil or flaxseed oil, which are both rich in $\Omega-3$ PUFAs, had significantly higher expression of GPR120 in the colon (Cheshmehkani et al., 2015).

Oh et al. (2010) conducted one of the first studies that linked GPR120 signaling to macrophage immunity after supplementation with DHA. In this in vitro study, LPS-induced proinflammatory cytokines, such as TNF- $\alpha$, IL-6, and MCP-1, are downregulated in response to DHA binding to GPR120 on mouse macrophage RAW264.7 cells, causing ligand binding of $\beta$-arrestin 2 with GPR120 and subsequent TAP1 
binding to $\beta$-arrestin 2 . This prevents TAK1 from associating with TAP1 and thus blocks the signaling cascade induced by LPS (Oh et al., 2010). Furthermore, an in vivo study using mice fed control or highfat diet enriched with $\Omega-3$ PUFAs demonstrated increased macrophage chemotaxis in the adipose stromal vascular fraction, decreased proinflammatory M1 markers, and increased anti-inflammatory M2 markers after $\Omega$-3 PUFA-enriched diet, which was not present in GPR120 KO mice (Oh et al., 2010). Further evidence of anti-inflammatory effects of $\Omega-3$ PUFA treatment on macrophages included inhibition of the inflammasome NLRP3 or proinflammatory NF$\kappa \mathrm{B}$ signaling (Yan et al., 2013; Williams-Bey et al., 2014). siRNA or GPR120 KO models abolished these effects on inflammasome and NF- $\kappa \mathrm{B}$ activation. This again emphasizes the anti-inflammatory effects of $\Omega-3$ PUFAs via GPR120 activation (Yan et al., 2013; Williams-Bey et al., 2014). In addition, DHA activation of GPR120 has been shown to inhibit the inflammasome pathway in macrophages in vitro and in vivo, contributing to an anti-inflammatory phenotype (Yan et al., 2013; Williams-Bey et al., 2014; Mo et al., 2020). DHA activation of GPR120 also inhibited the translocation of the nuclear factor p65, inhibiting NF- $\kappa \mathrm{B}$ expression in RAW264.7 cells, leading to an anti-inflammatory response after LPS incubation (Liu et al., 2014).

4. Clinical Application. The effects of $\Omega-3$ PUFAs and SCFAs in human studies have been described before in IV.D.4. Clinical Application.

\section{Other G-Coupled Protein Receptors}

A few GPRs are not discussed in detail because of the limited number of studies investigating the effects of nutritional components at time of writing. Nevertheless, a few results are important to mention to form a complete picture. GPR40 is a GPR that has affinity for certain nutritional components, and the downstream effects have been shown to influence the immunologic activity. It appears that $\Omega$-3 PUFAs suppress the activation of inflammasome NLRP3 in BV-2 microglial cells, murine bone marrow-derived macrophages, and mice and thus reduce inflammation (Yan et al., 2013; Mo et al., 2020), whereas $\Omega-6$ PUFAs, $\Omega-9$ PUFAs, and unsaturated fatty acids increase inflammation as observed by the upregulation of several mediators, including COX-2, CXCL-8, and IL-6 expression on mRNA and protein level, from certain cell types (Mena et al., 2016; Li et al., 2018). Furthermore, 10-hydroxy-cis-12-octadecenoic acid improves the intestinal epithelial barrier function in vitro via upregulation of zonula occludens (ZO) 1, ZO-2, and claudin-3 mediated through the MEK -ERK pathway (Miyamoto et al., 2015). Lactate binding to GPR81 exerted anti-inflammatory effects in both in vitro and in vivo studies (Hoque et al., 2014; Madaan et al., 2017). Bitter taste receptor GPR T2R activation by quinine led to an increase in nitric oxide production and subsequently accelerates ciliary beating in an air-liquid interface model with human sinonasal tissue from healthy individuals or patients with chronic rhinosinusitis (Workman et al., 2018). In addition, flavones apigenin, chrysin, and wogonin, as T2R agonists, demonstrated anti-inflammatory properties in airway cells in response to inflammatory stimuli (Hariri et al., 2017). For more details regarding these studies, see Table 3.

\section{Toll-Like Receptor}

\section{A. The Receptor}

TLRs are the most well characterized class of pattern-recognition receptors. They play a crucial role in "danger" recognition and are critical for eliciting a protective immune response against pathogens via the regulation of host immune effector functions, including cytokine production, inflammasome activation, autophagy, antigen presentation, and $\mathrm{B}$ and $\mathrm{T}$ cell activation (Kawasaki and Kawai, 2014; Mukherjee et al., 2019). TLRs can be categorized into transmembrane (TLR1, TLR2, TLR4, TLR5, TLR6, and TLR11) or intracellular receptors (TLR3, TLR7, TLR8, and TLR9) (Mukherjee et al., 2019). All TLRs consist of extracellular leucine-rich repeats and an intracellular Toll-IL receptor domain and can recognize pathogen-associated molecular patterns, microbe-associated molecular patterns, and damageassociated molecular pattern molecules and subsequently induce downstream signaling (Kawasaki and Kawai, 2014; Mukherjee et al., 2019). The effects of TLR activation within the cell can be MyD88-dependent or independent (Kawasaki and Kawai, 2014; Rocha et al., 2016; Mukherjee et al., 2019). The MyD88-dependent response involves a complex signal transduction cascade leading to the activation of NF$\kappa \mathrm{B}$ or AP-1 (see Fig. 4, A and C). Toll/IL-1 receptordomain-containing adapter-inducible IFN- $\beta$ recruits the proteins involved in the MyD88-independent pathway, which leads to a type I IFN response via TLR4 activation (Fig. 4A). Both pathways lead to a proinflammatory response and eventual recruitment of the innate immune system.

\section{B. Nutritional Activators}

Two different classes of nutritional components are known to activate TLRs. The first class is SFAs, in particular lauric acid (Rocha et al., 2016), and the second type includes the nondigestible oligosaccharides (NDOs) (Ayechu-Muruzabal et al., 2018). In Table 4, an overview of these nutritional components and their effect on the immune system via TLR is presented. 


\section{Immune Modulators}

TLRs are generally expressed on immune cells, such as monocytes, macrophages, dendritic cells, B lymphocytes, $\mathrm{T}$ lymphocytes, mast cells, neutrophils, and eosinophils, but also on nonimmune cells like epithelial cells, endothelium, fibroblasts, and adipocytes. Ligand binding triggers the signaling pathway to initiate immune-effector responses, both adaptive and innate immune responses (Dolasia et al., 2018). SFAs and NDOs have opposite effects on the immune system via TLR activation. Although the immunomodulatory effects of SFAs mainly exhibit a proinflammatory characteristic (Fig. 4, A and $\mathrm{C}$ ), NDOs possess a primarily anti-inflammatory capacity (Fig. 4, B and D).

In vitro studies have found that the SFAs palmitate, oleate, and lauric acid all induce proinflammatory activities in monocytes and macrophages via TLR2 and TLR4 (Lee et al., 2003; Shi et al., 2006; Nguyen et al., 2007; Suganami et al., 2007; Huang et al., 2012). The fatty acid -induced activation of the TLR signal transduction cascade leads to NF$\kappa \mathrm{B}$-activated induction of proinflammatory genes and cytokines, including COX-2, TNF- $\alpha$, IL-6, and MCP-1 in macrophages and BMDC (Lee et al., 2003; Shi et al., 2006; Nguyen et al., 2007; Suganami et al., 2007; Huang et al., 2012). In addition, the mRNA TLR4 expression was higher in adipose tissue of obese mice fed with a high-fat diet compared with mice fed a control diet (Shi et al., 2006). KO models and the use of short hairpin RNA confirmed that TLR4 is necessary for the fatty acid-induced NF- $\kappa \mathrm{B}$ activation (Shi et al., 2006; Nguyen et al., 2007; Suganami et al., 2007). An interesting murine study showed that offspring from mothers on a Western diet containing extra fat, cholesterol, and sucrose had skin inflammation and loss of body hair (Du et al., 2012). Crossfostering a normal diet mother with offspring from a Westernlike diet mother or weaning recovers these observed effects. This indicates that the negative effects observed in pups from mothers on a Western-like diet may be reversible. A TLR2/TLR4 double-KO model abolished the inflammation and hair loss in the offspring and highlighted that parental nutrition during lactation is also important for offspring health and dependent on TLR2/TLR4 (Du et al., 2012).

Nicholas et al. (2017) investigated the effects of palmitic acid on human DCs and found that the palmitic acid-stimulated DCs are matured and activated as seen by the upregulation of costimulatory factors CD86 and CD83. Furthermore, palmitic acid increased the production of the proinflammatory cytokine, IL-1 $\beta$, which was inhibited by blocking TLR4 with CLI-095. Therefore, it can be concluded that palmitate can induce a proinflammatory response mediated by TLR4. In addition, palmitic acid caused an increase in NLRC4 inflammasome in DCs, which could be responsible for cleavage of pro-IL-1 $\beta$, and palmitic acid exhibited the capacity to decrease proteins related to antigen presentation.

Besides their microbiota-dependent effect, various oligosaccharides also exhibit anti-inflammatory properties. In intestinal epithelial cells, fructo-oligosaccharides (FOSs), galacto-oligosaccharides (GOSs), inulins, and goat milk oligosaccharides activate TLR4, increasing the expression of human growthrelated oncogene- $\alpha$, MCP- 1 , and macrophage inflammatory protein 2, and enhance barrier function. These responses were decreased in a MyD88 and TLR4 gene knockdown model (Ortega-González et al., 2014). The barrier function of human intestinal epithelial cells is also improved by fructans. Although the exact mechanism of action is not yet clear, TLR2 might be involved, since TLR2 blocking antibodies reversed these protective effects (Vogt et al., 2014). In a murine model of colitis, the milk oligosaccharide sialyl $(\alpha 2,3)$ lactose (present in breast milk) modulated mucosal immunity and aggravated colitis triggering the proinflammatory profile by the expansion of Th1 and Th17 phenotypes, which was absent in TLR4deficient mice (Kurakevich et al., 2013).

In PBMC, FOS, GOS, and fructans have the capacity to modulate cytokine production, leading to more anti-inflammatory IL-10 production (Vogt et al., 2013; Capitán-Cañadas et al., 2014; Lehmann et al., 2015). This process was dependent on TLR2 (Vogt et al., 2013) or TLR4 (Capitán-Cañadas et al., 2014; Lehmann et al., 2015).

\section{Clinical Application}

Reviews have reported the beneficial effects of the NDOs, FOS, and GOS, in prevention and treatment of allergic diseases, including atopic dermatitis, eczema, asthma, allergic rhinitis, and food allergies. Because of risk of bias, heterogeneity of clinical trials, and inconsistency of the NDOs used, additional studies are needed (Osborn and Sinn, 2013; Cuello-Garcia et al., 2017; Brosseau et al., 2019). Boyle and colleagues (2016) investigated the effects of partially hydrolyzed whey formula containing oligosaccharides-neutral short-chain GOS, long-chain FOS, pectin, and hydrolysate-derived acidic oligosaccharidesin children with a predisposition to eczema based on family history before the age of 18 weeks. These children had increased levels of FoxP3 Treg cells and lower concentrations of IL- 4 , IL-13, INF- $\gamma$, and TNF- $\alpha$ in peripheral blood mononuclear cells compared with children fed with standard formula. Infants treated with formula containing GOS/FOS resulted in a beneficial antibody profile, since lower plasma levels of IgG1, IgG2, IgG3, and cow's milk-specific IgE antibodies were observed (van Hoffen et al., 2009). These two studies confirm that GOS/FOS supplementation 
in children may have beneficial effects on allergies via immune modulation. A review of Davani-Davari et al. (2019) described the effects of NDOs observed in IBD and colorectal cancer, and although some studies report positive results, other studies using NDOs were not effective. The same review also gives an overview of the immunomodulatory of GOS and FOS effects in clinical trials, including improved immune response toward vaccination and decrease in proinflammatory cytokines, such as IL- 6 , IL- $1 \beta$, and TNF- $\alpha$. Another review reported the reduction of the proinflammatory profile in people with obesity after supplementation with inulin type fructans or GOS (Fernandes et al., 2017). From these studies, it is not clear whether these effects are dependent on TLR2 or TLR4 signaling. Different articles emphasized the beneficial effects of these NDOs as a result of changes in the microbiota composition and in turn increased SCFA production, which could have been related to the observed antiinflammatory and protective effects (Brosseau et al., 2019; Tandon et al., 2019).

\section{Conclusions and Discussion}

This review describes in detail the effects of nutritional components and their metabolites on the immune system via specific (pharmacological) receptors, as summarized in Table 1-4. Nutritional components can promote both anti-inflammatory and proinflammatory processes, depending on the nutrient-receptor complex and interactions (and quantity of nutritional components). Generally, the nutritional components, including SFAs, tend to have proinflammatory effects. Conversely, nutritional components, such as vitamins, fibers, and unsaturated fatty acids, are able to resolve inflammation and are generally anti-inflammatory.

In the present review, we collated studies investigating the mechanistic effects of various nutritional components on major receptor types of the immune system, thereby providing a tool to better understand the proinflammatory and anti-inflammatory properties of these nutritional components that may assist efforts to prevent and treat NCDs. Understanding the mechanism of action of these nutritional components may be used to develop informed studies with the aim of developing natural therapeutic options when an imbalance in the immune system is observed. Previous studies have described possible beneficial effects of nutritional components for NCDs, such as cardiovascular diseases, autoimmune diseases, and inflammatory bowel disease, as observed by prevention and alleviation of clinical symptoms (Wędrychowicz et al., 2016; Mijan and Lim, 2018; Constantin et al., 2019; Li et al., 2019; Rivellese et al., 2019). Here, we extended possible descriptions of the pharmacological and physiologic mechanisms underlying these health benefits. Understanding the mode of action of these natural ligands means the manipulation of such receptors to improve the affinity of the natural ligand might be another potential course of action in tackling NCDs.

\section{A. Analytical Discussion (Murine) Experimental Models}

Remarkably, very little clinical research involving the immunomodulatory effects of nutritional components via receptor signaling is currently available. In vitro models have provided important tools for focusing on the mechanism behind the immune regulation by dietary components; nevertheless, the physiologic relevance of these monoculture and coculture models needs careful interpretation (Saeidnia et al., 2015). As described in this review, murine models utilizing inbred mouse strains and $\mathrm{KO}$ mice are also frequently used to unravel the mechanisms for immune modulation by nutritional components. Mouse models have advantages compared with other species, such as genome similarities between human and mouse and an excellent genetic/molecular toolbox. Balb/C and C57BL/6 backgrounds are the most widely used inbred strains and are considered as golden standard in biologic and biomedical research. However, the genetic background may alter the susceptibility to infection and other diseases, such as allergic diseases (Gueders et al., 2009; Hartmann et al., 2021). It is well known that C57BL/6 mice demonstrate a skewing toward Th1 responses, whereas the Balb/c mice are regarded as a Th2-dominant mouse strain (Yagi et al., 2006). Recently, a study pointed out that Treg subsets take the lead in the regulation of immune responses during infection in Balb/c, whereas various immune regulatory pathways occur in $\mathrm{C} 57 \mathrm{BL} / 6$ mice (Hartmann et al., 2021). The use of these strains may mask immunologic pathways that exist in human beings and may even overshadow the consequence of the targeted mutation (Rivera and Tessarollo, 2008).

Therefore, care should be taken when drawing conclusions based on the results from a single genetic background and extrapolating this to the human situation (Rivera and Tessarollo, 2008). Despite the many similarities, differences in the organization of the immune system of man and mouse are highlighted by critics, which makes direct translation of murine data to the human situation difficult (Vandamme, 2014; Zschaler et al., 2014). Outbred mice will show higher levels of genetic variation contributing to individual variation in response to a dietary intervention, and therefore the experimental data may be more applicable to human populations (Tuttle et al., 2018). These outbred mice, but especially humanized mice models (mice engrafted with human cells/tissues or mice that transgenically express human genes), represent promising tools for investigating human immune 
responses in future preclinical studies (Allen et al., 2019). Of course, clinical studies are needed in the future to confirm the preclinical results and to investigate the effect of nutritional components on the genetic heterogeneity in humans.

The information provided in this review may serve pharmacologists, health care professionals, and researchers that aim to find solutions for NCDs. Increasing evidence shows that particularly during the early stages of disease, lifestyle interventions, such as specific nutritional components, are by no means inferior to medical treatment (Carruba et al., 2016; Hyseni et al., 2017; Witkamp and van Norren, 2018). Pharmacologists as well as nutritionists are increasingly aware that multifactorial diseases, such as NCD, may require a multitarget approach because of their complexity and the involvement of multiple signaling pathways (Witkamp and van Norren, 2018). Therefore, successful concepts to treat, prevent, or delay these diseases might be found in combinations of medicines and nutritional components to increase efficacy and reduce adverse effects. The understanding of the pharmacological modulation of immune responses by nutritional components will move the disciplines of pharmacology and nutrition toward each other in science as well as in the clinic.

There is extreme variation in the production and consumption of food between cultures, regions, and countries and even among individuals depending on multiple factors, such as socioeconomic status or age (Mertens et al., 2019). These factors impact the level of nutritional components and metabolites in the body significantly. Some of the nutritional components mentioned in this review are present in high levels in certain diets, but other diets lack specific foods and these single nutritional components. Sometimes the effective dosage of these nutritional components will be reached, whereas in other populations the optimal dose is not ingested, and in some circumstances, it could even be exceeded. The effective dosage is not only based on intake levels but also depends on the bioavailability of these nutritional components after ingestion. The bioavailability is influenced by 1) bioaccessibility, including the release of nutritional components from food matrices, 2) absorption by the epithelial layer, and 3) chemical and biochemical transformations (Dima et al., 2020). Therefore, it is essential but very difficult to give an unambiguous advice on the efficiency, safety, and toxicity of these nutritional components.

In addition, we must be aware that consumers can respond differently to dietary interventions. Individual differences like age, gender, metabolism, and microbiome composition might contribute to these individual responses. It has even been recognized that genetic variations might affect individual nutritional requirements and bioavailability of nutrients between individuals (Bashiardes et al., 2018). In this regard, personalized nutrition might be a good strategy to improve human health (Adams et al., 2020).

\section{Authorship Contributions}

Wrote or contributed to the writing of the manuscript: van Daal, Folkerts, Garssen, Braber.

\section{References}

Adams SH, Anthony JC, Carvajal R, Chae L, Khoo CSH, Latulippe ME, Matusheski NV, McClung HL, Rozga M, Schmid CH, et al. (2020) Perspective: Guiding principles for the implementation of personalized nutrition approaches that benefit health and function. Adv Nutr 11:25-34.

A-Gonzalez N, Bensinger SJ, Hong C, Beceiro S, Bradley MN, Zelcer N, Deniz J, Ramirez C, Díaz M, Gallardo G, et al. (2009) Apoptotic cells promote their own clearance and immune tolerance through activation of the nuclear receptor LXR. Immunity 31:245-258.

Allen TM, Brehm MA, Bridges S, Ferguson S, Kumar P, Mirochnitchenko O, Palucka K, Pelanda R, Sanders-Beer B, Shultz LD, et al. (2019) Humanized immune system mouse models: progress, challenges and opportunities. Nat Immunol 20:770-774.

Alwan A and Maclean DR (2009) A review of non-communicable disease in lowand middle-income countries. Int Health 1:3-9.

Annweiler C, Hanotte B, Grandin de l'Eprevier C, Sabatier JM, Lafaie L, and Célarier T (2020a) Vitamin D and survival in COVID-19 patients: A quasiexperimental study. J Steroid Biochem Mol Biol 204:105771.

Annweiler G, Corvaisier M, Gautier J, Dubée V, Legrand E, Sacco G, and Annweiler C (2020b) Vitamin d supplementation associated to better survival in hospitalized frail elderly COVID-19 patients: The GERIA-COVID quasiexperimental study. Nutrients 12:3377.

Arihiro S, Nakashima A, Matsuoka M, Suto S, Uchiyama K, Kato T, Mitobe J, Komoike N, Itagaki M, Miyakawa Y, et al. (2019) Randomized trial of vitamin D supplementation to prevent seasonal influenza and upper respiratory infection in patients with inflammatory bowel disease. Inflamm Bowel Dis 25:1088-1095.

Arpaia N, Campbell C, Fan X, Dikiy S, van der Veeken J, deRoos P, Liu H, Cross JR, Pfeffer K, Coffer PJ, et al. (2013) Metabolites produced by commensal bacteria promote peripheral regulatory T-cell generation. Nature 504:451-455

Aucoin M, Cooley K, Knee C, Fritz H, Balneaves LG, Breau R, Fergusson D, Skidmore B, Wong R, and Seely D (2017) Fish-derived omega-3 fatty acids and prostate cancer: A systematic review. Integr Cancer Ther 16:32-62.

Ayechu-Muruzabal V, van Stigt AH, Mank M, Willemsen LEM, Stahl B, Garssen J, and Van't Land B (2018) Diversity of human milk oligosaccharides and effects on early life immune development. Front Pediatr 6:239.

Bashiardes S, Godneva A, Elinav E, and Segal E (2018) Towards utilization of the human genome and microbiome for personalized nutrition. Curr Opin Biotechnol 51:57-63.

Bensinger SJ and Tontonoz P (2008) Integration of metabolism and inflammation by lipid-activated nuclear receptors. Nature 454:470-477.

Benson JM and Shepherd DM (2011) Dietary ligands of the aryl hydrocarbon receptor induce anti-inflammatory and immunoregulatory effects on murine dendritic cells. Toxicol Sci 124:327-338.

Berthon BS, Macdonald-Wicks LK, Gibson PG, and Wood LG (2013) Investigation of the association between dietary intake, disease severity and airway inflammation in asthma. Respirology 18:447-454.

Bikle DD (2014) Vitamin D metabolism, mechanism of action, and clinical applications. Chem Biol 21:319-329.

Boyle RJ, Tang ML, Chiang WC, Chua MC, Ismail I, Nauta A, Hourihane JOB, Smith P, Gold M, Ziegler J, et al.; PATCH study investigators (2016) Prebioticsupplemented partially hydrolysed cow's milk formula for the prevention of eczema in high-risk infants: a randomized controlled trial. Allergy 71:701-710.

Bozzetto S, Carraro S, Giordano G, Boner A, and Baraldi E (2012) Asthma, allergy and respiratory infections: the vitamin D hypothesis. Allergy 67:10-17.

Brosseau C, Selle A, Palmer DJ, Prescott SL, Barbarot S, and Bodinier M (2019) Prebiotics: mechanisms and preventive effects in allergy. Nutrients 11:1841.

Cait A, Cardenas E, Dimitriu PA, Amenyogbe N, Dai D, Cait J, Sbihi H, Stiemsma L, Subbarao P, Mandhane PJ, et al. (2019) Reduced genetic potential for butyrate fermentation in the gut microbiome of infants who develop allergic sensitization. $J$ Allergy Clin Immunol 144:1638-1647.e3.

Calder PC (2013) Omega-3 polyunsaturated fatty acids and inflammatory processes: nutrition or pharmacology? Br J Clin Pharmacol 75:645-662.

Cao R, Ma Y, Li S, Shen D, Yang S, Wang X, Cao Y, Wang Z, Wei Y, Li S, et al. (2020) $1,25(\mathrm{OH})_{2} \quad \mathrm{D}_{3}$ alleviates DSS-induced ulcerative colitis via inhibiting NLRP3 inflammasome activation. J Leukoc Biol 108:283-295.

Capitán-Cañadas F, Ortega-González M, Guadix E, Zarzuelo A, Suárez MD, de Medina FS, and Martínez-Augustin O (2014) Prebiotic oligosaccharides directly modulate proinflammatory cytokine production in monocytes via activation of TLR4. Mol Nutr Food Res 58:1098-1110.

Carruba G, Cocciadiferro L, Di Cristina A, Granata OM, Dolcemascolo C, Campisi I, Zarcone M, Cinquegrani M, and Traina A (2016) Nutrition, aging and cancer: lessons from dietary intervention studies. Immun Ageing 13:13. 
Cassidy A, Rogers G, Peterson JJ, Dwyer JT, Lin H, and Jacques PF (2015) Higher dietary anthocyanin and flavonol intakes are associated with anti-inflammatory effects in a population of US adults. Am J Clin Nutr 102:172-181.

Castro-Rodriguez JA, Garcia-Marcos L, Alfonseda Rojas JD, Valverde-Molina J, and Sanchez-Solis M (2008) Mediterranean diet as a protective factor for wheezing in preschool children. J Pediatr 152:823-828, 828.e1-828.e2.

Chai JT, Digby JE, and Choudhury RP (2013) GPR109A and vascular inflammation. Curr Atheroscler Rep 15:325.

Chang HY, Lee H-N, Kim W, and Surh Y-J (2015) Docosahexaenoic acid induces M2 macrophage polarization through peroxisome proliferator-activated receptor activation. Life Sci 120:39-47.

Cheshmehkani A, Senatorov IS, Kandi P, Singh M, Britt A, Hayslett R, and Moniri NH (2015) Fish oil and flax seed oil supplemented diets increase FFAR4 expression in the rat colon. Inflamm Res 64:809-815.

Cintra DE, Ropelle ER, Moraes JC, Pauli JR, Morari J, Souza CT, Grimaldi R, Stahl M, Carvalheira JB, Saad MJ, et al. (2012) Unsaturated fatty acids revert diet-induced hypothalamic inflammation in obesity. PLoS One 7:e30571.

Constantin MM, Nita IE, Olteanu R, Constantin T, Bucur S, Matei C, and Raducan A (2019) Significance and impact of dietary factors on systemic lupus erythematosus pathogenesis. Exp Ther Med 17:1085-1090.

Contreras AV, Torres N, and Tovar AR (2013) PPAR- $\alpha$ as a key nutritional and environmental sensor for metabolic adaptation. Adv Nutr 4:439-452.

Costa EM and Feldman D (1987) Measurement of 1,25-dihydroxyvitamin D3 receptor turnover by dense amino acid labeling: changes during receptor upregulation by vitamin D metabolites. Endocrinology 120:1173-1178.

Cuello-Garcia C, Fiocchi A, Pawankar R, Yepes-Nuñez JJ, Morgano GP, Zhang Y, Agarwal A Gandhi S, Terracciano L, Schünemann HJ, et al. (2017) Prebiotics for the prevention of allergies: a systematic review and meta-analysis of randomized controlled trials. Clin Exp Allergy 47:1468-1477.

Cunningham TJ and Duester G (2015) Mechanisms of retinoic acid signalling and its roles in organ and limb development. Nat Rev Mol Cell Biol 16:110-123.

da Costa JP (2017) A current look at nutraceuticals - key concepts and future prospects. Trends Food Sci Technol 62:68-78.

Dallas C, Gerbi A, Elbez Y, Caillard P, Zamaria N, and Cloarec M (2014) Clinical study to assess the efficacy and safety of a citrus polyphenolic extract of red orange, grapefruit, and orange (Sinetrol-XPur) on weight management and metabolic parameters in healthy overweight individuals. Phytother Res 28:212-218.

Davani-Davari D, Negahdaripour M, Karimzadeh I, Seifan M, Mohkam M, Masoumi SJ, Berenjian A, and Ghasemi Y (2019) Prebiotics: definition, types, sources, mechanisms, and clinical applications. Foods 8.92.

Davis-Yadley AH and Malafa MP (2015) Vitamins in pancreatic cancer: a review of underlying mechanisms and future applications. Adv Nutr 6:774-802.

Dawson MI and Xia Z (2012) The retinoid X receptors and their ligands. Biochim Biophys Acta 1821:21-56.

DeFelice SL (1995) The nutraceutical revolution: its impact on food industry R\&D. Trends Food Sci Technol 6:59-61.

Del Priore G, Gudipudi DK, Montemarano N, Restivo AM, Malanowska-Stega J, and Arslan AA (2010) Oral diindolylmethane (DIM): pilot evaluation of a nonsurgical treatment for cervical dysplasia. Gynecol Oncol 116:464-467.

Di Daniele N (2019) The role of preventive nutrition in chronic non-communicable diseases. Nutrients 11:1074.

Digby JE, Martinez F, Jefferson A, Ruparelia N, Chai J, Wamil M, Greaves DR, and Choudhury RP (2012) Anti-inflammatory effects of nicotinic acid in human monocytes are mediated by GPR109A dependent mechanisms. Arterioscler Thromb Vasc Biol 32:669-676.

Dima C, Assadpour E, Dima S, and Jafari SM (2020) Bioavailability of nutraceuticals: role of the food matrix, processing conditions, the gastrointestinal tract, and nanodelivery systems. Compr Rev Food Sci Food Saf 19:954-994.

Di Sabatino A, Morera R, Ciccocioppo R, Cazzola P, Gotti S, Tinozzi FP, Tinozzi S, and Corazza GR (2005) Oral butyrate for mildly to moderately active Crohn's disease. Aliment Pharmacol Ther 22:789-794.

Dolasia K, Bisht MK, Pradhan G, Udgata A, and Mukhopadhyay S (2018) TLRs/ NLRs: shaping the landscape of host immunity. Int Rev Immunol 37:3-19.

Du Y, Yang M, Lee S, Behrendt CL, Hooper LV, Saghatelian A, and Wan Y (2012) Maternal western diet causes inflammatory milk and TLR2/4-dependent neonatal toxicity. Genes Dev 26:1306-1311.

Duscha A, Gisevius B, Hirschberg S, Yissachar N, Stangl GI, Eilers E, Bader V, Haase S, Kaisler J, David C, et al. (2020) Propionic acid shapes the multiple sclerosis disease course by an immunomodulatory mechanism. Cell 180:1067-1080 e16.

El Amrousy D, El Ashry H, Hodeib H, and Hassan S (2020) Vitamin D in children with inflammatory bowel disease. J Clin Gastroenterol Epub ahead.

Entrenas Castillo M, Entrenas Costa LM, Vaquero Barrios JM, Alcalá Díaz JF, López Miranda J, Bouillon R, and Quesada Gomez JM (2020) "Effect of calcifediol treatment and best available therapy versus best available therapy on intensive care unit admission and mortality among patients hospitalized for COVID-19: a pilot randomized clinical study". J Steroid Biochem Mol Biol 203:105751.

Eussen S, Klungel O, Garssen J, Verhagen H, van Kranen H, van Loveren H, and Rompelberg C (2010) Support of drug therapy using functional foods and dietary supplements: focus on statin therapy. Br J Nutr 103:1260-1277.

Farhangi MA, Keshavarz SA, Eshraghian M, Ostadrahimi A, and Saboor-Yaraghi A-A (2013) Vitamin A supplementation and serum Th1- and Th2-associated cytokine response in women. J Am Coll Nutr 32:280-285.

Feng X, Qin H, Shi Q, Zhang Y, Zhou F, Wu H, Ding S, Niu Z, Lu Y, and Shen P (2014) Chrysin attenuates inflammation by regulating M1/M2 status via activating PPAR $\gamma$. Biochem Pharmacol 89:503-514.

Feng X, Weng D, Zhou F, Owen YD, Qin H, Zhao J, WenYu, Huang Y, Chen J, Fu $\mathrm{H}$, et al. (2016) Activation of PPAR $\gamma$ by a natural flavonoid modulator, apigenin ameliorates obesity-related Inflammation via regulation of macrophage polarization EBioMedicine 9:61-76.

Fernandes R, do Rosario VA, Mocellin MC, Kuntz MGF, and Trindade EBSM (2017) Effects of inulin-type fructans, galacto-oligosaccharides and related synbiotics on inflammatory markers in adult patients with overweight or obesity: a systematic review. Clin Nutr 36:1197-1206.

Fernández J, Redondo-Blanco S, Gutiérrez-del-Río I, Miguélez EM, Villar CJ, and Lombó F (2016) Colon microbiota fermentation of dietary prebiotics towards short-chain fatty acids and their roles as anti-inflammatory and antitumour agents: a review. J Funct Foods 25:511-522.

Fessler MB (2018) The challenges and promise of targeting the liver X receptors for treatment of inflammatory disease. Pharmacol Ther 181:1-12.

Fowler AJ, Sheu MY, Schmuth M, Kao J, Fluhr JW, Rhein L, Collins JL, Willson TM, Mangelsdorf DJ, Elias PM, et al. (2003) Liver X receptor activators display anti-inflammatory activity in irritant and allergic contact dermatitis models: liver-X-receptor-specific inhibition of inflammation and primary cytokine production. J Invest Dermatol 120:246-255.

Freitas RDS and Campos MM (2019) Protective effects of omega-3 fatty acids in cancer-related complications. Nutrients 11:945.

Fu Y, Zhou E, Wei Z, Wang W, Wang T, Yang Z, and Zhang N (2014) Cyanidin-3-O$\beta$-glucoside ameliorates lipopolysaccharide-induced acute lung injury by reducing TLR4 recruitment into lipid rafts. Biochem Pharmacol 90:126-134.

Geissmann F, Revy P, Brousse N, Lepelletier Y, Folli C, Durandy A, Chambon P, and Dy M (2003) Retinoids regulate survival and antigen presentation by immature dendritic cells. J Exp Med 198:623-634.

Georgiou NA, Garssen J, and Witkamp RF (2011) Pharma-nutrition interface: the gap is narrowing. Eur J Pharmacol 651:1-8.

Ghisletti S, Huang W, Ogawa S, Pascual G, Lin ME, Willson TM, Rosenfeld MG, and Glass CK (2007) Parallel SUMOylation-dependent pathways mediate geneand signal-specific transrepression by LXRs and PPARgamma. Mol Cell 25:57-70.

Gill PA, van Zelm MC, Muir JG, and Gibson PR (2018) Review article: short chain fatty acids as potential therapeutic agents in human gastrointestinal and inflammatory disorders. Aliment Pharmacol Ther 48:15-34.

Gioxari A, Kaliora AC, Marantidou F, and Panagiotakos DP (2018) Intake of $\omega$-3 polyunsaturated fatty acids in patients with rheumatoid arthritis: a systematic review and meta-analysis. Nutrition 45:114-124.e4.

Glass CK and Saijo K (2010) Nuclear receptor transrepression pathways that regulate inflammation in macrophages and $\mathrm{T}$ cells. Nat Rev Immunol 10:365-376.

Gombart AF, Borregaard N, and Koeffler HP (2005) Human cathelicidin antimicrobial peptide (CAMP) gene is a direct target of the vitamin $\mathrm{D}$ receptor and is strongly up-regulated in myeloid cells by 1,25-dihydroxyvitamin D3. FASEB J 19:1067-1077.

Gonçalves D, Lima C, Ferreira P, Costa P, Costa A, Figueiredo W, and Cesar T (2017) Orange juice as dietary source of antioxidants for patients with hepatitis C under antiviral therapy. Food Nutr Res 61:1296675.

Goverse G, Molenaar R, Macia L, Tan J, Erkelens MN, Konijn T, Knippenberg M, Cook ECL, Hanekamp D, Veldhoen M, et al. (2017) Diet-derived short chain fatty acids stimulate intestinal epithelial cells to induce mucosal tolerogenic dendritic cells. J Immunol 198:2172-2181.

Griffin MD, Lutz WH, Phan VA, Bachman LA, McKean DJ, and Kumar R (2000) Potent inhibition of dendritic cell differentiation and maturation by vitamin D analogs. Biochem Biophys Res Commun 270:701-708.

Gueders MM, Paulissen G, Crahay C, Quesada-Calvo F, Hacha J, Van Hove C, Tournoy K, Louis R, Foidart J-M, Noël A, et al. (2009) Mouse models of asthma: a comparison between $\mathrm{C} 57 \mathrm{BL} / 6$ and $\mathrm{BALB} / \mathrm{c}$ strains regarding bronchial responsiveness, inflammation, and cytokine production. Inflamm Res 58:845-854 Springer.

Gutiérrez-Vázquez C and Quintana FJ (2018) Regulation of the immune response by the aryl hydrocarbon receptor. Immunity 48:19-33.

Hamer HM, Jonkers DMAE, Vanhoutvin SALW, Troost FJ, Rijkers G, de Bruıne A Bast A, Venema K, and Brummer R-JM (2010) Effect of butyrate enemas on inflammation and antioxidant status in the colonic mucosa of patients with ulcerative colitis in remission. Clin Nutr 29:738-744.

Hammerschmidt-Kamper C, Biljes D, Merches K, Steiner I, Daldrup T, BolSchoenmakers M, Pieters RHH, and Esser C (2017) Indole-3-carbinol, a plant nutrient and AhR-ligand precursor, supports oral tolerance against OVA and improves peanut allergy symptoms in mice. PLoS One 12:e0180321.

Hariri BM, McMahon DB, Chen B, Freund JR, Mansfield CJ, Doghramji LJ, Adappa ND, Palmer JN, Kennedy DW, Reed DR, et al. (2017) Flavones modulate respiratory epithelial innate immunity: anti-inflammatory effects and activation of the T2R14 receptor. J Biol Chem 292:8484-8497.

Hartmann W, Blankenhaus B, Brunn M-L, Meiners J, and Breloer M (2021) Elucidating different pattern of immunoregulation in BALB/c and C57BL/6 mice and their F1 progeny. Sci Rep 11:1536.

Hauser AS, Attwood MM, Rask-Andersen M, Schiöth HB, and Gloriam DE (2017) Trends in GPCR drug discovery: new agents, targets and indications. Nat Rev Drug Discov 16:829-842.

Hedin C, Whelan K, and Lindsay JO (2007) Evidence for the use of probiotics and prebiotics in inflammatory bowel disease: a review of clinical trials. Proc Nutr Soc 66:307-315.

Hoque R, Farooq A, Ghani A, Gorelick F, and Mehal WZ (2014) Lactate reduces liver and pancreatic injury in Toll-like receptor- and inflammasome-mediated inflammation via GPR81-mediated suppression of innate immunity. Gastroenterology 146:1763-1774.

Huang S, Rutkowsky JM, Snodgrass RG, Ono-Moore KD, Schneider DA, Newman JW, Adams SH, and Hwang DH (2012) Saturated fatty acids activate TLRmediated proinflammatory signaling pathways. J Lipid Res 53:2002-2013. 
Huang W, Man Y, Gao C, Zhou L, Gu J, Xu H, Wan Q, Long Y, Chai L, Xu Y, et al. (2020) Short-chain fatty acids ameliorate diabetic nephropathy via GPR43mediated inhibition of oxidative stress and NF- $\kappa \mathrm{B}$ signaling. Oxid Med Cell Longev 2020:4074832.

Huang Z, Jiang Y, Yang Y, Shao J, Sun X, Chen J, Dong L, and Zhang J (2013) 3,3'Diindolylmethane alleviates oxazolone-induced colitis through Th2/Th17 suppression and Treg induction. Mol Immunol 53:335-344.

Hubbard TD, Murray IA, and Perdew GH (2015) Indole and tryptophan metabolism: endogenous and dietary routes to Ah receptor activation. Drus Metab Dispos 43:1522-1535.

Hufnagl K and Jensen-Jarolim E (2019) Does a carrot a day keep the allergy away? Immunol Lett 206:54-58.

Hyseni L, Atkinson M, Bromley H, Orton L, Lloyd-Williams F, McGill R, and Capewell S (2017) The effects of policy actions to improve population dietary patterns and prevent diet-related non-communicable diseases: scoping review. Eur J Clin Nutr 71:694-711.

Innes JK and Calder PC (2020) Marine omega-3 (N-3) fatty acids for cardiovascular health: an update for 2020. Int J Mol Sci 21:1362.

Isobe J, Maeda S, Obata Y, Iizuka K, Nakamura Y, Fujimura Y, Kimizuka T, Hattori K, Kim YG, Morita T, et al. (2020) Commensal-bacteria-derived butyrate promotes the T-cell-independent IgA response in the colon. Int Immunol 32:243-258.

Iwami D, Zhang Q, Aramaki O, Nonomura K, Shirasugi N, and Niimi M (2009) Purified eicosapentaenoic acid induces prolonged survival of cardiac allografts and generates regulatory T cells. Am J Transplant 9:1294-1307.

Iwata M, Eshima Y, and Kagechika H (2003) Retinoic acids exert direct effects on T cells to suppress Th1 development and enhance Th2 development via retinoic acid receptors. Int Immunol 15:1017-1025.

Iwata M, Hirakiyama A, Eshima Y, Kagechika H, Kato C, and Song SY (2004) Retinoic acid imprints gut-homing specificity on T cells. Immunity 21:527-538.

Jaudszus A, Gruen M, Watzl B, Ness C, Roth A, Lochner A, Barz D, Gabriel H, Rothe M, and Jahreis G (2013) Evaluation of suppressive and pro-resolving effects of EPA and DHA in human primary monocytes and T-helper cells. J Lipid Res 54:923-935.

Jolliffe DA, Griffiths CJ, and Martineau AR (2013) Vitamin D in the prevention of acute respiratory infection: systematic review of clinical studies. J Steroid Biochem Mol Biol 136:321-329.

Joseph SB, Castrillo A, Laffitte BA, Mangelsdorf DJ, and Tontonoz P (2003) Reciprocal regulation of inflammation and lipid metabolism by liver $\mathrm{X}$ receptors. Nat Med 9:213-219.

Julliard W, De Wolfe TJ, Fechner JH, Safdar N, Agni R, and Mezrich JD (2017) Amelioration of Clostridium difficile infection in mice by dietary supplementation with indole-3-carbinol. Ann Surg 265:1183-1191.

Kang SG, Lim HW, Andrisani OM, Broxmeyer HE, and Kim CH (2007) Vitamin A metabolites induce gut-homing FoxP3+ regulatory $\mathrm{T}$ cells. $J$ Immunol 179:3724-3733.

Kang SG, Park J, Cho JY, Ulrich B, and Kim CH (2011) Complementary roles of retinoic acid and TGF- $\beta 1$ in coordinated expression of mucosal integrins by $\mathrm{T}$ cells. Mucosal Immunol 4:66-82.

Kau AL, Ahern PP, Griffin NW, Goodman AL, and Gordon JI (2011) Human nutrition, the gut microbiome and the immune system. Nature 474:327-336.

Kawasaki T and Kawai T (2014) Toll-like receptor signaling pathways. Front Immunol 5:461.

Khammissa RAG, Fourie J, Motswaledi MH, Ballyram R, Lemmer J, and Feller L (2018) The biological activities of vitamin D and its receptor in relation to calcium and bone homeostasis, cancer, immune and cardiovascular systems, skin biology, and oral health. BioMed Res Int 2018:9276380.

Kidani Y and Bensinger SJ (2012) Liver X receptor and peroxisome proliferatoractivated receptor as integrators of lipid homeostasis and immunity. Immunol Rev 249:72-83.

Kim HC and Oh SM (2013) Noncommunicable diseases: current status of major modifiable risk factors in Korea. J Prev Med Public Health 46:165-172.

Kim MH, Kang SG, Park JH, Yanagisawa M, and Kim CH (2013) Short-chain fatty acids activate GPR41 and GPR43 on intestinal epithelial cells to promote inflammatory responses in mice. Gastroenterology 145:396-406.e1, 10

Kiss M, Czimmerer Z, and Nagy L (2013) The role of lipid-activated nuclear receptors in shaping macrophage and dendritic cell function: From physiology to pathology. J Allergy Clin Immunol 132:264-286.

Kojetin DJ, Matta-Camacho E, Hughes TS, Srinivasan S, Nwachukwu JC, Cavett V, Nowak J, Chalmers MJ, Marciano DP, Kamenecka TM, et al. (2015) Structural mechanism for signal transduction in RXR nuclear receptor heterodimers. Nat Commun 6:8013.

Kolodziejczyk AA, Zheng D, and Elinav E (2019) Diet-microbiota interactions and personalized nutrition. Nat Rev Microbiol 17:742-753.

Komati R, Spadoni D, Zheng S, Sridhar J, Riley KE, and Wang G (2017) Ligands of therapeutic utility for the liver X receptors. Molecules 22:88.

Kong W, Yen JH, Vassiliou E, Adhikary S, Toscano MG, and Ganea D (2010) Docosahexaenoic acid prevents dendritic cell maturation and in vitro and in vivo expression of the IL-12 cytokine family. Lipids Health Dis 9:12.

Kostoglou-Athanassiou I, Athanassiou L, and Athanassiou P (2020) The effect of omega-3 fatty acids on rheumatoid arthritis. Mediterr $J$ Rheumatol 31:190-194.

Kostylina G, Simon D, Fey MF, Yousefi S, and Simon HU (2008) Neutrophil apoptosis mediated by nicotinic acid receptors (GPR109A). Cell Death Differ 15:134-142.

Kulie T, Groff A, Redmer J, Hounshell J, and Schrager S (2009) Vitamin D: an evidence-based review. $J$ Am Board Fam Med 22:698-706.

Kurakevich E, Hennet T, Hausmann M, Rogler G, and Borsig L (2013) Milk oligosaccharide sialyl $(\alpha 2,3)$ lactose activates intestinal CD11c + cells through TLR4. Proc Natl Acad Sci USA 110:17444-17449.
Lackey DE, Ashley SL, Davis AL, and Hoag KA (2008) Retinoic acid decreases adherence of murine myeloid dendritic cells and increases production of matrix metalloproteinase-9. J Nutr 138:1512-1519.

Larange A (2017) Retinoic acid and immunity, in $e L S$ p, John Wiley \& Sons, Ltd (E.d.), Chichester, UK

Larange A and Cheroutre H (2016) Retinoic acid and retinoic acid receptors as pleiotropic modulators of the immune system. Annu Rev Immunol 34:369-394.

Lavelle A and Sokol H (2020) Gut microbiota-derived metabolites as key actors in inflammatory bowel disease. Nat Rev Gastroenterol Hepatol 17:223-237.

Lee JY, Ye J, Gao Z, Youn HS, Lee WH, Zhao L, Sizemore N, and Hwang DH (2003) Reciprocal modulation of Toll-like receptor-4 signaling pathways involving MyD88 and phosphatidylinositol 3-kinase/AKT by saturated and polyunsaturated fatty acids. J Biol Chem 278:37041-37051.

Lee KP, Park SJ, Kang S, Koh JM, Sato K, Chung HY, Okajima F, and Im DS (2017) $\omega-3$ Polyunsaturated fatty acids accelerate airway repair by activating FFA4 in club cells. Am J Physiol Lung Cell Mol Physiol 312:L835-L844.

Lehmann S, Hiller J, van Bergenhenegouwen J, Knippels LMJ, Garssen J, and Traidl-Hoffmann C (2015) In vitro evidence for immune-modulatory properties of non-digestible oligosaccharides: direct effect on human monocyte derived dendritic cells. PLoS One 10:e132304.

Li H, Ruan XZ, Powis SH, Fernando R, Mon WY, Wheeler DC, Moorhead JF, and Varghese Z (2005) EPA and DHA reduce LPS-induced inflammation responses in HK-2 cells: evidence for a PPAR- $\gamma$-dependent mechanism. Kidney Int 67:867-874. Li X, Ballantyne LL, Che X, Mewburn JD, Kang JX, Barkley RM, Murphy RC, Yu Y, and Funk CD (2015) Endogenously generated omega-3 fatty acids attenuate vascular inflammation and neointimal hyperplasia by interaction with free fatty acid receptor 4 in mice. $J$ Am Heart Assoc 4:e001856.

Li X, Bi X, Wang S, Zhang Z, Li F, and Zhao AZ (2019) Therapeutic potential of $\omega-3$ polyunsaturated fatty acids in human autoimmune diseases. Front Immunol 10:2241.

Li Y, Ahmad A, Kong D, Bao B, and Sarkar FH (2014) Recent progress on nutraceutical research in prostate cancer. Cancer Metastasis Rev 33:629-640.

Li Y, Lu Z, Ru JH, Lopes-Virella MF, Lyons TJ, and Huang Y (2018) Saturated fatty acid combined with lipopolysaccharide stimulates a strong inflammatory response in hepatocytes in vivo and in vitro. Am J Physiol Endocrinol Metab 315:E745-E757.

Liu PT, Stenger S, Li H, Wenzel L, Tan BH, Krutzik SR, Ochoa MT, Schauber J, Wu K, Meinken C, Kamen DL, Wagner M, Bals R, Steinmeyer A, Zügel U, Gallo RL, Eisanberg D, Hewison M, Hollis BW, Adams JS, Bloom BR, and Modlin RL (2006) Toll-like receptor triggering of a vitamin D-mediated human antimicrobial response. Science (80-) 311:1770-1773.

Liu Y, Chen L-Y, Sokolowska M, Eberlein M, Alsaaty S, Martinez-Anton A, Logun C, Qi HY, and Shelhamer JH (2014) The fish oil ingredient, docosahexaenoic acid, activates cytosolic phospholipase $\mathrm{A}_{2}$ via GPR120 receptor to produce prostaglandin $\mathrm{E}_{2}$ and plays an anti-inflammatory role in macrophages. Immunology 143:81-95.

Lopez-Garcia E, Rodriguez-Artalejo F, Li TY, Fung TT, Li S, Willett WC, Rimm EB, and Hu FB (2014) The Mediterranean-style dietary pattern and mortality among men and women with cardiovascular disease. Am J Clin Nutr 99:172-180.

Lührs H, Gerke T, Müller JG, Melcher R, Schauber J, Boxberge F, Scheppach W, and Menzel T (2002) Butyrate inhibits NF-kappaB activation in lamina propria macrophages of patients with ulcerative colitis. Scand $J$ Gastroenterol 37:458-466.

Luo W, Xu Q, Wang Q, Wu H, and Hua J (2017) Effect of modulation of PPARactivity on Kupffer cells M1/M2 polarization in the development of non-alcoholic fatty liver disease. Sci Rep 7:44612.

MacDonald L, Foster BC, and Akhtar H (2009) Food and therapeutic product interactions - a therapeutic perspective. J Pharm Pharm Sci 12:367-377.

Macia L, Tan J, Vieira AT, Leach K, Stanley D, Luong S, Maruya M, Ian McKenzie C, Hijikata A, Wong C, et al. (2015) Metabolite-sensing receptors GPR43 and GPR109A facilitate dietary fibre-induced gut homeostasis through regulation of the inflammasome. Nat Commun 6:6734.

Madaan A, Nadeau-Vallée M, Rivera JC, Obari D, Hou X, Sierra EM, Girard S, Olson DM, and Chemtob S (2017) Lactate produced during labor modulates uterine inflammation via GPR81 ( $\left.\mathrm{HCA}_{1}\right)$. Am J Obstet Gynecol 216:60.e1-60.e17.

Martens P-J, Gysemans C, Verstuyf A, and Mathieu AC (2020) Vitamin D's effect on immune function. Nutrients 12:1248.

Marton LT, Goulart RA, Carvalho ACA, and Barbalho SM (2019) Omega fatty acids and inflammatory bowel diseases: an overview. Int J Mol Sci 20:4851.

Maslowski KM, Vieira AT, Ng A, Kranich J, Sierro F, Yu D, Schilter HC, Rolph MS, Mackay F, Artis D, et al. (2009) Regulation of inflammatory responses by gut microbiota and chemoattractant receptor GPR43. Nature 461:1282-1286.

Medrano M, Carrillo-Cruz E, Montero I, and Perez-Simon JA (2018) Vitamin D: effect on haematopoiesis and immune system and clinical applications. Int $J \mathrm{Mol}$ Sci 19:2663.

Mena SJ, Manosalva C, Carretta MD, Teuber S, Olmo I, Burgos RA, and Hidalgo MA (2016) Differential free fatty acid receptor-1 (FFAR1/GPR40) signalling is associated with gene expression or gelatinase granule release in bovine neutrophils. Innate Immun 22:479-489.

Mertens E, Kuijsten A, Dofková M, Mistura L, D’Addezio L, Turrini A, Dubuisson C, Favret S, Havard S, Trolle E, et al. (2019) Geographic and socioeconomic diversity of food and nutrient intakes: a comparison of four European countries. Eur J Nutr 58:1475-1493.

Mijan MA and Lim BO (2018) Diets, functional foods, and nutraceuticals as alternative therapies for inflammatory bowel disease: present status and future trends. World $J$ Gastroenterol 24:2673-2685.

Miles EA and Calder PC (2017) Can early omega-3 fatty acid exposure reduce risk of childhood allergic disease? Nutrients 9:784 
Milligan G, Alvarez-Curto E, Hudson BD, Prihandoko R, and Tobin AB (2017) FFA4/GPR120: pharmacology and therapeutic opportunities. Trends Pharmacol Sci 38:809-821.

Miyamoto J, Mizukure T, Park SB, Kishino S, Kimura I, Hirano K, Bergamo P, Rossi M, Suzuki T, Arita M, et al. (2015) A gut microbial metabolite of linoleic acid, 10-hydroxy-cis-12-octadecenoic acid, ameliorates intestinal epithelial barrier impairment partially via GPR40-MEK-ERK pathway. $J$ Biol Chem 290:2902-2918.

Mo Z, Tang C, Li H, Lei J, Zhu L, Kou L, Li H, Luo S, Li C, Chen W, et al. (2020) Eicosapentaenoic acid prevents inflammation induced by acute cerebral infarction through inhibition of NLRP3 inflammasome activation. Life Sci 242:117133.

Mohammadi S, Memarian A, Sedighi S, Behnampour N, and Yazdani Y (2018) Immunoregulatory effects of indole-3-carbinol on monocyte-derived macrophages in systemic lupus erythematosus: A crucial role for aryl hydrocarbon receptor Autoimmunity 51:199-209.

Mora JR, Iwata M, and von Andrian UH (2008) Vitamin effects on the immune system: vitamins A and D take centre stage. Nat Rev Immunol 8:685-698.

Moreira IS (2014) Structural features of the G-protein/GPCR interactions. Biochim Biophys Acta 1840:16-33.

Mottaghi A, Salehi E, Keshvarz A, Sezavar H, and Saboor-Yaraghi A-A (2012) The influence of vitamin A supplementation on Foxp3 and TGF- $\beta$ gene expression in atherosclerotic patients. J Nutrigenet Nutrigenomics 5:314-326.

Mozaffari H, Daneshzad E, Larijani B, Bellissimo N, and Azadbakht L (2020) Dietary intake of fish, n-3 polyunsaturated fatty acids, and risk of inflammatory bowel disease: a systematic review and meta-analysis of observational studies. Eur J Nutr 59:1-17.

Mucida D, Park Y, Kim G, Turovskaya O, Scott I, Kronenberg M, and Cheroutre H (2007) Reciprocal TH17 and regulatory T cell differentiation mediated by retinoic acid. Science (80-) 317:256-260

Mukherjee S, Huda S, and Sinha Babu SP (2019) Toll-like receptor polymorphism in host immune response to infectious diseases: a review. Scand J Immunol 90:e12771.

Myles IA (2014) Fast food fever: reviewing the impacts of the Western diet on immunity. Nutr $J$ 13:61.

Nagy L, Szanto A, Szatmari I, and Széles L (2012) Nuclear hormone receptors enable macrophages and dendritic cells to sense their lipid environment and shape their immune response. Physiol Rev 92:739-789.

Nakajima A, Kaga N, Nakanishi Y, Ohno H, Miyamoto J, Kimura I, Hori S, Sasaki T, Hiramatsu K, Okumura K, et al. (2017a) Maternal high fiber diet during pregnancy and lactation influences regulatory $\mathrm{T}$ cell differentiation in offspring in mice. J Immunol 199:3516-3524.

Nakajima A, Nakatani A, Hasegawa S, Irie J, Ozawa K, Tsujimoto G, Suganami T, Itoh H, and Kimura I (2017b) The short chain fatty acid receptor GPR43 regulates inflammatory signals in adipose tissue M2-type macrophages. PLoS One 12: 0179696.

Nguyen MT, Favelyukis S, Nguyen AK, Reichart D, Scott PA, Jenn A, Liu-Bryan R, Glass CK, Neels JG, and Olefsky JM (2007) A subpopulation of macrophages infiltrates hypertrophic adipose tissue and is activated by free fatty acids via Toll-like receptors 2 and 4 and JNK-dependent pathways. $J$ Biol Chem 282:35279-35292.

Nicholas DA, Zhang K, Hung C, Glasgow S, Aruni AW, Unternaehrer J, Payne KJ, Langridge WHR, and De Leon M (2017) Palmitic acid is a toll-like receptor 4 ligand that induces human dendritic cell secretion of IL-1 $\beta$. PLoS One 12:e0176793.

Nolting J, Daniel C, Reuter S, Stuelten C, Li P, Sucov H, Kim BG, Letterio JJ, Kretschmer K, Kim HJ, et al. (2009) Retinoic acid can enhance conversion of naive into regulatory $\mathrm{T}$ cells independently of secreted cytokines. $J$ Exp Med 206:2131-2139.

Nurmatov U, Devereux G, and Sheikh A (2011) Nutrients and foods for the primary prevention of asthma and allergy: systematic review and meta-analysis. $J$ Allergy Clin Immunol 127:724-733.e1-30.

Ociepa-Zawal M, Rubiś B, Laciński M, and Trzeciak WH (2007) The effect of indole-3-carbinol on the expression of CYP1A1, CYP1B1 and AhR genes and proliferation of MCF-7 cells. Acta Biochim Pol 54:113-117.

Oh DY, Talukdar S, Bae EJ, Imamura T, Morinaga H, Fan W, Li P, Lu WJ, Watkins SM, and Olefsky JM (2010) GPR120 is an omega-3 fatty acid receptor mediating potent anti-inflammatory and insulin-sensitizing effects. Cell 142:687-698.

Olivas-Aguirre FJ, Rodrigo-García J, Martínez-Ruiz NDR, Cárdenas-Robles AI, Mendoza-Díaz SO, Álvarez-Parrilla E, González-Aguilar GA, de la Rosa LA Ramos-Jiménez A, and Wall-Medrano A (2016) Cyanidin-3-O-glucoside: physicalchemistry, foodomics and health effects. Molecules 21:1264.

Ortega-González M, Ocón B, Romero-Calvo I, Anzola A, Guadix E, Zarzuelo A Suárez MD, Sánchez de Medina F, and Martínez-Augustin O (2014) Nondigestible oligosaccharides exert nonprebiotic effects on intestinal epithelial cells enhancing the immune response via activation of TLR4-NF $\kappa$ B. Mol Nutr Food Res 58:384-393.

Osborn DA and Sinn JK (2013) Prebiotics in infants for prevention of allergy. Cochrane Database Syst Rev 28:CD006474.

Pantazi E, Marks E, Stolarczyk E, Lycke N, Noelle RJ, and Elgueta R (2015) Cutting edge: retinoic acid signaling in B cells is essential for oral immunization and microflora composition. J Immunol 195:1368-1371.

Parada Venegas D, De la Fuente MK, Landskron G, González MJ, Quera R, Dijkstra G, Harmsen HJM, Faber KN, and Hermoso MA (2019) Short chain fatty acids (SCFAs)-mediated gut epithelial and immune regulation and its relevance for inflammatory bowel diseases. Front Immunol 10:277.

Park Y, Subar AF, Hollenbeck A, and Schatzkin A (2011) Dietary fiber intake and mortality in the NIH-AARP diet and health study. Arch Intern Med 171:1061-1068.
Patel MB, Oza NA, Anand IS, Deshpande SS, and Patel CN (2008) Liver x receptor: a novel therapeutic target. Indian J Pharm Sci 70:135-144.

Phillips CM, Chen LW, Heude B, Bernard JY, Harvey NC, Duijts L, Mensink-Bout SM, Polanska K, Mancano G, Suderman M, et al. (2019) Dietary inflammatory index and non-communicable disease risk: a narrative review. Nutrients 11:1873.

Rahman M, Muhammad S, Khan MA, Chen H, Ridder DA, Müller-Fielitz H, Pokorná B, Vollbrandt T, Stölting I, Nadrowitz R, et al. (2014) The $\beta$-hydroxybutyrate receptor HCA2 activates a neuroprotective subset of macrophages. Nat Commun 5:3944.

Rakhshandehroo M, Knoch B, Müller M, and Kersten S (2010) Peroxisome proliferator-activated receptor alpha target genes. PPAR Res 2010:1-20.

Rivellese AA, Ciciola P, Costabile G, Vetrani C, and Vitale M (2019) The possible role of nutraceuticals in the prevention of cardiovascular disease. High Blood Press Cardiovasc Prev 26:101-111.

Rivera J and Tessarollo L (2008) Genetic background and the dilemma of translating mouse studies to humans. Immunity 28:1-4.

Rocha DM, Caldas AP, Oliveira LL, Bressan J, and Hermsdorff HH (2016) Saturated fatty acids trigger TLR4-mediated inflammatory response. Atherosclerosis 244:211-215.

Roduit C, Frei R, Ferstl R, Loeliger S, Westermann P, Rhyner C, Schiavi E, Barcik W, Rodriguez-Perez N, Wawrzyniak M, et al.; PASTURE/EFRAIM study group (2019) High levels of butyrate and propionate in early life are associated with protection against atopy. Allergy 74:799-809.

Rothhammer V and Quintana FJ (2019) The aryl hydrocarbon receptor: an environmental sensor integrating immune responses in health and disease. Nat Rev Immunol 19:184-197.

Rouse M, Singh NP, Nagarkatti PS, and Nagarkatti M (2013) Indoles mitigate the development of experimental autoimmune encephalomyelitis by induction of reciprocal differentiation of regulatory $\mathrm{T}$ cells and Th17 cells. $\mathrm{Br} \mathrm{J}$ Pharmacol 169:1305-1321.

Saboor-Yaraghi AA, Harirchian MH, Mohammadzadeh Honarvar N, Bitarafan S, Abdolahi M, Siassi F, Salehi E, Sahraian MA, Eshraghian MR, Roostaei T, et al. (2015) The effect of vitamin A supplementation on FoxP3 and TGF- $\beta$ gene expression in Avonex-treated multiple sclerosis patients. $J$ Mol Neurosci 56:608-612.

Saeidnia S, Manayi A, and Abdollahi M (2015) From in vitro experiments to in vivo and clinical studies; pros and cons. Curr Drug Discov Technol 12:218-224.

Salehi B, Fokou PVT, Sharifi-Rad M, Zucca P, Pezzani R, Martins N, and SharifiRad J (2019) The therapeutic potential of naringenin: a review of clinical trials. Pharmaceuticals (Basel) 12:11.

Sassi F, Tamone C, and D'Amelio P (2018) Vitamin D: nutrient, hormone, and immunomodulator. Nutrients 10:1656.

Saurer L, McCullough KC, and Summerfield A (2007) In vitro induction of mucosatype dendritic cells by all-trans retinoic acid. J Immunol 179:3504-3514.

Schambach F, Schupp M, Lazar MA, and Reiner SL (2007) Activation of retinoic acid receptor-alpha favours regulatory $\mathrm{T}$ cell induction at the expense of IL-17secreting T helper cell differentiation. Eur J Immunol 37:2396-2399.

Schulte KW, Green E, Wilz A, Platten M, and Daumke O (2017) Structural basis for aryl hydrocarbon receptor-mediated gene activation. Structure 25:1025-1033.e3.

Seo G-Y, Jang Y-S, Kim H-A, Lee M-R, Park M-H, Park S-R, Lee J-M, Choe J, and Kim P-H (2013) Retinoic acid, acting as a highly specific IgA isotype switch factor, cooperates with TGF- $\beta 1$ to enhance the overall IgA response. $J$ Leukoc Biol 94:325-335.

Seo GY, Jang YS, Kim J, Choe J, Han HJ, Lee JM, Kang SH, Rhee KJ, Park SR, Kim WS, et al. (2014) Retinoic acid acts as a selective human IgA switch factor Hum Immunol 75:923-929.

Sethi S, Ziouzenkova O, Ni H, Wagner DD, Plutzky J, and Mayadas TN (2002) Oxidized omega-3 fatty acids in fish oil inhibit leukocyte-endothelial interactions through activation of PPAR alpha. Blood 100:1340-1346.

Sharifi A, Vahedi H, Nedjat S, Rafiei H, and Hosseinzadeh-Attar MJ (2019) Effect of single-dose injection of vitamin $\mathrm{D}$ on immune cytokines in ulcerative colitis patients: a randomized placebo-controlled trial. APMIS 127:681-687.

Shi H, Kokoeva MV, Inouye K, Tzameli I, Yin H, and Flier JS (2006) TLR4 links innate immunity and fatty acid-induced insulin resistance. $J$ Clin Invest 116:3015-3025.

Silva JPB, Navegantes-Lima KC, Oliveira ALB, Rodrigues DVS, Gaspar SLF, Monteiro VVS, Moura DP, and Monteiro MC (2018) Protective mechanisms of butyrate on inflammatory bowel disease. Curr Pharm Des 24:4154-4166.

Sina C, Gavrilova O, Förster M, Till A, Derer S, Hildebrand F, Raabe B, Chalaris A, Scheller J, Rehmann A, et al. (2009) G protein-coupled receptor 43 is essential for neutrophil recruitment during intestinal inflammation. $J$ Immunol 183:7514-7522

Singh N, Gurav A, Sivaprakasam S, Brady E, Padia R, Shi H, Thangaraju M, Prasad PD, Manicassamy S, Munn DH, et al. (2014) Activation of Gpr109a, receptor for niacin and the commensal metabolite butyrate, suppresses colonic inflammation and carcinogenesis. Immunity 40:128-139.

Singh NP, Singh UP, Rouse M, Zhang J, Chatterjee S, Nagarkatti PS, and Nagarkatti M (2016) Dietary indoles suppress delayed-type hypersensitivity by inducing a switch from proinflammatory Th17 cells to anti-inflammatory Regulatory T cells through regulation of microRNA. J Immunol 196:1108-1122.

Sivaprakasam S, Prasad PD, and Singh N (2016) Benefits of short-chain fatty acids and their receptors in inflammation and carcinogenesis. Pharmacol Ther 164:144-151.

Smith PM, Howitt MR, Panikov N, Michaud M, Gallini CA, Bohlooly-Y M, Glickman JN, and Garrett WS (2013) The microbial metabolites, short-chain fatty acids, regulate colonic Treg cell homeostasis. Science (80-) 341:569-573.

Stockinger B, Di Meglio P, Gialitakis M, and Duarte JH (2014) The ary hydrocarbon receptor: multitasking in the immune system. Annu Rev Immunol 32:403-432. 
Suganami T, Tanimoto-Koyama K, Nishida J, Itoh M, Yuan X, Mizuarai S, Kotani H, Yamaoka S, Miyake K, Aoe S, et al. (2007) Role of the Toll-like receptor 4/NFkappaB pathway in saturated fatty acid-induced inflammatory changes in the interaction between adipocytes and macrophages. Arterioscler Thromb Vasc Biol 27:84-91.

Sun M, Wu W, Liu Z, and Cong Y (2017) Microbiota metabolite short chain fatty acids, GPCR, and inflammatory bowel diseases. J Gastroenterol 52:1-8.

Takaki H, Ichiyama K, Koga K, Chinen T, Takaesu G, Sugiyama Y, Kato S, Yoshimura A, and Kobayashi T (2008) STAT6 inhibits TGF- $\beta 1$-mediated Foxp3 induction through direct binding to the Foxp3 promoter, which is reverted by retinoic acid receptor. J Biol Chem 283:14955-14962.

Tan J, McKenzie C, Vuillermin PJ, Goverse G, Vinuesa CG, Mebius RE, Macia L, and Mackay CR (2016) Dietary fiber and bacterial SCFA enhance oral tolerance and protect against food allergy through diverse cellular pathways. Cell Rep 15:2809-2824.

Tan JK, McKenzie C, Mariño E, Macia L, and Mackay CR (2017) Metabolitesensing G protein-coupled receptors-facilitators of diet-related immune regulation. Annu Rev Immunol 35:371-402.

Tandon D, Haque MM, Gote M, Jain M, Bhaduri A, Dubey AK, and Mande SS (2019) A prospective randomized, double-blind, placebo-controlled, dose-response relationship study to investigate efficacy of fructo-oligosaccharides (FOS) on human gut microflora. Sci Rep 9:5473.

Tang XH and Gudas LJ (2011) Retinoids, retinoic acid receptors, and cancer. Annu Rev Pathol 6:345-364.

Thomson CA, Chow HHS, Wertheim BC, Roe DJ, Stopeck A, Maskarinec G, Altbach M, Chalasani P, Huang C, Strom MB, et al. (2017) A randomized, placebo-controlled trial of diindolylmethane for breast cancer biomarker modulation in patients taking tamoxifen. Breast Cancer Res Treat 165:97-107.

Thorburn AN, Macia L, and Mackay CR (2014) Diet, metabolites, and "westernlifestyle" inflammatory diseases. Immunity 40:833-842.

Trombetta AC, Paolino S, and Cutolo M (2018) Vitamin D, inflammation and immunity: review of literature and considerations on recent translational and clinical research developments. Open Rheumatol $J$ 12:201-213.

Trompette A, Gollwitzer ES, Yadava K, Sichelstiel AK, Sprenger N, Ngom-Bru C, Blanchard C, Junt T, Nicod LP, Harris NL, et al. (2014) Gut microbiota metabolism of dietary fiber influences allergic airway disease and hematopoiesis. Nat Med 20:159-166.

Tuttle AH, Philip VM, Chesler EJ, and Mogil JS (2018) Comparing phenotypic variation between inbred and outbred mice. Nat Methods 15:994-996.

Ulven T and Christiansen E (2015) Dietary fatty acids and their potential for controlling metabolic diseases through activation of FFA4/GPR120. Annu Rev Nutr 35:239-263.

Vandamme TF (2014) Use of rodents as models of human diseases. J Pharm Bioallied Sci 6:2-9.

van Hoffen E, Ruiter B, Faber J, M'Rabet L, Knol EF, Stahl B, Arslanoglu S, Moro G, Boehm G, and Garssen J (2009) A specific mixture of short-chain galactooligosaccharides and long-chain fructo-oligosaccharides induces a beneficial immunoglobulin profile in infants at high risk for allergy. Allergy 64:484-487.

Villablanca EJ, Raccosta L, Zhou D, Fontana R, Maggioni D, Negro A, Sanvito F, Ponzoni M, Valentinis B, Bregni M, et al. (2010) Tumor-mediated liver X receptor-alpha activation inhibits $\mathrm{CC}$ chemokine receptor-7 expression on dendritic cells and dampens antitumor responses. Nat Med 16:98-105.

Vinolo MAR, Ferguson GJ, Kulkarni S, Damoulakis G, Anderson K, Bohlooly-Y M, Stephens L, Hawkins PT, and Curi R (2011) SCFAs induce mouse neutrophil chemotaxis through the GPR43 receptor. PLoS One 6:e21205

Vogt L, Ramasamy U, Meyer D, Pullens G, Venema K, Faas MM, Schols HA, and de Vos $P$ (2013) Immune modulation by different types of $\beta 2 \rightarrow 1$-fructans is tolllike receptor dependent. PLoS One 8:e68367.

Vogt LM, Meyer D, Pullens G, Faas MM, Venema K, Ramasamy U, Schols HA, and de Vos P (2014) Toll-like receptor 2 activation by $\beta 2 \rightarrow 1$-fructans protects barrier function of T84 human intestinal epithelial cells in a chain length-dependent manner. J Nutr 144:1002-1008.

von Essen MR, Kongsbak M, Schjerling P, Olgaard K, łdum N, and Geisler C (2010) Vitamin D controls T cell antigen receptor signaling and activation of human T cells. Nat Immunol 11:344-349.

Wang B and Tontonoz P (2018) Liver X receptors in lipid signalling and membrane homeostasis. Nat Rev Endocrinol 14:452-463.

Wang Q, He Y, Shen Y, Zhang Q, Chen D, Zuo C, Qin J, Wang H, Wang J, and Yu Y (2014) Vitamin D inhibits COX-2 expression and inflammatory response by targeting thioesterase superfamily member 4. J Biol Chem 289:11681-11694.

Wang T-T, Nestel FP, Bourdeau V, Nagai Y, Wang Q, Liao J, Tavera-Mendoza L, Lin R, Hanrahan JW, Mader S, et al. (2004) Cutting edge: 1,25-dihydroxyvitamin D3 is a direct inducer of antimicrobial peptide gene expression. J Immunol 173:2909-2912.

Wedrychowicz A, Zajac A, and Tomasik P (2016) Advances in nutritional therapy in inflammatory bowel diseases: Review. Review World $J$ Gastroenterol 22:1045-1066.
Wellhauser L and Belsham DD (2014) Activation of the omega-3 fatty acid receptor GPR120 mediates anti-inflammatory actions in immortalized hypothalamic neurons. J Neuroinflammation 11:60.

Williams-Bey Y, Boularan C, Vural A, Huang NN, Hwang IY, Shan-Shi C, and Kehrl JH (2014) Omega-3 free fatty acids suppress macrophage inflammasome activation by inhibiting $\mathrm{NF}-\kappa \mathrm{B}$ activation and enhancing autophagy. PLoS One 9:e97957.

Witkamp RF and van Norren K (2018) Let thy food be thy medicine.... when possible. Eur J Pharmacol 836:102-114.

Workman AD, Maina IW, Brooks SG, Kohanski MA, Cowart BJ, Mansfield C, Kennedy DW, Palmer JN, Adappa ND, Reed DR, et al. (2018) The role of quinine-responsive taste receptor family 2 in airway immune defense and chronic rhinosinusitis. Front Immunol 9:624.

World Health Organization (2013) Global Action Plan for the Prevention and Control of Noncommunicable Diseases 2013-2020, World Health Organization, Geneva, Switzerland.

Wu D, Lewis ED, Pae M, and Meydani SN (2019) Nutritional modulation of immune function: analysis of evidence, mechanisms, and clinical relevance. Front Immunol 9:3160.

Wu W, Sun M, Chen F, Cao AT, Liu H, Zhao Y, Huang X, Xiao Y, Yao S, Zhao Q, et al. (2017) Microbiota metabolite short-chain fatty acid acetate promotes intestinal IgA response to microbiota which is mediated by GPR43. Mucosal Immunol 10:946-956.

Xue Z, Li D, Yu W, Zhang Q, Hou X, He Y, and Kou X (2017) Mechanisms and therapeutic prospects of polyphenols as modulators of the aryl hydrocarbon receptor. Food Funct 8:1414-1437.

Yagi J, Arimura Y, Takatori H, Nakajima H, Iwamoto I, and Uchiyama T (2006) Genetic background influences Th cell differentiation by controlling the capacity for IL-2-induced IL-4 production by naive $\mathrm{CD} 4+\mathrm{T}$ cells. Int Immunol 18:1681-1690.

Yan Y, Jiang W, Spinetti T, Tardivel A, Castillo R, Bourquin C, Guarda G, Tian Z, Tschopp J, and Zhou R (2013) Omega-3 fatty acids prevent inflammation and metabolic disorder through inhibition of NLRP3 inflammasome activation. Immunity 38:1154-1163.

Yang S, Tan L, Chen Y, Liu A, Hong M, and Peng Z (2020) DIM mitigates the development of experimental autoimmune encephalomyelitis by maintaining the stability and suppressive function of regulatory $\mathrm{T}$ cells. Cell Immunol 358:104238.

Yates CM, Calder PC, and Ed Rainger G (2014) Pharmacology and therapeutics of omega-3 polyunsaturated fatty acids in chronic inflammatory disease. Pharmacol Ther 141:272-282.

Ye P, Li J, Wang S, Xie A, Sun W, and Xia J (2012) Eicosapentaenoic acid disrupts the balance between Tregs and IL-17+ T cells through PPAR $\gamma$ nuclear receptor activation and protects cardiac allografts. J Surg Res 173:161-170.

Yepes-Nuñez JJ, Brożek JL, Fiocchi A, Pawankar R, Cuello-García C, Zhang Y, Morgano GP, Agarwal A, Gandhi S, Terracciano L, et al. (2018) Vitamin D supplementation in primary allergy prevention: systematic review of randomized and non-randomized studies. Allergy 73:37-49.

Yokota-Nakatsuma A, Takeuchi H, Ohoka Y, Kato C, Song SY, Hoshino T, Yagita H, Ohteki T, and Iwata M (2014) Retinoic acid prevents mesenteric lymph node dendritic cells from inducing IL-13-producing inflammatory Th2 cells. Mucosal Immunol 7:786-801.

Yu S and Cantorna MT (2011) Epigenetic reduction in invariant NKT cells following in utero vitamin D deficiency in mice. J Immunol 186:1384-1390.

Yu S and Cantorna MT (2008) The vitamin D receptor is required for iNKT cell development. Proc Natl Acad Sci USA 105:5207-5212.

Yuzefpolskiy Y, Baumann FM, Penny LA, Studzinski GP, Kalia V, and Sarkar S (2014) Vitamin D receptor signals regulate effector and memory CD8 T cell responses to infections in mice. J Nutr 144:2073-2082.

Zapata-Gonzalez F, Rueda F, Petriz J, Domingo P, Villarroya F, Diaz-Delfin J, de Madariaga MA, and Domingo JC (2008) Human dendritic cell activities are modulated by the omega-3 fatty acid, docosahexaenoic acid, mainly through $\operatorname{PPAR}(\gamma): \operatorname{RXR}$ heterodimers: comparison with other polyunsaturated fatty acids. J Leukoc Biol 84:1172-1182.

Zhang Y and Kutateladze TG (2018) Diet and the epigenome. Nat Commun 9:3375. Zhao Y, Chen F, Wu W, Sun M, Bilotta AJ, Yao S, Xiao Y, Huang X, Eaves-Pyles TD, Golovko G, et al. (2018) GPR43 mediates microbiota metabolite SCFA regulation of antimicrobial peptide expression in intestinal epithelial cells via activation of mTOR and STAT3. Mucosal Immunol 11:752-762.

Zhu X, Zhu Y, Li C, Yu J, Ren D, Qiu S, Nie Y, Yu X, Xu X, and Zhu W (2019) 1,25Dihydroxyvitamin D regulates macrophage polarization and ameliorates experimental inflammatory bowel disease by suppressing miR-125b. Int Immunopharmacol 67:106-118.

Zschaler J, Schlorke D, and Arnhold J (2014) Differences in innate immune response between man and mouse. Crit Rev Immunol 34:433-454 